\title{
WestVirginiaUniversity
}

THE RESEARCH REPOSITORY @ WVU

Graduate Theses, Dissertations, and Problem Reports

2014

\section{Burden of Illness among Elderly Individuals with Parkinson's disease}

\author{
Sandipan Bhattacharjee
}

Follow this and additional works at: https://researchrepository.wvu.edu/etd

\section{Recommended Citation}

Bhattacharjee, Sandipan, "Burden of Illness among Elderly Individuals with Parkinson's disease" (2014). Graduate Theses, Dissertations, and Problem Reports. 5204.

https://researchrepository.wvu.edu/etd/5204

This Dissertation is protected by copyright and/or related rights. It has been brought to you by the The Research Repository @ WVU with permission from the rights-holder(s). You are free to use this Dissertation in any way that is permitted by the copyright and related rights legislation that applies to your use. For other uses you must obtain permission from the rights-holder(s) directly, unless additional rights are indicated by a Creative Commons license in the record and/ or on the work itself. This Dissertation has been accepted for inclusion in WVU Graduate Theses, Dissertations, and Problem Reports collection by an authorized administrator of The Research Repository @ WVU.

For more information, please contact researchrepository@mail.wvu.edu. 
Burden of Illness among Elderly Individuals with Parkinson's disease

Sandipan Bhattacharjee

Dissertation submitted

to the School of Pharmacy

at West Virginia University

in partial fulfillment of the requirements for the degree of

Doctor of Philosophy

in

Pharmaceutical and Pharmacological Sciences

Usha Sambamoorthi, Ph.D., Chair

Cindy Tworek, Ph.D.

Xiaoyun Pan, Ph.D.

Aaron Metzger, Ph.D.

Wenhui Wei, Ph.D., M.B.A

This study was supported by a grant from the Agency for Healthcare Research and Quality

(AHRQ):1R24 HS018622-01

Department of Pharmaceutical Systems and Policy

Morgantown, West Virginia

2014

Keywords: Parkinson's disease, Elderly, Expenditures, Informal Caregiver burden, Chronic Illness with Complexity

Copyright 2014 Sandipan Bhattacharjee 


\title{
ABSTRACT \\ Burden of Illness among Elderly Individuals with Parkinson's disease
}

\author{
Sandipan Bhattacharjee, B. Pharm., M.S.
}

Parkinson's disease (PD) is the second most common neurodegenerative disease affecting an estimated one million individuals in the United States (U.S.) and five million individuals globally. With increasing age, the prevalence of PD also increases. Challenges of PD include high economic burden of formal care, informal caregiving burden, and also management of a chronic illness (e.g. type 2 diabetes mellitus) in the presence of PD. The purpose of this study was to use observational data from real-world settings to provide a comprehensive view of the burden of illness among elderly individuals with PD by assessing the formal economic burden, informal caregiving burden and the state of management of chronic illness with complexity (CIC) in the presence of two debilitating conditions (PD and type 2 diabetes mellitus). This study used a triangulation approach by using three different datasets: (i) National Medicare 5\% sample claims database to evaluate the formal economic burden; (ii) the National Alliance for Caregiving (NAC) data to assess the informal caregiver burden; and (iii) the nationwide claims database of Humana Medicare Advantage Part D enrollees to evaluate the state of management of chronic illness with complexity. The specific aims of the three studies were: (1) among elderly Medicare beneficiaries aged 65 or older, estimate excess home healthcare use and expenditures among individuals with PD compared to individuals without PD and analyze predisposing, enabling, need factors, personal health behaviors, and external environment associated with excess home healthcare use and expenditures among individuals with PD; (2) assess the informal caregiver burden and estimate costs associated with informal caregiving burden among caregivers providing care to elderly individuals; and (3) assess process, and intermediate clinical outcomes of diabetes care among individuals with chronic illness with complexity defined as cooccurring PD and diabetes. From the results of the first study, we found that elderly Medicare beneficiaries with PD had significantly higher home healthcare use and expenditures compared to those without PD. The differences in home healthcare use and expenditures among elderly Medicare beneficiaries with and without PD were mainly explained by personal health behaviors such as baseline resource use and need factors such as physical and mental health conditions. In terms of the economic burden of informal caregiving, we did not observe a significant difference in informal caregiving costs between caregivers of elderly individuals with and without PD, despite the costs of informal caregiving for elderly individuals with PD being 1.27 times higher than those without PD. Individuals with CIC were less likely to achieve American Diabetes Association recommended annual HbA1c and lipid testing goals compared to those without CIC (T2DM without PD). However, individuals with CIC achieved glycemic and lipid control outcomes. Thus, these findings taken together underscore the advantage of using an integrated delivery system with better care coordination and providing "holistic care approach." As majority of elderly individuals with PD are community-dwelling, novel intervention techniques are needed to be developed to reduce the informal caregiving burden. 


\section{Contents}

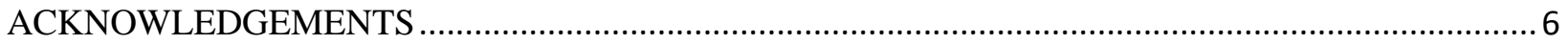

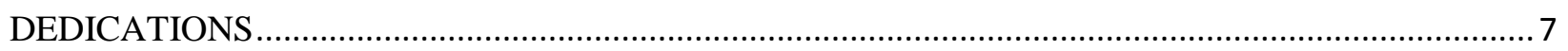

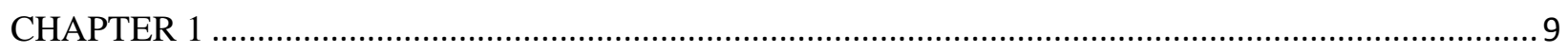

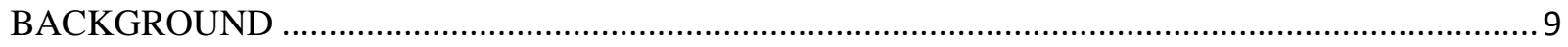

Prevalence of Parkinson's disease ………………………………………………………... 9

Parkinson's disease and economic burden among elderly .............................................................

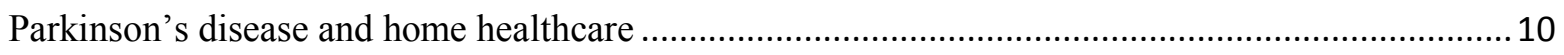

Parkinson's disease and informal care giver burden ........................................................................ 11

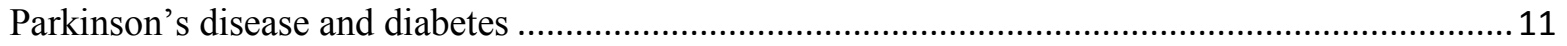

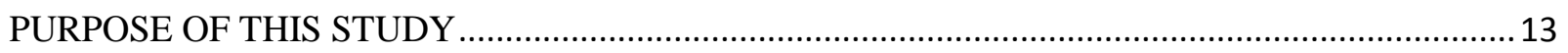

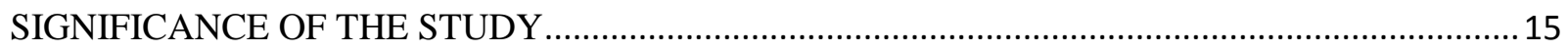

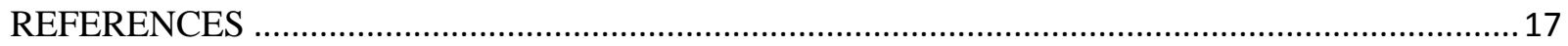

CHAPTER 2: Home Care Use and Expenditures and Parkinson's disease among Elderly Medicare

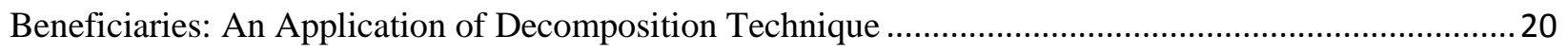

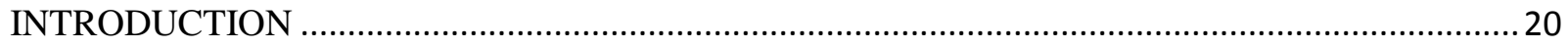

Parkinson's disease and home healthcare expenditures .................................................................20

PD and home healthcare use ………………………………………………………………... 21

Factors associated with home healthcare use and expenditures........................................................2

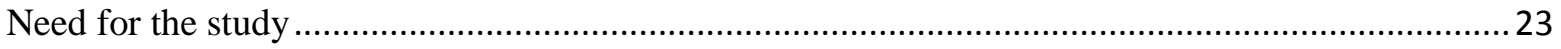

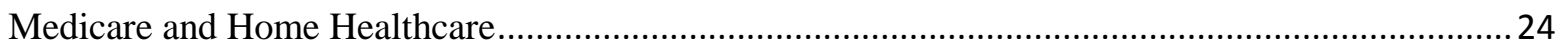

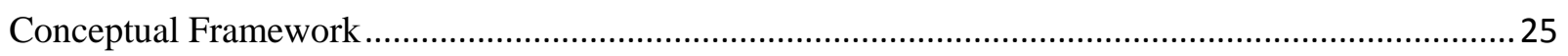

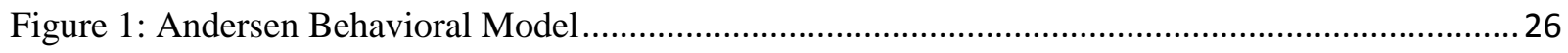

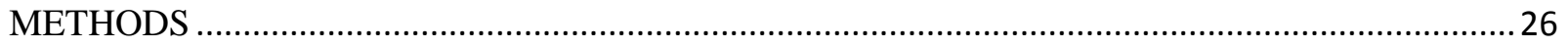

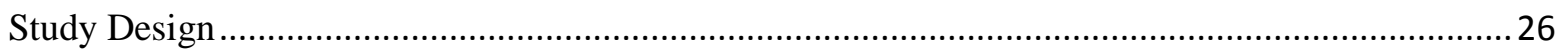

Data Source: Medicare Five-Percent Sample Claims Database........................................................2

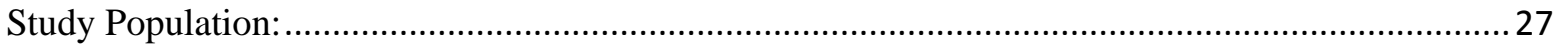

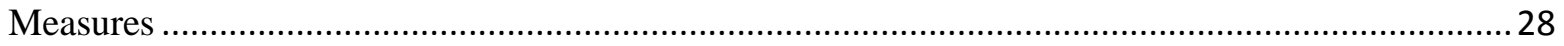

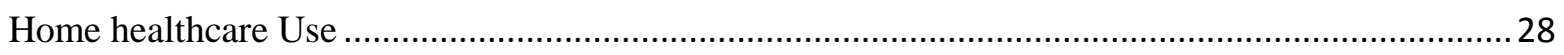

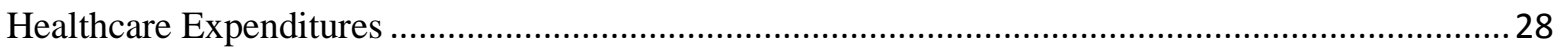

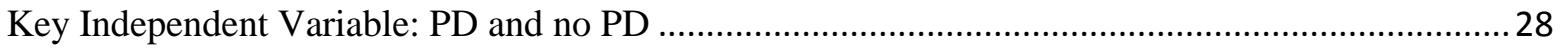




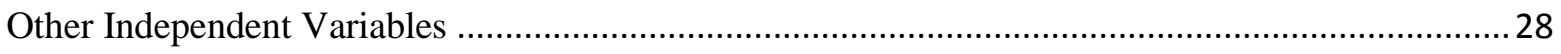



Post-Regression Linear Decomposition of Home Healthcare Expenditures .......................................29

Post-Regression Non-Linear Decomposition of Home Healthcare Use .......................................... 31

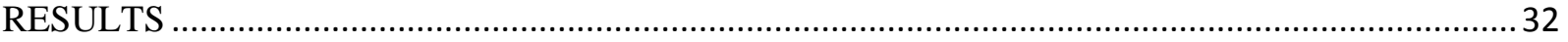

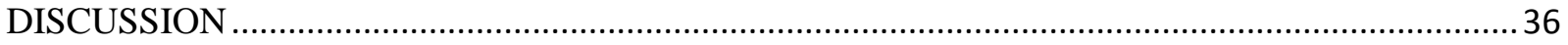

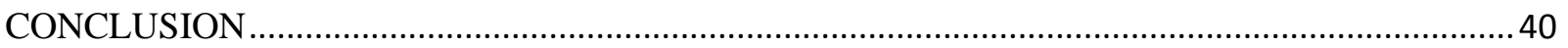

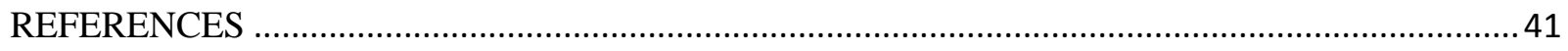

Table 1: Description of Study Sample by Parkinson's disease Status ..................................................4 44

Table 2: Number and Percent with Home Healthcare Use by Parkinson's disease...............................47

Table 3: Adjusted Odds Ratios and 95\% Confidence Intervals from Logistic Regression on Home

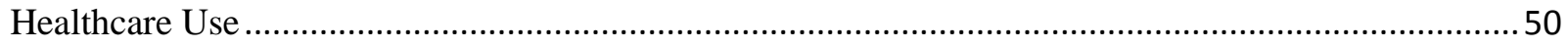

Table 4: Average Total and Home Healthcare Expenditures among Home Healthcare Users...............53

Table 5: Regression Estimates, Standard Errors from Ordinary Least Squares Regression on Logtransformed Home Healthcare Expenditures .............................................................................. 54

Table 6: Non-Linear decomposition of baseline home healthcare use among elderly ........................57

Table 7: Linear decomposition of logged home healthcare expenditures among elderly Medicare

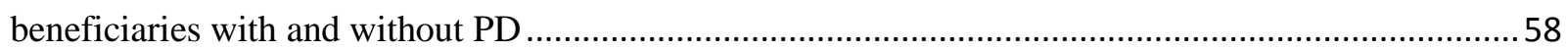

CHAPTER 3: Parkinson's disease and Burden on Informal Caregivers: Results from the National

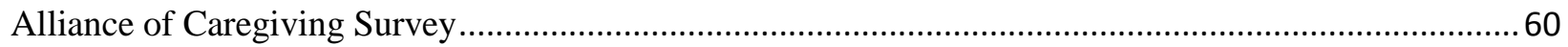

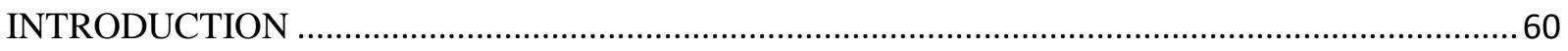

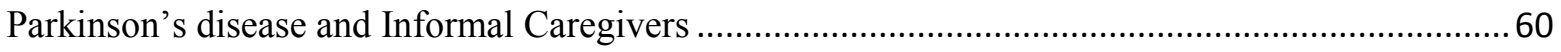

Parkinson's disease and Informal Caregiver Burden ................................................................... 61

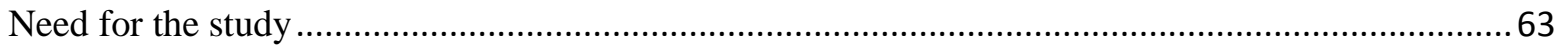

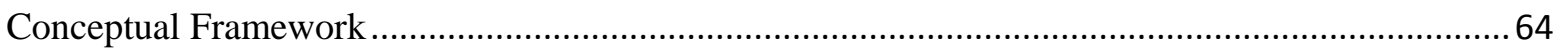

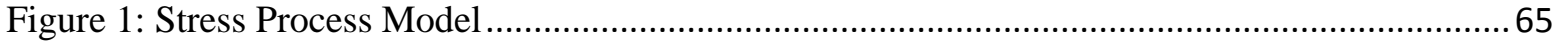

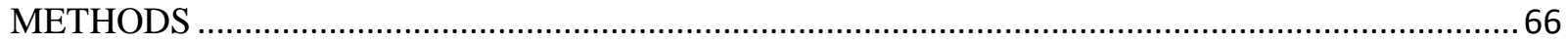

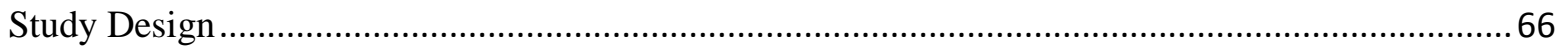

Data Source: National Alliance for Caregiving (NAC) …......................................................... 66

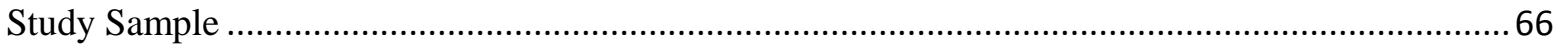

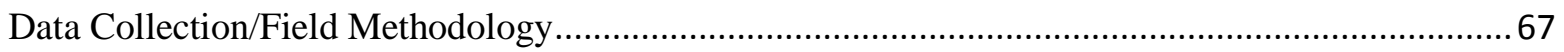

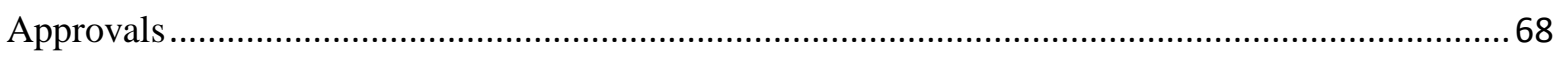

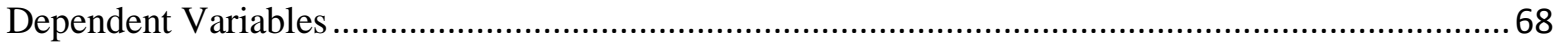




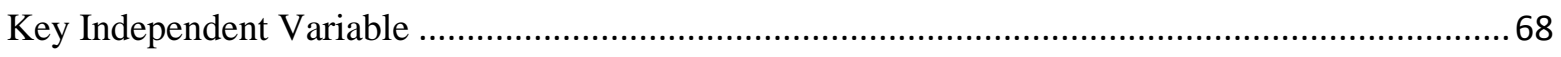

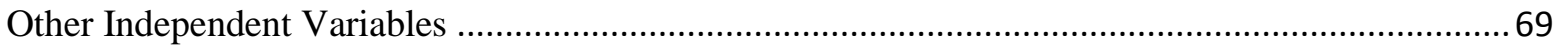

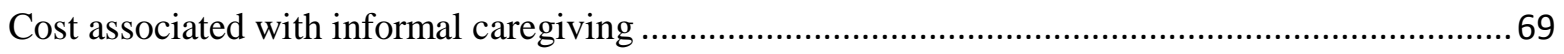

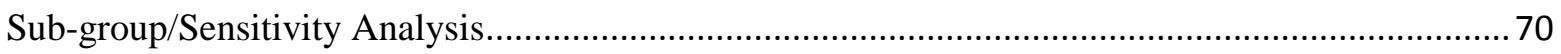



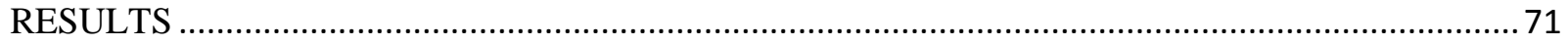

Sample description by care-recipient characteristics ............................................................... 71

Sample description by caregiver characteristics ..................................................................... 71

Other Independent Variables .............................................................................................. 71

Unadjusted group differences by care-recipient characteristics................................................... 72

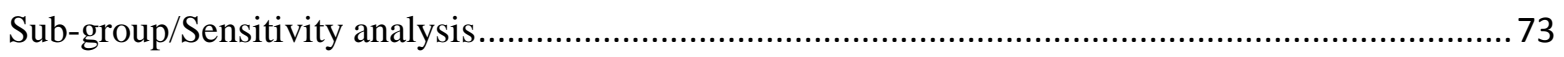

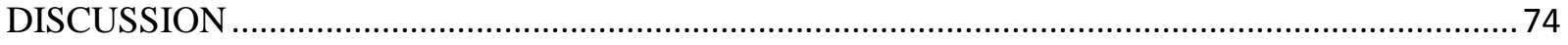

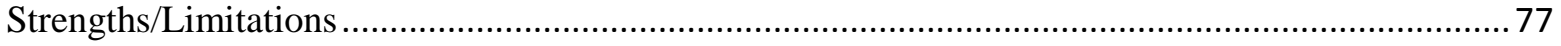

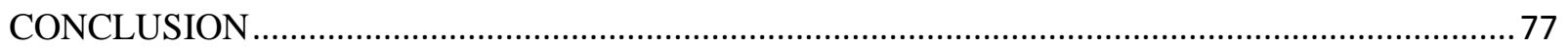

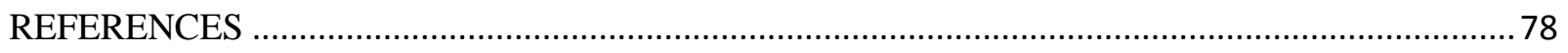

Table 1: Demographic characteristics of Caregivers and Care-recipients of Elderly Individuals with

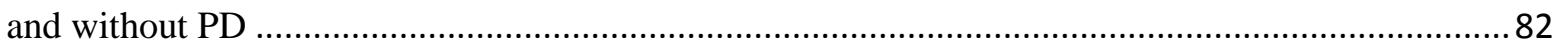

Table 2: Caregiver Burden (Mean and Standard Deviations) by Caregiver and Other Characteristics

Table 3: Parameter Estimates and Standard Errors from Ordinary Least Square Regressions on Caregiver Burden, Number of Caregiving Hours and Log-transformed Costs Associated with Informal Care giving

CHAPTER 4: Chronic Illness with Complexity: Diabetes Care among Elderly Medicare Beneficiaries

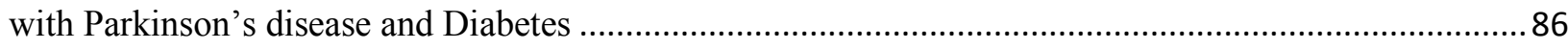

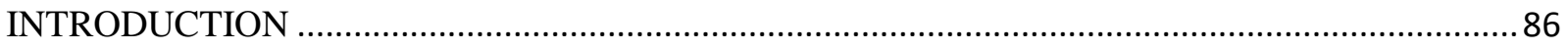

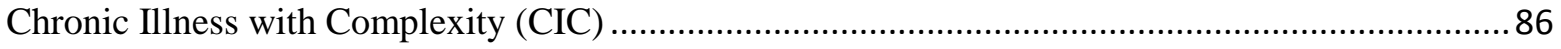

Chronic Illness with Complexity: Co-occurring Parkinson's Diseases and Diabetes........................ 87

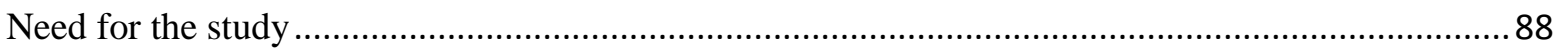

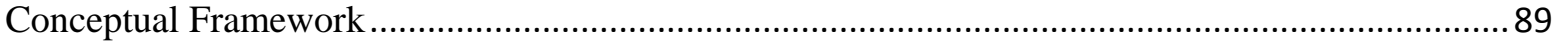

Figure 1: Conceptual Framework: Vector model of Complexity ..................................................... 90

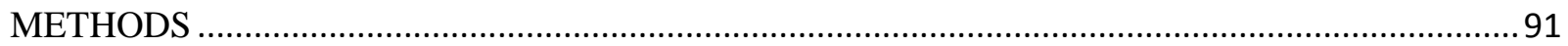

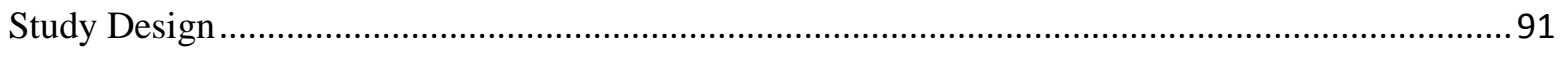

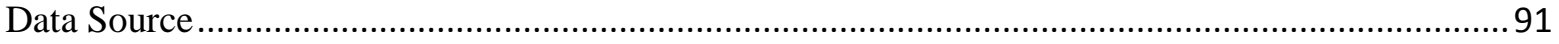




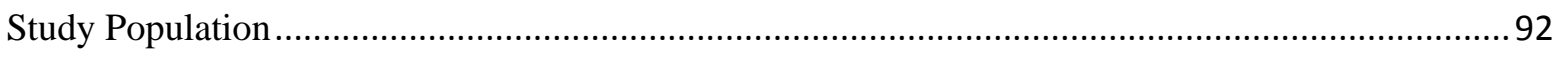

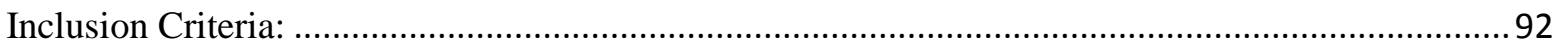

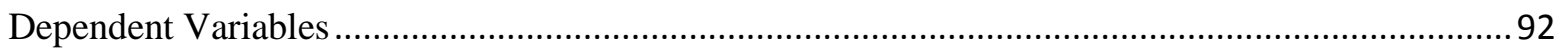

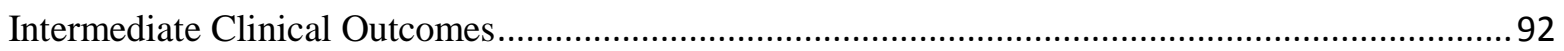

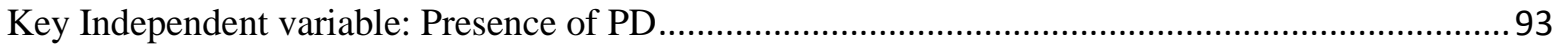



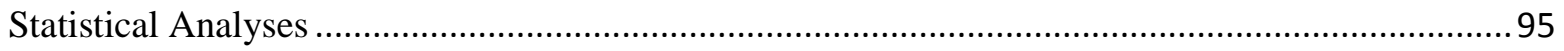

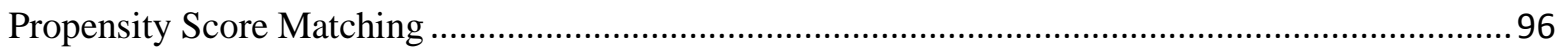

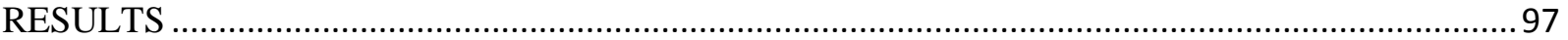

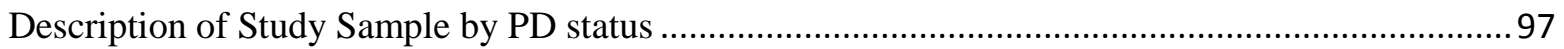

Description of Process of Care and Intermediate Clinical Outcomes ............................................. 98

Multivariable Conditional Logistic Regression on Process of Care .................................................98

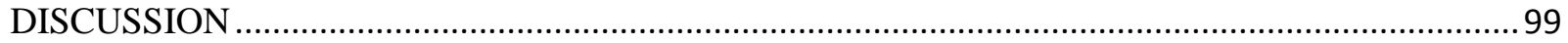

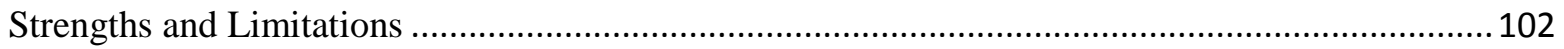



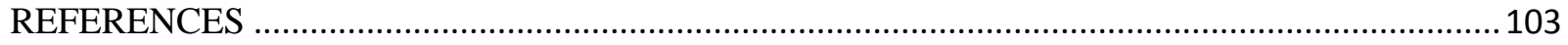

Table 1: Distribution of Matching Variables before and after Propensity Score Matching.............. 108

Table 2: Distribution of matching variables after Propensity Score Matching ............................... 109

Table 3: Baseline characteristics of Elderly Medicare Beneficiaries after matching.......................110

Table 4: Description of Process of Care and Intermediate Clinical Outcomes................................. 112

Table 5: Adjusted Odds Ratios and 95\% Confidence Intervals from Conditional Logistic Regressions Process of Care Measures as per ADA Guidelines .................................................................. 113

Table 6: Adjusted Odds Ratios and 95\% Confidence Intervals from Multinomial Conditional Logistic Regressions on Intermediate Outcomes .................................................................... 114

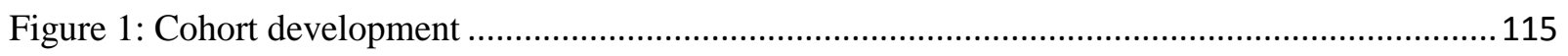

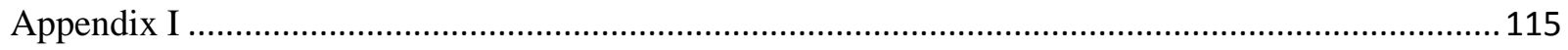

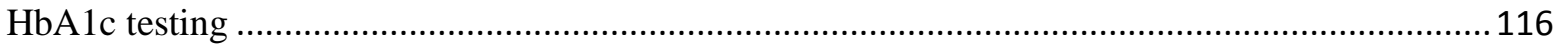

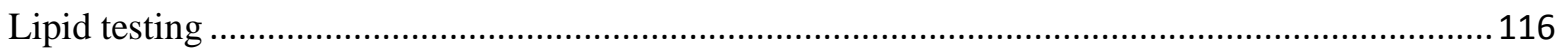

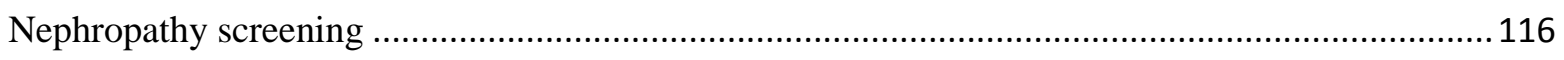










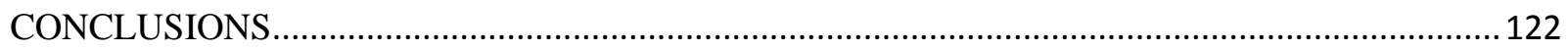



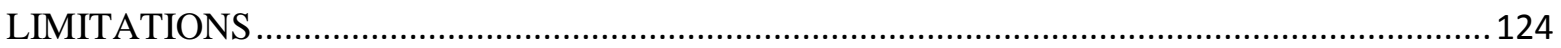

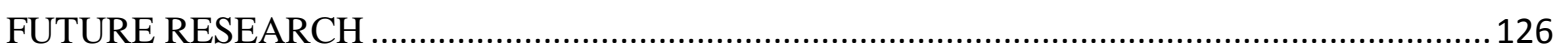

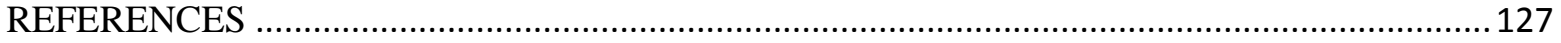




\section{ACKNOWLEDGEMENTS}

I would like to take this opportunity to recognize and thank a lot of people in my life who gave me continuous support not only during my Ph.D. program in Pharmaceutical Systems and Policy at the West Virginia University but also during my entire life. Firstly, I would like to thank my major advisor Dr. Usha Sambamoorthi for all her valuable guidance, help and encouragements. I truly believe that working with a stalwart researcher such as Dr. Sambamoorthi has enriched me a lot and has helped me to understand how to conduct independent research work. She was always there to help me whenever I needed something. I take great pride in attributing the attainment of my Ph.D. degree to her constant guidance and encouragement.

I would also like to thank my committee members Drs. Tworek, Pan, Metzger and Wei. Their valuable suggestions and insights have helped me to strengthen my study. A special thanks go to Dr. Wei for helping me with the access to Humana database. I would also like to convey my heartiest thanks to the entire faculty and staff members at West Virginia University for their constant help and support.

I would like to thank the National Alliance for Caregiving for providing me their dataset. The statements, findings, conclusions, views, and opinions contained and expressed in the specific Aim 2 of this dissertation are those of the authors and not of National Alliance for Caregiving/American Association of Retired Persons or any other affiliated entities.

My parents have been a source of constant support for me. I really do not have words to describe my love and gratitude to them. Mom and Dad, you are the best things in my life. My dear sister Kamalika is very supportive and we share a terrific chemistry, even though I am always pulling her legs, she and I both know how much we love and miss each other. Heartiest thanks to my parents and sister for always being there for me.

I have to mention two wonderful persons in my life without whom I would have never been able to reach where I am at present. Firstly, my maternal grandfather (Dadu), who taught me, from my childhood days. His constant guidance and teaching gave me the hope and aspirations to continue my studies and to always take it to the next level. I attribute all my academic achievements to this great scholar. My Uncle (Ranga-Jethu) has been like a "Guiding Star" throughout my life. I feel short of words to describe my gratitude to this great person who has always supported me in all aspects of life. I feel that if he were not there to support me, I would not have been able to make it here.

Finally, I would like to thank my wife Rituparna. I consider myself really lucky to have her by my side. She is immensely supportive, and I would never forget those days in my life when anything was going right for me, but she was always there to lend her support to me. Words cannot describe my love and feelings for you. I would also like to thank her parents, who were also very supportive of my higher studies. 


\section{DEDICATIONS}

I dedicate my dissertation to my dad, Mr. Pranab Kumar Bhattacharjee. 


\section{CHAPTER 1}

Page 8 of 129 


\section{CHAPTER 1}

\section{BACKGROUND}

\section{Prevalence of Parkinson's disease}

Parkinson's disease (PD) is the second most common neurodegenerative disease affecting an estimated one million individuals in the United States (U.S.) and 5 million individuals globally (Olanow, Stern, \& Sethi, 2009). With increasing age, the prevalence of PD also increases. The prevalence of PD is estimated to be $1 \%$ among individuals 60 years or older (Olanow et al., 2009) and it increases to $4 \%$ among individuals 80 or older (Terriff et al. 2012). It has also been projected that there will be a two-fold increase in the number of individuals with PD by 2030 (Dorsey, 2007). In the US, projections indicate a substantial increase in the number of elderly individuals (baby-boomers) and as the prevalence of PD increases with age, it is important to study the healthcare management of elderly individuals in order to achieve better health outcomes and decrease the steeply rising cost curve among this population.

\section{Parkinson's disease and economic burden among elderly}

It has been observed that despite the low prevalence of PD, individuals with PD experience substantially higher healthcare expenditures compared to those without PD (Noyes et al., 2006; Olanow, Stern, \& Sethi, 2009). In the United States (U.S.), a nationally representative study of Medicare beneficiaries found that the average healthcare expenditures among individuals with PD were approximately twice as high as those without PD (Noyes et al., 2006). As the prevalence of elderly individuals is estimated to rise significantly over the next couple of decades, there will be a consequent increase in the prevalence of individuals with PD. As the 
elderly individuals with PD experience high economic burden due to their disease state, the increase in the prevalence of elderly individuals with PD can be a major public health concern.

\section{Parkinson's disease and home healthcare}

Limitations of ADLs, IADLs, motor and non-motor symptoms, cognitive impairment, behavioral issues and greater need for home health care among individuals with PD can lead to greater caregiving needs for individuals with PD. This has also translated into higher home healthcare use and expenditures among individuals with PD. Indeed, in all the studies that have compared healthcare expenditures among individuals with and without PD (Bhattacharjee \& Sambamoorthi, 2013; Noyes et al., 2006; Pressley et al., 2003; Rubenstein, Chrischilles, \& Voelker, 1997), a consistent finding has been greater home healthcare expenditures among individuals with PD compared to those without PD. However, none of these studies has systematically examined the contributors to excess home health expenditures among individuals with PD. This study extends previous studies by not only providing estimates of formal and informal caregiving but examining the factors that contribute to excess formal caregiving expenditures by analyzing the individual-level factors associated with them.

This provides the rationale for our Aim 1, which estimates the excess home healthcare use and expenditures associated with PD and examine factors associated with this excess use and expenditures. This study aim was accomplished by conducting a comparative analysis of individuals with and without PD. This aim further quantifies the extent to which each of the different set of factors can explain excess home healthcare expenditures among individuals with PD compared to those without PD. 


\section{Parkinson's disease and informal care giver burden}

In addition to formal home healthcare, individuals with PD also rely on home healthcare provided by informal caregivers. As the majority of elderly individuals with PD live in communities, caregiving is mainly provided by spouse or children of individuals with PD (Lau 2011). When caregiving is provided by close family members, relatives, or friends who do not have any organizational affiliations or certificates for caregiving they are considered as informal caregivers (Rakoski, 2012). Some studies have documented that caregivers of PD suffer from substantial caregiving burden because of fear or uncertainty, shift in roles, financial burden, social isolation, little time alone, demands of constant care and feel of guilt. In fact, many informal caregivers spend on an average 96 hours/week providing care to individuals with PD (Parish 2003).

This leads us to Aim 2, which was to assess caregiver burden of individuals providing care to elderly (age $\geq 65$ years) individuals with PD compared to caregivers of elderly individuals without PD and to estimate costs associated with providing informal care to elderly individuals with PD compared to informal caregiving of elderly individuals without PD.

\section{Parkinson's disease and diabetes}

One of the drivers of formal and informal home healthcare use and expenditures is the presence of complexity in PD. Individuals with PD can have co-occurring chronic conditions including type 2 diabetes mellitus (T2DM), which may increase economic and morbidity burden. Of specific importance is the presence of T2DM and PD because co-occurring T2DM among individuals with PD is associated with substantially (over five times) higher home healthcare expenditures compared to matched controls without PD but with diabetes (Bhattacharjee \& Sambamoorthi 2013). In addition, biological and epidemiological connections between T2DM and PD have been considered, although the relationship remains inconclusive. Furthermore, 
studies on diabetes care among individuals with multimorbidity have not proven that guidelineconsistent diabetes care can actually improve quality and outcomes of care (Woodard, Urech, Landrum, Wang, \& Petersen, 2011; Fischer et al., 2000).

Therefore, it is important to assess the state of diabetes care among individuals with PD and the association between CIC and outcomes and quality of diabetes care. This provides the rationale for our Aim 3, which is to assess process, outcomes, and quality of diabetes care among individuals with chronic illness with complexity defined as co-occurring PD and diabetes.

As PD has a higher prevalence among elderly ( $\geq 65$ years) than among other age groups, most of these individuals will be eligible for Medicare. Therefore, most of healthcare spending will be borne by Medicare. Although less than 5\% of total spending was for home health care, Medicare home healthcare spending has grown substantially over the past decade. Indeed, in 2010, Medicare spending on home healthcare was estimated at \$19.4 billion (Health Care Spending-Medicare). Because of the escalating home healthcare expenditures Centers for Medicare and Medicaid Services (CMS) has been exploring ways to reduce the excess home healthcare expenditures. It has been estimated that individuals with PD accounts for a significant portion of home healthcare visits (National Home and Hospice Care Survey, 2011). Therefore, an understanding of factors contributing to home healthcare among all elderly and specifically those with PD who are high utilizers of home healthcare is critical.

Although individuals with PD rely on formal home healthcare, informal care continues to be one of the main components of home health care received by individuals with PD. Care givers of individuals with PD often suffer from poor quality of life, financial burden, social isolation, little time alone, demands of constant care and feel of guilt. Some studies have evaluated informal caregiver burden among individuals with PD. These studies are limited by geographical 
locations within the U.S. (Edwards \& Ruettiger, 2002). Many of these studies are outdated with data from as early as1999 (Parrish et al., 2003). Additionally, none of these studies estimated costs associated with informal caregiving among caregivers of individuals with PD. As the number of elderly individuals as well as those with PD are expected to increase substantially over the next decade, it can also be expected that there will be higher needs for informal caregiving for these aging population. In this context, it is important to identify caregivers who are at high risk for high care burden so that programs and interventions can be developed to improve the well-being of the caregivers.

As stated before, chronic illness with complexity is a major issue among individuals with PD because of the prevalence of other chronic conditions including diabetes. Almost all clinical practice guidelines are developed based on the expert consensus and the scientific evidence for a single disease state (Boyd et al., 2005) rather than for multiple conditions. There are separate guidelines for treating diabetes (such as the guidelines of the American Diabetes Association) and PD (European Parkinson's Disease Standards of Care Consensus Statement). Therefore, it is not known as to whether guideline consistent care is provided to individuals with co-occurring chronic conditions and so it is important to explore the current state of standards of care and health outcomes among individuals with co-occurring chronic conditions such as T2DM and PD.

\section{PURPOSE OF THIS STUDY}

The purpose of this study was to use observational data from real-world settings to provide a comprehensive view of the burden of illness among elderly individuals with PD by assessing the economic burden, informal caregiving burden and the state of management of chronic illness with complexity in the presence of two debilitating conditions (PD and type 2 diabetes mellitus). This study used a triangulation approach by using data from different sources 
to answer the specific aims as there is no single data available that consists of all the variables

used in this study. We used the National Medicare 5\% sample claims database to evaluate the economic burden. To assess the informal caregiver burden, we used the nationally representative sample of National Alliance for Caregiving (NAC) data. To evaluate the state of management of chronic illness with complexity, we used the nationwide sample of Humana Medicare Advantage Part D enrollees.

Aim 1: Among elderly Medicare beneficiaries aged 65 or older, estimate excess home healthcare use and expenditures among individuals with PD compared to individuals without PD and analyze predisposing, enabling, need factors, personal health behaviors, and external environment associated with excess home healthcare use and expenditures among individuals with PD.

Objective 1.1: Among elderly Medicare beneficiaries aged 65 or older, estimate excess home healthcare use among individuals with PD compared to individuals without PD.

Hypothesis 1.1: We hypothesized that elderly Medicare beneficiaries with PD will be more likely to have home healthcare use compared to those without PD after adjusting for predisposing (age, gender, racelethnicity), enabling (public assistance), need [(co-occurring chronic conditions), healthcare use (baseline healthcare use)], personal health behaviors (substance use, baseline resource use), and external environmental (census region, metro-status) factors.

Aim 1.2: Among elderly Medicare beneficiaries aged 65 or older and among users of home healthcare, estimate excess home healthcare expenditures among individuals with PD compared to individuals without PD.

Hypothesis 1.2: We hypothesized that home healthcare expenditures among individuals with PD will be higher compared to those without PD after adjusting for predisposing (age, gender, racelethnicity), need (co-occurring chronic conditions), personal health behaviors (substance use disorders, baseline resource use), and external environmental (census region, metro-status) factors.

Objective 1.3: Analyze the extent to which differences in predisposing, enabling, need factors, personal health behaviors, and external environment characteristics between PD and no PD groups contribute to the excess home healthcare use and expenditures among elderly Medicare beneficiaries with PD.

Hypothesis 1.3: We hypothesized that differences in need factors as measured by co-occurring chronic condition will explain higher rates of home healthcare use and expenditures among elderly Medicare beneficiaries with and without PD. 
Aim 2: Assess the informal caregiver burden and estimate costs associated with informal caregiving burden among caregivers providing care to elderly individuals (age $\geq 65$ years).

Objective 2.1: To assess caregiver burden of individuals providing care to elderly carerecipients with PD compared to caregivers of elderly care-recipients without PD.

Hypotheses 2.1: We hypothesized that informal caregivers of individuals with PD will have higher burden compared to the caregivers of individuals without PD after adjusting for carerecipient and caregiver characteristics.

Objective 2.2: To estimate costs associated with providing informal care to elderly individuals with and without PD.

Hypotheses 2.2: We hypothesized that costs of providing informal care to individuals with PD will be higher than costs of providing informal care to individuals without PD after adjusting for care-recipient and caregiver characteristics.

Aim 3: To assess process and intermediate clinical outcomes of diabetes care among individuals with chronic illness with complexity defined as co-occurring PD and diabetes.

Objective 3.1: Evaluate diabetes process of care among elderly individuals with CIC (T2DM and PD) compared to those without CIC (T2DM and no PD) within a multivariate framework.

Hypothesis 3.1: We hypothesized that the process of diabetes will be poor among elderly individuals with CIC (T2DM and PD) compared to those without CIC (T2DM without PD) within a multivariate framework.

Objective 3.2: Examine intermediate clinical outcomes among elderly individuals with CIC (T2DM and PD) compared to those without CIC (T2DM without PD) within a multivariate framework.

Hypothesis 3.2: We hypothesized that the intermediate clinical outcomes will be poor among elderly individuals with CIC (T2DM and PD) compared to those without CIC (T2DM without $P D)$ within a multivariate framework.

\section{SIGNIFICANCE OF THE STUDY}

The present study makes a unique contribution to the knowledgebase by evaluating economic burden, informal caregiver burden and the state of management of chronic illness with complexity with two debilitating diseases (PD and type 2 diabetes mellitus) of individuals with PD and caregivers of PD. To the best of our knowledge, no study till date has been conducted to provide a holistic view of PD healthcare management by focusing on all these different aspects. 
Moreover, as the population of United States is aging, these studies are timely and appropriate as they focus on an aging problem such as PD, which may become a major public health concern in the near future. Furthermore, the datasets used for each of the specific aims of this dissertation is a nationally representative or nationwide data. Till date, there are no studies available that have used a nationally representative or nationwide data to answer these research questions from home healthcare perspective. Using observational data from real-world settings, this dissertation will fill this critical knowledge gap on the economic burden, caregiver burden and the state of management of chronic illness with complexity among elderly individuals with PD by providing estimates at national level. 


\section{REFERENCES}

Bhattacharjee, S., \& Sambamoorthi, U. (2013). Co-occurring chronic conditions and healthcare expenditures associated with parkinson's disease: A propensity score matched analysis. Parkinsonism \& Related Disorders.

Boyd, C. M., Darer, J., Boult, C., Fried, L. P., Boult, L., \& Wu, A. W. (2005). Clinical practice guidelines and quality of care for older patients with multiple comorbid diseases: Implications for pay for performance. JAMA: The Journal of the American Medical Association, 294(6), 716-724.

Dorsey ER, Constantinescu R, Thompson JP, Biglan KM, Holloway RG, Kieburtz K, Marshall FJ, Ravina BM, Schifitto G, Siderowf A, Tanner CM. Projected number of people with Parkinson disease in the most populous nations, 2005 through 2030. Neurology. 2007 Jan 30;68(5):384-6.

Edwards NE, Scheetz PS. Predictors of burden for caregivers of patients with Parkinson's disease. J Neurosci Nurs. 2002 Aug;34(4):184-90.

Fischer, C. J., Stiefel, F. C., De Jonge, P., Guex, P., Troendle, A., Bulliard, C., et al. (2000). Case complexity and clinical outcome in diabetes mellitus. A prospective study using the INTERMED. Diabetes \& Metabolism, 26(4), 295-302.

Home Health Care and Discharged Hospice Care Patients: United States, 2000 and 2007. April 2011. Available from URL: http://www.cdc.gov/nchs/data/nhsr/nhsr038.pdf [Accessed 2014 May 24].

Lau, K., \& Au, A. (2011). Correlates of informal caregiver distress in parkinson's disease: A meta-analysis. Clinical Gerontologist, 34(2), 117-131. doi:10.1080/07317115.2011.539521

Noyes, K., Liu, H., Li, Y., Holloway, R., \& Dick, A. W. (2006). Economic burden associated with parkinson's disease on elderly medicare beneficiaries. Movement Disorders: Official Journal of the Movement Disorder Society, 21(3), 362-372.

Olanow, C. W., Stern, M. B., \& Sethi, K. (2009). The scientific and clinical basis for the treatment of parkinson disease (2009). Neurology, 72(21), S1-S136. doi:10.1212/WNL.0b013e3181a1d44c

Parrish, M., Giunta, N., \& Adams, S. (2003). Parkinson's disease caregiving: Implications for care management. Care Management Journals: Journal of Case Management ; the Journal of Long Term Home Health Care, 4(1), 53-60.

Pressley, J. C., Louis, E. D., Tang, M., Cote, L., Cohen, P. D., Glied, S., et al. (2003). The impact of comorbid disease and injuries on resource use and expenditures in parkinsonism. Neurology, 60(1), 87-93. 
Rakoski MO, McCammon RJ, Piette JD, Iwashyna TJ, Marrero JA, Lok AS, Langa KM, Volk ML. Burden of cirrhosis on older Americans and their families: analysis of the health and retirement study. Hepatology. 2012 Jan;55(1):184-91.

Rubenstein, L. M., Chrischilles, E. A., \& Voelker, M. D. (1997). The impact of parkinson's disease on health status, health expenditures, and productivity. estimates from the national medical expenditure survey. PharmacoEconomics, 12(4), 486-498.

Terriff DL, Williams JV, Patten SB, Lavorato DH, Bulloch AG. Patterns of disability, care needs, and quality of life of people with Parkinson's disease in a general population sample. Parkinsonism Relat Disord. 2012 Aug;18(7):828-32.

Whetten-Goldstein, K., Sloan, F., Kulas, E., Cutson, T., \& Schenkman, M. (1997). The burden of parkinson's disease on society, family, and the individual. Journal of the American Geriatrics Society, 45(7), 844-849.

Woodard, L. D., Urech, T., Landrum, C. R., Wang, D., \& Petersen, L. A. (2011). Impact of comorbidity type on measures of quality for diabetes care. Medical Care, 49(6), 605-610. 


\section{CHAPTER 2}

Page 19 of 129 


\section{CHAPTER 2: Home Care Use and Expenditures and Parkinson's disease among Elderly Medicare Beneficiaries: An Application of Decomposition Technique}

\section{INTRODUCTION}

\section{Parkinson's disease and home healthcare expenditures}

Despite the low prevalence of Parkinson's disease (PD) (approximately 1-2\% in individuals 60 years or older), individuals with PD experience substantially higher healthcare expenditures compared to those without PD (Noyes, Liu, Li, Holloway, \& Dick, 2006; Olanow, Stern, \& Sethi, 2009). Specifically, home healthcare expenditures have been observed to be consistently and substantially higher among individuals with PD compared to those without PD (Bhattacharjee \& Sambamoorthi, 2013; Noyes et al., 2006; Pressley et al., 2003; Rubenstein, Chrischilles, \& Voelker, 1997). The magnitude of the difference varied depending on the year in which the studies were conducted. Using data from Medicare Current Beneficiary Survey (MCBS) it has been reported that average annual home healthcare expenditures among elderly Medicare beneficiaries with PD (US\$1,422) was 3.2 times as high as home healthcare expenditures compared to those without PD (US\$448) expressed in 2002 US dollars (Noyes et al., 2006). Another recent study conducted using Medical Expenditure Panel Survey data on community-dwelling elderly individuals aged 65 years or older living in the U.S., which used propensity score matching to derive no PD group, found that individuals with PD had approximately 2.5 times higher home healthcare expenditures $(\$ 2,559)$ compared to those without PD (\$1,017) expressed in 2009 dollars (Bhattacharjee \& Sambamoorthi, 2013). Among users of home healthcare, similar differences were found between elderly individuals with and without PD. 


\section{PD and home healthcare use}

Home healthcare use has also been shown to be higher among elderly with PD compared to those without PD. Rates of home healthcare use among community-dwelling Medicare beneficiaries with PD were 3.5 times as high as those without PD (Noyes et al., 2006). Among community-dwelling and institutionalized elderly (age 65 years or older) Medicare beneficiaries participating in the National Long-Term Care Survey (NLTCS), it was observed that home healthcare use among Medicare beneficiaries with PD was two times as high as those without PD. This study suggested that the presence of co-occurring conditions contributed to higher use of home healthcare services among individuals with PD compared to those without PD (Pressley et al., 2003). Unpublished data from the authors (Bhattacharjee \& Sambamoorthi, 2013) revealed that home healthcare use among individuals with PD was two times as high as those of propensity-score matched individuals without PD.

\section{Factors associated with home healthcare use and expenditures}

Higher home healthcare use and expenditures among elderly with PD can be due to many factors. PD is characterized by bradykinesia (difficulty or slowness of starting movements), resting tremors (shaking of limbs involuntarily), rigidity (stiffness of arms, legs, and/or neck), and imbalance (Park \& Stacy, 2009; Vickers \& O'Neill, 1998). These physical conditions can lead to difficulties in carrying out activities of daily living (ADLs) and instrumental activities of daily living (IADLs). Common geriatric issues such as medication management is particularly challenging in PD population because of "on-off" phenomenon with medication therapies. Additionally, individuals with PD may require greater surveillance at home to monitor the sideeffects of antiparkinsonian (APD) medications, decline in effectiveness of APD medications and 
worsening of PD symptoms (Vickers \& O'Neill, 1998). Moreover, APDs can induce cognitive decline, which may require careful monitoring at home (Moore \& O'Keeffe, 1999). Furthermore, home healthcare professionals are required for individuals with PD to alter their diet, understand sleep cycle disturbances and teach newer techniques to execute ADLs and IADLs (Vickers \& O'Neill, 1998). While all these problems are common among many elderly, PD presents particular challenges. For example, findings from a study that compared functional problems experienced by caregivers and care-recipients suggested that those with PD have greater home healthcare needs (Parrish, Giunta, \& Adams, 2003) compared to other cognitively impaired (stroke, Alzheimer's disease, multi-infarct dementia, other degenerative disease/dementia, traumatic brain injury, brain tumor, other non-degenerative disease, multiple sclerosis, amyotrophic lateral sclerosis, or unreported diagnosis) individuals. According to this study, PD care-recipients reported on an average 10 functional problems which included difficulties in ADLs (eating, bathing, dressing, toileting, transferring), and IADLs (taking medication, performing household chores, managing money/finances).

Although not specific to PD, previous literature suggests that limitations of ADL, IADL, cognitive impairment, older age, as well as co-occurring chronic diseases were associated with higher home healthcare use (Fortinsky, Fenster, \& Judge, 2004; Henton, Hays, Walker, \& Atwood, 2002; Moon \& Shin, 2006). A study conducted among Medicare-Medicaid dual eligible using data from Connecticut Long Term Care Health (CLTC) between the time period of August 1995 to December 1997 found that higher limitations of activities of daily living (ADLs), dependence in walking and climbing stairs, and mild cognitive impairment were statistically significantly associated with higher Medicare home healthcare use and expenditures (Fortinsky et al., 2004). Using data from 1996 Medical Expenditure Panel Survey (MEPS), it was observed 
that among elderly individuals (aged 65 years or older) being old-old, non-white, and having greater functional limitations were associated with higher per-capita annual Medicare home healthcare expenditures (Henton et al., 2002). Another study using data from 1996-2000 MEPS among Medicare-Medicaid dual eligible population found that poor health and co-occurring chronic diseases were significantly associated with higher home healthcare use (Moon \& Shin, 2006).

\section{Need for the study}

As PD has a higher prevalence among elderly ( $\geq 65$ years) than among other age groups, most of these individuals are eligible for Medicare. Therefore, most of home healthcare spending will be borne by Medicare. Indeed, in 2010, Medicare spending on home healthcare was estimated at \$19.4 billion (Health Care Spending-Medicare). Although less than 5\% of total spending was for home health care, Medicare home healthcare spending has grown substantially over the past decade. It has been estimated that total Medicare home healthcare expenditures increased from by $129 \%$ between 2000 and 2010 (Home Healthcare Services-Chapter 8). This steep increase has been partly attributed to the aging population of the United States (U.S.). The number of home healthcare users also increased from 2.5 million to 3.4 million between 20022010 (Health Care Spending-Medicare).

According to the 2007 National Home and Hospice Care Survey (NHHCS), diabetes $(10.1 \%)$, diseases of central nervous system $(8.4 \%)$, were the top two common primary diagnoses at the time of home healthcare visit (National Health Statistics Report 2011). Among diseases of the central nervous system, nearly $15 \%$ of the home healthcare visits were for individuals with PD. Because of the escalating home healthcare expenditures Centers for Medicare and Medicaid Services (CMS) has been exploring ways to reduce the excess home 
healthcare expenditures. Thus, an understanding of factors contributing to home healthcare among all elderly and specifically those with PD who are high utilizers of home healthcare is critical. However, to the best of authors' knowledge, no study has analyzed various factors associated with higher home healthcare use and expenditures among individuals with PD. Therefore, the primary purpose of the study was to estimate excess home healthcare use and expenditures associated with PD and examine factors associated with excess use and expenditures.

The current study further highlighted the extent to which each of the different set of factors explain excess home healthcare use and expenditures among individuals with PD compared to those without PD. The current study used data on 5\% sample of nation-wide feefor-service Medicare beneficiaries.

\section{Medicare and Home Healthcare}

As the current study focuses on elderly Medicare beneficiaries, we briefly describe the eligibility requirements to receive Medicare paid home healthcare services, as well as the services covered under Medicare. To be eligible to receive home healthcare services an elderly Medicare beneficiary must satisfy the following criteria: (1) need of a part-time (less than 8 hours/day) or sporadic skilled care (care obtained from a nurse, physical, or speech therapist); (2) not able to leave their house without help from others or without considerable self-effort; (3) certification from a physician stating the need for home healthcare; and (iv) home healthcare should be provided according to a care plan established by a physician, and the care should also be regularly reviewed by the physician.

Starting in 2000, the CMS adopted a prospective payment system (PPS) which pays for

home healthcare in a 60-day episode at a predetermined rate. The payment rates are adjusted in 
terms of severity of the beneficiary (condition of the beneficiary and service use) and also to reflect the level of market input prices based on the geographical area of service delivery (MedPAC payment basis). The severity of beneficiaries is calculated on the basis of case-mix index that depends on the beneficiaries' clinical and functional characteristics as well as certain services that they might use. In case of less than 5 visits during a 60-day episode, the home health agency is reimbursed on the basis of visit rather than by type of visit. The payments are also modified under certain circumstances as for instance when there are high-cost outliers. After the end of the initial 60-day period, if further home healthcare service is needed then that is counted as a new episode (Home Healthcare Services-Chapter 8).

\section{Conceptual Framework}

The conceptual behavioral model by Andersen was used to examine the predisposing, enabling, need, personal health choices and external environmental factors associated with the healthcare expenditures (Andersen, 1995). The Andersen Behavioral Model (ABM) has been used in various studies related to usage of health services (both healthcare use and expenditures). The ABM posits an individual's use of health services as a function of (1) predisposing, (2) enabling, (3) need factors, (4) personal health choices and (5) external environment. The individual's characteristics that are predisposing include demographic characteristics (e.g. gender, age, race/ethnicity). The ability of an individual to access a health service is termed as an enabling factor (e.g. public assistance). Need factors are represented by a subjective acknowledgement of need such as a patient's symptoms, or a professional's judgment of the need for healthcare based on disease characteristics. Personal health choices and external environment characteristics also influence an individual's use of health services. 
Figure 1: Andersen Behavioral Model

Environment
Population Characteristics

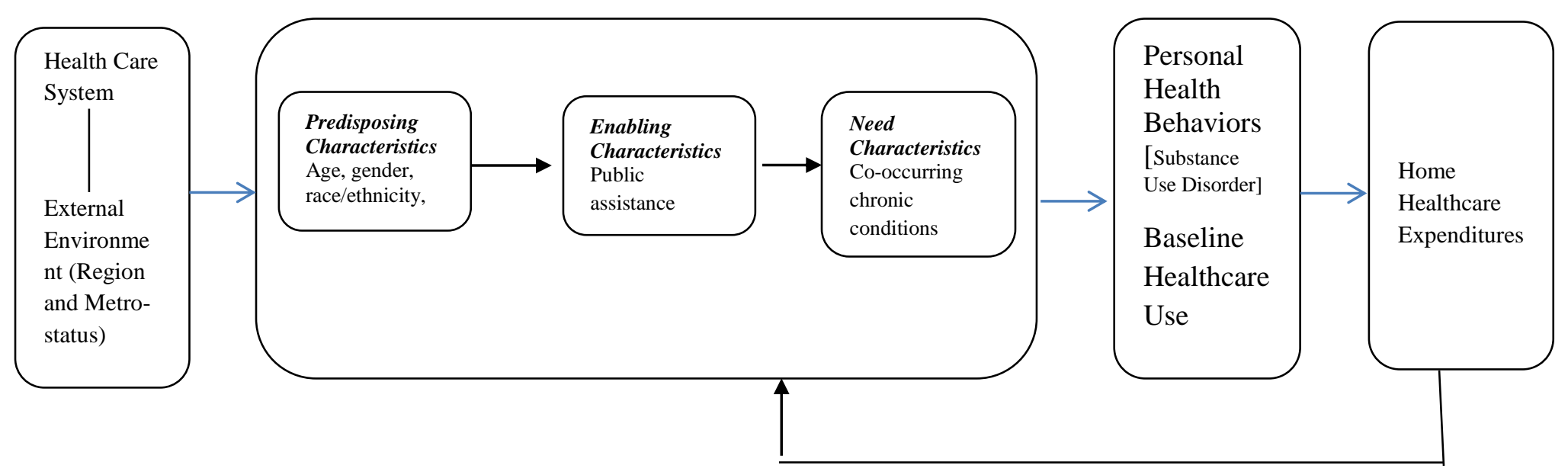

RM Andersen. Revisiting the behavioral model and access to medical care: does it matter? $J$ Health Social Behavior 1995; 36:1-10

\section{METHODS}

\section{Study Design}

We used a retrospective, observational, cohort study design. For the purposes of this study we used the Medicare 5\% sample claims database for years 2006-2007.

\section{Data Source: Medicare Five-Percent Sample Claims Database}

The Medicare 5\% sample claims database contains all final action claims data for a random five percent sample of all claims of Medicare beneficiaries (http://aspe.hhs.gov/datacncl/datadir/cms.htm). Available standard analytic files (SAF) in Medicare 5\% sample claims database are: (1) inpatient, (2) outpatient (encompassing claims from physician office), (3) skilled nursing facility, (4) carrier, (5) hospice care, (6) home health, and (7) durable medical equipment analytic data files. The Medicare 5\% sample claims database can be used to conduct both cross-sectional and longitudinal studies. A unique, de-identified Medicare beneficiary identifier is assigned to each enrollee, which is used to follow them 
longitudinally. Several studies have been conducted using this database (Bozic et al., 2012;

Bozic et al., 2013; Escarce \& McGuire, 2003). The information recorded in the claims dataset include dates of service provided, charge and payment amounts, clinical diagnosis codes, as well as procedure codes. Information on demographic characteristics such as age, gender, and race/ethnicity are available in the denominator files of Medicare claims dataset.

The SAF for home healthcare consist of fee-for-service claims for Medicare-certified services, service dates, claim payment amount, primary diagnosis code (ICD-9-CM codes), up to 9 other diagnosis codes, and total number of home healthcare visits. In the home healthcare SAF, the service begin and end dates does not necessarily reflect dates of services and some of the detailed information on types of care received by Medicare beneficiaries are available in revenue center files.

\section{Study Population:}

Our study population comprised of community-dwelling elderly Medicare beneficiaries aged 65 years and older. Additionally, we required that the elderly Medicare beneficiaries have continuous Medicare Part A and B enrollment for 2006 and 2007. Medicare individuals enrolled in Health Maintenance Organizations (HMO) were excluded due to unavailability of HMO claims in the Medicare 5\% sample database. Individuals with PD were identified using International Classification of Diseases, Ninth Revision, Clinical Modification (ICD-9-CM) codes of 332.xx in calendar year 2006. Previous literature has shown that identifying PD individuals with ICD-9-CM codes from Medicare database to be reliable with modest sensitivity $(61.13 \%)$ and positive predictive value $(65.13 \%)$, and the very high specificity $(99.08 \%)$ when all standard analytic files were used (Noyes, Liu, Holloway, \& Dick, 2007). To be included in the final study sample, individuals with and without PD were required to have positive direct 
healthcare expenditures. Individuals with end-stage renal disease (ESRD) as well as those without full year enrollments due to death or some other reason were excluded from the final sample.

\section{Measures}

Dependent Variable:

\section{Home healthcare Use}

Home healthcare visits were identified from the home healthcare SAF. Elderly Medicare beneficiaries with any home healthcare visit during 2007 were considered to be home health users.

\section{Healthcare Expenditures}

Among users of home healthcare, we examined home healthcare expenditures. We used actual Medicare payments to estimate home healthcare expenditures from home healthcare file. Expenditure data are generally skewed to the right. Therefore, we transformed expenditures with natural logarithm.

\section{Key Independent Variable: PD and no PD}

Presence or absence of PD constituted the key independent variable for this study.

Presence of PD was ascertained by using ICD-9-CM codes of 332.xx during 2006 calendar year.

\section{Other Independent Variables}

The predisposing characteristics comprised of gender (male/female), race/ethnicity

(white, African American, Latino and other), and age (65-74; and 75 years and older). Enabling characteristics will consist of public assistance (which was indicated by Medicare premiums and deductibles that were subsidized by the state keeping in view the financial status of the enrollee). The need factors constituted of co-occurring chronic conditions. $\underline{\text { Healthcare behavior }}$ consisted 
of substance use disorders that included alcohol, tobacco and drug use. This domain also included baseline healthcare use. The external environment factors comprised of census region and metro status.

\section{Statistical Methods}

Statistically significant differences in home healthcare use in 2007 by presence of PD were ascertained with chi-square tests. We used logistic regressions to examine the association between home healthcare use and PD after controlling for predisposing, enabling, need factors, personal health behaviors and external environment.

We examined the differences in average home healthcare expenditures between PD and no PD groups by using t-tests. We also conducted Ordinary Least Square (OLS) regressions on logged home healthcare expenditures in 2007 adjusting for all the independent variables to examine the relationship between PD and home healthcare expenditures.

\section{Post-Regression Linear Decomposition of Home Healthcare Expenditures}

The Blinder and Oaxaca decomposition technique has been used for several decades after it was initially developed to explain wage differentials between men and women (Oaxaca, 1973). Blinder-Oaxaca decomposition technique can be expressed with the following sets of equations:

$$
Y_{i}=\beta_{0 i}+\Sigma_{j=1}^{n} X_{i}^{\prime} \beta_{i}+€_{i}
$$

Where $Y_{i}$ represents the dependent variable (in this case logged home healthcare expenditures) for $\mathrm{i}^{\text {th }}$ individual who may or may not have PD; $\mathrm{X}^{\prime}$ represents the vector of independent variables such predisposing, enabling, need, personal health behavior and external environment factors which may be associated with home healthcare expenditures; $\beta_{\mathrm{i}}$ is the 
parameter vector and $\epsilon_{\mathrm{i}}$ is the error term which follows a standard normal distribution $\left(0, \sigma_{\epsilon}\right)$; and $\beta_{0 \mathrm{i}}$ is the estimated intercept.

According to the Blinder-Oaxaca decomposition technique, the difference in logtransformed home healthcare expenditures among individuals with and without PD can be expressed as follows:

$$
\bar{Y}^{P D}-\bar{Y}^{N P D}=\left(\hat{\beta}_{0}^{P D}-\hat{\beta}_{0}^{N P D}\right)+\left(\sum_{j=1}^{n} \hat{\beta}_{j}^{P D} \bar{X}_{j}^{P D}-\sum_{j=1}^{n} \hat{\beta}_{j}^{N P D} \bar{X}_{j}^{N P D}\right)
$$

Where the intercepts of the OLS regressions among individuals with and without PD are represented respectively as $\hat{\beta}_{0}^{P D}$ and $\hat{\beta}_{0}^{N P D}$; the estimated $\mathrm{j}^{\text {th }}$ coefficient of the OLS regression among individuals with and without PD are represented as $\hat{\beta}_{j}^{P D}$ and $\hat{\beta}_{j}^{N P D}$ respectively; and the average distribution of the jth measured characteristics among individuals with and without PD are represented by $\bar{X}_{j}^{P D}$ and $\bar{X}_{j}^{N P D}$ respectively. The estimated differences in expenditures can be divided further into two components: explained and unexplained differences.

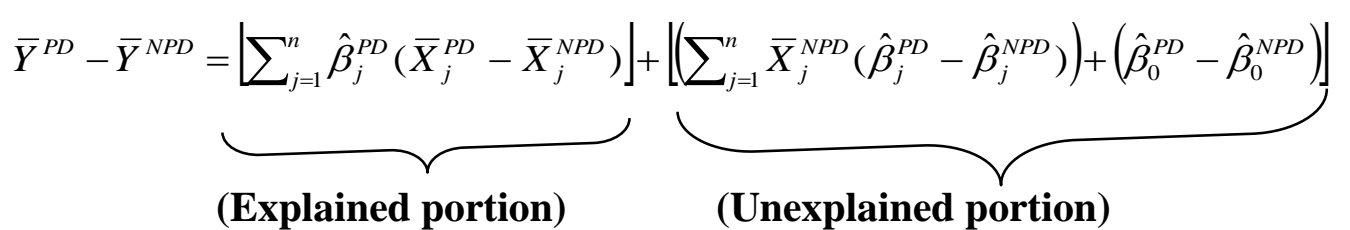

The explained portion of the gap is the sum of the differences between individuals with and without PD in terms of the observed or measured characteristics weighted by the estimated coefficients of individuals with PD. The unexplained portion of the gap represents the sum of the differences of the estimated coefficients between individuals with and without PD weighted by the estimated coefficient of individuals without PD. There is an 'index-number' problem that exists in this approach which arises based on the group which is taken as reference. As for 
instance, the estimated explained and unexplained gaps might differ depending on whether individuals with PD or without PD are taken as the reference. One possible solution to this problem suggested by Neumark (1988) is to use the regression estimates from pooled regressions. The equation for Neumark's decomposition using the pooled regression coefficient is as follows:

$$
\begin{aligned}
& \bar{Y}^{P D}-\bar{Y}^{N P D}=\left\lfloor\sum_{j=1}^{n} \hat{\beta}_{j}^{\text {pooled }}\left(\bar{X}_{j}^{P D}-\bar{X}_{j}^{N P D}\right)\right\rfloor+\left[\left(\sum_{j=1}^{n} \bar{X}_{j}^{P D}\left(\hat{\beta}_{j}^{P D}-\hat{\beta}_{j}^{\text {pooled }}\right)\right)+\left(\sum_{j=1}^{n} \bar{X}_{j}^{\text {NPD }}\left(\hat{\beta}_{0}^{\text {pooled }}-\hat{\beta}_{0}^{\text {NPD }}\right)\right)\right]
\end{aligned}
$$

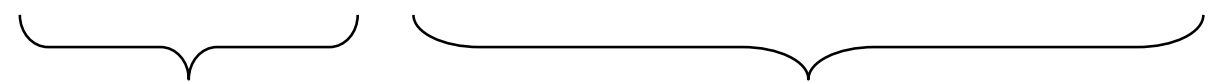

$$
\begin{aligned}
& \text { (Explained portion using (Unexplained portion using pooled }
\end{aligned}
$$

According to the Neumark's decomposition using the pooled regression coefficient, the explained portion of the gap is the sum of the differences between individuals with and without PD in terms of the observed or measured characteristics weighted by the estimated pooled coefficients of the regression. The unexplained portion of the gap in this case represents the sum of the differences of the estimated coefficients between individuals with and without PD weighted by the estimated pooled coefficient of regression. In this study we report estimates from pooled, individuals with PD, and individuals without PD regressions to differentiate between the explained and unexplained portion of the home healthcare costs among individuals with and without PD (Neumark 1988).

\section{Post-Regression Non-Linear Decomposition of Home Healthcare Use}

To assess the extent to which differences in home healthcare use among individuals with and without PD can be explained by predisposing, enabling, need factors, personal health behaviors and external environment we used a post-regression non-linear decomposition technique. The differences in home healthcare use between the two groups of elderly individuals 
with and without PD are compartmentalized into two parts: 1) one part is attributable to the differences in characteristics, which is the explained portion of the differences and 2) the other part is the differences attributable to differences in coefficients. The contribution of each of the individual-level factors to the gap in terms of home healthcare use between the two groups is estimated by the change in the mean predicted probability by superimposing the distribution of elderly Medicare beneficiaries with PD to those without PD, keeping all other factors constant (Fairlie, 2003). Some of the common problems associated with the non-linear decomposition techniques include the "index number" problem and path dependency. The multivariate technique developed by Powers et al. 2011 overcomes the “index number" problem by using pooled coefficients. Moreover, the mvdcmp technique of Powers et al. 2011, uses an algorithm that helps in transforming the estimates from the general regression equation using an ANOVAtype or centered-effects restriction into normalized equation. This helps in overcoming the bias due to reference groups.

All analyses were conducted using SAS version 9.3 (SAS Institute Inc., Cary, NC) and STATA version 13.0. Microsoft Excel 2010 was used to perform the Blinder-Oaxaca linear decomposition and multivariate non-linear decomposition.

\section{RESULTS}

Table 1 displays the description of the study sample. The study sample consisted of 10,865 elderly Medicare beneficiaries with PD and 997,785 elderly Medicare beneficiaries without PD. In terms of predisposing, enabling, personal health behavior, need and external environmental factors, all the characteristics were statistically significantly different between elderly Medicare beneficiaries with and without PD except for baseline substance use disorder and cancer. 
Predisposing characteristics: Among elderly Medicare beneficiaries with PD, a higher percentage were men (50.1\%) and among those without PD a significantly lower percentage were men (39.8\%). A greater proportion of elderly Medicare beneficiaries with PD were 75 years and older (63.9\%) and a lower proportion of elderly Medicare beneficiaries without PD were 75 years and older $(48.5 \%)$. The study sample consisted of an overwhelming majority of whites in both the groups (around $90 \%$ in both groups).

Enabling characteristics: A higher percentage of elderly Medicare beneficiaries were on public assistance among those with PD (16.0\%) compared to those without PD (11.4\%).

Need characteristics: Significantly higher proportion of elderly Medicare beneficiaries with PD had mental health conditions such as anxiety (10.9\% vs $5.9 \%)$ and depression ( $23.6 \%$ vs. $8.8 \%)$ compared to those without PD. In terms of the physical health conditions, elderly Medicare beneficiaries with PD compared to those without PD had a higher proportion of arthritis (33.9\% vs. 29.5\%), Chronic Obstructive Pulmonary Disorders (COPD) (18.0\% vs. 16.6\%), Chronic Renal Failure (CRF) (8.4\% vs 5.9\%), Chronic Renal Problems (CRP) (8.8\% vs. 6.5\%), heart disease (62.5\% vs. $51.9 \%)$, stroke (17.0\% vs. $6.9 \%)$, and thyroid disorder (26.1\% vs. $22.5 \%)$. $\underline{\text { Healthcare Behavior: }}$ : Elderly Medicare beneficiaries with PD had significantly higher rates of baseline inpatient, outpatient, hospice, skilled nursing facilities, and durable medical equipment use.

External Environment: An overwhelmingly higher percentage of elderly Medicare beneficiaries resided in the metro regions in both the two groups (approximately $80 \%$ in both groups). Elderly Medicare beneficiaries in both PD and no PD groups resided primarily in the Southern census region (around 38\% in both groups) followed by Mid-West, North-East and Western regions. 
Table 2 exhibits the relationship between predisposing, enabling, personal health behavior, need and external environmental factors and home healthcare use by PD status. For convenience of reading, we only present those with home healthcare use by PD status. There were 2,445 and 91,971 elderly Medicare beneficiaries with and without PD respectively who had positive home healthcare use. It was observed that for predisposing, enabling, need, personal health behavior and external environmental factors, the home healthcare use was statistically significantly higher among elderly Medicare beneficiaries with PD compared to those without PD.

Table 3 summarizes the findings from the logistic regression analyses of home healthcare use in the study sample. It was observed that after controlling for predisposing, enabling, need, personal health behavior, and external environmental factors, elderly individuals with PD were greater than two times (Adjusted Odds Ratio: 2.07; 95\% Confidence Interval- 1.97-2.17) more likely to have home healthcare use compared to those without PD.

Table 4 provides the average total and home healthcare of expenditures among those with home healthcare use. The average total expenditures among elderly Medicare beneficiaries (who used home healthcare service) with PD $(\$ 31,154)$ was significantly higher compared to those without PD $(\$ 29,465)$. The average home healthcare expenditures among elderly Medicare beneficiaries (who used home healthcare service) with PD was 1.34 times higher compared to those without PD (\$6,792 vs. \$5,060).

Table 5 presents the results from the OLS regressions on log-transformed home healthcare expenditures among elderly individuals with and without PD, who had a positive home healthcare expenditure. Table 5 also provides results from OLS regression on a pooled sample which included both elderly Medicare beneficiaries with and without PD. The bottom 
panel of Table 5 provides the parameters estimates of the key independent variable of this study (presence or absence of PD). It can be noted from this part that elderly Medicare beneficiaries with PD had approximately $37 \%$ (calculated using the formula $\exp ^{(\beta)}-1$ ) higher home healthcare expenditure compared to those without PD.

Table 6 shows the results from the non-linear decomposition on the home healthcare use (yes/no). Elderly Medicare beneficiaries with PD had higher home healthcare use compared to those without PD (22.50\% vs. 9.22\%). This translated into a 13.28 percentage point difference between these two groups in terms of home healthcare use. From the multivariate decomposition analysis, it was observed that out of the 13.28 percentage point difference in home healthcare use among elderly Medicare beneficiaries, 3.54 percentage point difference was explained by the individual level variables included in this study. Thus, approximately $27 \%$ difference in home healthcare use among elderly Medicare beneficiaries with and without PD was explained by the predisposing, need, personal health choice and external environmental factors. Need characteristics (physical and mental health conditions) and personal health behaviors (baseline resource use) of the elderly Medicare beneficiaries explained the highest (approximately 80\%) proportion of the home healthcare use differences between elderly Medicare beneficiaries with and without PD.

Table 7 displays the results of linear decomposition of home healthcare expenditures among elderly Medicare beneficiaries with and without PD. These analyses were restricted to only those who used home healthcare. The mean log-transformed home healthcare expenditures among elderly Medicare beneficiaries with and without PD was 8.44 and 8.10 units respectively. This translated into a 0.34 unit difference in mean log-transformed home healthcare expenditures. Using PD, No PD and pooled weights, the explained portion of the home 
healthcare expenditure differences among elderly Medicare beneficiaries with and without PD ranged from $10.8 \%, 7.8 \%$ and $7.7 \%$ respectively. The remaining majority of the home healthcare expenditure differences remained unexplained. It was observed that baseline resource use explained the highest proportion of the home healthcare expenditure differences followed by the mental health conditions (anxiety and depression). Using the pooled weights, it can be inferred that ceteris paribus, if the baseline resource use was similar between elderly Medicare beneficiaries with and without PD, then the log-transformed home healthcare expenditure would decrease by 0.1 units. The negative coefficient of the predisposing characteristics signifies that if the gender, race/ethnicity and age characteristics of elderly Medicare beneficiaries with and without PD were similar, then the difference in log-transformed home healthcare expenditures would increase by 0.06 units.

\section{DISCUSSION}

The present study examined the magnitude of the difference in home healthcare resource use and expenditures among elderly Medicare beneficiaries with and without PD. This study also evaluated the extent to which predisposing, enabling, need, personal health behaviors and external environmental factors explained the differences among elderly Medicare beneficiaries with and without PD. It was observed that after adjusting for the predisposing, need, personal health choice and external environmental factors, elderly Medicare beneficiaries with PD had $13.28 \%$ and $37 \%$ higher home healthcare use and expenditures respectively compared to those without PD. Previous studies have consistently pointed that home healthcare use and expenditures among individuals with PD are significantly higher among individuals with PD ((Bhattacharjee \& Sambamoorthi, 2013; Noyes et al., 2006; Pressley et al., 2003; Rubenstein, Chrischilles, \& Voelker, 1997)). However, no study examined the factors associated with higher 
home healthcare use and expenditures among elderly individuals with PD and to what extent the individual-level factors explain the differences. The unique contribution of this study is to provide the factors associated with higher home healthcare resource use and expenditures among elderly Medicare beneficiaries with PD and provide a quantified assessment of the extent to which these individual-level factors explain the use and expenditures differences using a nationally representative sample of Medicare beneficiaries.

In terms of resource use, approximately $27 \%$ of the 13.28 percentage point differences in home healthcare use among elderly Medicare beneficiaries were explained by the individuallevel factors adjusted in this study. The remaining $73 \%$ unexplained portion can be due to several factors such as severity and duration of PD, medication adherence and inclination towards seeking health care. Findings from this study suggest that the need characteristics such as baseline comorbidities and personal health behavior characteristics such as resource use (apart from home healthcare) explained the highest proportion of the explained differences. These findings underscore the importance of developing interventions such as development of appropriate evidence based co-management of multiple chronic conditions. Moreover, these findings also suggest that there is a need of collaborative care among different specialists such as neurologists, endocrinologists, mental health specialists to provide a complete and holistic care to these elderly individuals with chronic diseases. Integrated Delivery Systems (IDS) where primary physicians serve as the gate-keeper and maintain a good referral system can also be helpful in treating elderly individuals with multiple chronic conditions. In the light of recent Affordable Care Act (ACA), there is an emphasis on team-based approaches such Patient Centered Medical Home (PCMH) where continuous and well-coordinated care is provided by a team of healthcare providers 
(http://www.acponline.org/advocacy/state_health_policy/hottopics/pcmh.pdf). The aims of these PCMHs are to provide evidence based treatments for acute and chronic conditions, as well as providing preventive services. These types of care models may improve health outcomes of elderly individuals and hence has the potential to reduce service use and expenditures.

In terms of the home healthcare expenditures among elderly Medicare beneficiaries having positive home healthcare use, it was observed that only $11 \%$ of the differences in home healthcare were explained by the individual-level factors adjusted in this study. One of the major reasons of the high unexplained portion may be due to absence of certain variables such as activities of daily living (ADL), instrumental activities of daily living (IADL), mental and physical health status. Elderly individuals with PD require high assistance with their daily activities. Moreover, as the disease progresses, individuals with PD experience higher impairment in their mental and physical health status, which in turn leads to compromised quality of life. In a study by Noyes et al. (2006) among Medicare beneficiaries it was observed that elderly Medicare beneficiaries with PD had significantly higher limitations of ADLs (average of 2.9 ADLs for individuals with PD vs. 0.8 ADL for individuals without PD) compared to those without PD that may be attributed to the higher home healthcare use and expenditures. Due to the limitation of the dataset, this important variable was not adjusted which may be attributed to the higher unexplained portion.

One of the notable findings from this study is that the mental health conditions, particularly depression contributed a significant proportion of the explained portion of both home healthcare use and expenditures. This finding is consistent with a recent study among community-dwelling elderly individuals with PD, which found that mental health conditions such as depression and anxiety are the major drivers of higher home healthcare expenditures 
(Bhattacharjee \& Sambamoorthi). It has been well documented in the existing literature that mental health conditions such as depression often leads to psychosocial disabilities as well as ADL impairment among individuals with PD, which in turn may lead to excess negative health outcomes (Oluwadamilola et al. 2012). The prevalence of depression in our study sample was approximately 3 times higher among elderly Medicare beneficiaries with PD compared to those without PD. Given this high prevalence of depression in the study sample and the associated negative health outcomes, it is possible that co-occurring depression may lead to higher home healthcare use and expenditures. Moreover, it is noted that overall, need and personal health behavior factors explained the biggest proportion of the explained portions in both use and expenditures.

The study strengths are large sample size, representative sample, and comprehensive list of variables. While interpreting the findings, the following limitations need to be noted. Prescription drug expenditures information was not available. The findings from this study are not generalizable to other populations or setting. Fee-for-service, HMO enrollees are excluded from the study sample. Users of home healthcare may be different from non-users of home health care in unobserved variables. Our study does not control for such selection bias. Five percent Medicare sample will not include many variables that are associated with home healthcare use. This may lead to underestimation of the explained portion of the estimated differences in home healthcare expenditures among individuals with and without PD. However, by using a representative sample of Medicare beneficiaries with linked Medicare claims, we can estimate the extent to which unmeasured factors can underestimate explained portion of the differences in expenditures among individuals with and without PD. 


\section{CONCLUSION}

Notwithstanding the limitations, this study examined the magnitude of the difference in home healthcare resource use and expenditures among elderly Medicare beneficiaries with and without PD and also evaluated the extent to which predisposing, enabling, need, personal health choice and external environmental factors explained these differences. Elderly individuals with PD had $13.28 \%$ and $37 \%$ higher home healthcare use and expenditures compared to those without PD. Individual-level factors used in this study explained $28 \%$ and $10 \%$ of the differences in home healthcare use and expenditures respectively. Future studies should include some of the factors such as ADL, IADL, and physical and mental health status to understand their influence on the home healthcare use and expenditures among individuals with PD. 


\section{REFERENCES}

A Data Book: Health Care Spending and the Medicare Program. June 2012. Available from URL: http://www.medpac.gov/documents/Jun12DataBookEntireReport.pdf [Accessed 2013 May 24].

Andersen, R. M. (1995). Revisiting the behavioral model and access to medical care: Does it matter? Journal of Health and Social Behavior, 36(1), 1-10.

Bhattacharjee, S., \& Sambamoorthi, U. (2013). Co-occurring chronic conditions and healthcare expenditures associated with parkinson's disease: A propensity score matched analysis. Parkinsonism \& Related Disorders.

Blinder, AS (1973). Wage Discrimination: Reduced Form and Structural Variables". Journal of Human Resources, 8, 436-455.

Bozic, K. J., Lau, E., Kurtz, S., Ong, K., Rubash, H., Vail, T. P., et al. (2012). Patient-related risk factors for periprosthetic joint infection and postoperative mortality following total hip arthroplasty in medicare patients. The Journal of Bone and Joint Surgery.American Volume, 94(9), 794-800. doi:10.2106/JBJS.K.00072

Bozic, K. J., Ong, K., Lau, E., Berry, D. J., Vail, T. P., Kurtz, S. M., et al. (2013). Estimating risk in medicare patients with THA: An electronic risk calculator for periprosthetic joint infection and mortality. Clinical Orthopaedics and Related Research, 471(2), 574-583. doi:10.1007/s11999-012-2605-z

Bureau of Labor Statistics (BLS).Available from: http://data.bls.gov/cgi-bin/surveymost. [accessed May 25, 2013].

Eppig, F. J., \& Chulis, G. S. (1997). Matching MCBS (medicare current beneficiary survey) and medicare data: The best of both worlds. Health Care Financing Review, 18(3), 211-229.

Escarce, J. J., \& McGuire, T. G. (2003). Methods for using medicare data to compare procedure rates among asians, blacks, hispanics, native americans, and whites. Health Services Research, 38(5), 1303-1317.

Fairlie, RW (2003). An Extension of the Blinder-Oaxaca Decomposition Technique to Logit and Probit Models. Center Discussion Paper no. 873, Yale University.

Fortinsky, R. H., Fenster, J. R., \& Judge, J. O. (2004). Medicare and medicaid home health and medicaid waiver services for dually eligible older adults: Risk factors for use and correlates of expenditures. The Gerontologist, 44(6), 739-749.

Henton, F. E., Hays, B. J., Walker, S. N., \& Atwood, J. R. (2002). Determinants of medicare home healthcare service use among medicare recipients. Nursing Research, 51(6), 355-362. 
Home Health Care and Discharged Hospice Care Patients: United States, 2000 and 2007. April 2011. Available from URL: http://www.cdc.gov/nchs/data/nhsr/nhsr038.pdf [Accessed 2013 May 24].

Home Healthcare Services- Chapter 8. March 2012. Available from URL: http://www.medpac.gov/chapters/Mar12_Ch08.pdf [Accessed 2013 May 23].

Moon, S., \& Shin, J. (2006). Health care utilization among medicare-medicaid dual eligibles: A count data analysis. BMC Public Health, 6, 88-88.

Moore, A. R., \& O'Keeffe, ,S.T. (1999). Drug-induced cognitive impairment in the elderly. Drugs \& Aging, 15(1), 15-28.

Neumark, D. Employers' discriminatory behavior and the estimation of wage discrimination. J Hum Resour. 1988; 23(3), 279-95.

Noyes, K., Liu, H., Holloway, R., \& Dick, A. W. (2007). Accuracy of medicare claims data in identifying parkinsonism cases: Comparison with the medicare current beneficiary survey. Movement Disorders: Official Journal of the Movement Disorder Society, 22(4), 509-514.

Noyes, K., Liu, H., Li, Y., Holloway, R., \& Dick, A. W. (2006). Economic burden associated with parkinson's disease on elderly medicare beneficiaries. Movement Disorders: Official Journal of the Movement Disorder Society, 21(3), 362-372.

Olanow, C. W., Stern, M. B., \& Sethi, K. (2009). The scientific and clinical basis for the treatment of parkinson disease (2009). Neurology, 72(21), S1-S136.

doi:10.1212/WNL.0b013e3181a1d44c

Oluwadamilola OO, Njideka OU, Frank OI, Mustapha DA. Frequency of cognitive impairment and depression in Parkinson's disease: A preliminary case-control study. Niger Med J. 2012;53: 65-70.

Oaxaca R. Male-female wage differentials in urban labor markets. International Econ Rev. 1973; 14(3):693-709

Park, A., \& Stacy, M. (2009). Non-motor symptoms in parkinson's disease. Journal of Neurology, 256 Suppl 3, 293-298. doi:10.1007/s00415-009-5240-1

Parrish, M., Giunta, N., \& Adams, S. (2003). Parkinson's disease caregiving: Implications for care management. Care Management Journals: Journal of Case Management ; the Journal of Long Term Home Health Care, 4(1), 53-60.

Powers, D.A., Yoshika, H, \& Yun, M (2011). mvdcmp: Multivariate decomposition for nonlinear response models. The Stata Journal, 11(4), 556-576. 
Pressley, J. C., Louis, E. D., Tang, M., Cote, L., Cohen, P. D., Glied, S., et al. (2003). The impact of comorbid disease and injuries on resource use and expenditures in parkinsonism.

Neurology, 60(1), 87-93.

Rubenstein, L. M., Chrischilles, E. A., \& Voelker, M. D. (1997). The impact of parkinson's disease on health status, health expenditures, and productivity. estimates from the national medical expenditure survey. PharmacoEconomics, 12(4), 486-498.

Vickers, L. F., \& O'Neill, ,C.M. (1998). An interdisciplinary home healthcare program for patients with parkinson's disease. Rehabilitation Nursing: The Official Journal of the Association of Rehabilitation Nurses, 23(6), 286. 


\begin{tabular}{|c|c|c|c|c|c|}
\hline \multicolumn{6}{|c|}{$\begin{array}{c}\text { Table 1: Description of Study Sample by Parkinson's disease Status } \\
\text { National Medicare 5\% Sample - 2006, } 2007\end{array}$} \\
\hline Variables & PD & Col \% & No PD & Col \% & Sig \\
\hline & $\mathrm{N}=\mathbf{1 0 , 8 6 5}$ & & $\mathrm{N}=\mathbf{9 9 7 , 7 8 5}$ & & \\
\hline \multicolumn{6}{|c|}{ Predisposing characteristics } \\
\hline Gender & & & & & $* * *$ \\
\hline Female & 5,421 & 49.9 & 600,932 & 60.2 & \\
\hline Male & 5,444 & 50.1 & 396,853 & 39.8 & \\
\hline Race/Ethnicity & & & & & $* * *$ \\
\hline White & 10,007 & 92.1 & 891,280 & 89.3 & \\
\hline $\mathrm{AA}$ & 425 & 3.9 & 65,266 & 6.5 & \\
\hline Other & 433 & 4.0 & 41,239 & 4.1 & \\
\hline Age Group & & & & & $* * *$ \\
\hline $65-74$ & 3,927 & 36.1 & 514,211 & 51.5 & \\
\hline $75,+$ & 6,938 & 63.9 & 483,574 & 48.5 & \\
\hline \multicolumn{6}{|c|}{ Enabling characteristic } \\
\hline Public assistance & & & & & $* * *$ \\
\hline Yes & 1,742 & 16.0 & 113,528 & 11.4 & \\
\hline No & 9,123 & 84.0 & 884,257 & 88.6 & \\
\hline \multicolumn{6}{|c|}{ External Environmental characteristics } \\
\hline Census region & & & & & $* * *$ \\
\hline North-East & 2,399 & 22.1 & 192,983 & 19.3 & \\
\hline Midwest & 2,837 & 26.1 & 258,335 & 25.9 & \\
\hline South & 3,931 & 36.2 & 386,457 & 38.7 & \\
\hline West & 1,698 & 15.6 & 160,010 & 16.0 & \\
\hline Metro status & & & & & $* * *$ \\
\hline Metro & 8,448 & 77.8 & 752,534 & 75.4 & \\
\hline Non-Metro & 2,417 & 22.2 & 245,251 & 24.6 & \\
\hline \multicolumn{6}{|c|}{ Personal Health Behavior } \\
\hline Substance Use & & & & & \\
\hline Yes & 440 & 4.0 & 38,529 & 3.9 & \\
\hline No & 10,425 & 96.0 & 959,256 & 96.1 & \\
\hline Inpatient visit & & & & & $* * *$ \\
\hline Yes & 3,584 & 33.0 & 185,807 & 18.6 & \\
\hline No & 7,281 & 67.0 & 811,978 & 81.4 & \\
\hline DME visit & & & & & $* * *$ \\
\hline Yes & 4,679 & 43.1 & 292,847 & 29.3 & \\
\hline No & 6,186 & 56.9 & 704,938 & 70.7 & \\
\hline Hospice visit & & & & & $* * *$ \\
\hline Yes & 122 & 1.1 & 2,746 & 0.3 & \\
\hline No & 10,743 & 98.9 & 995,039 & 99.7 & \\
\hline SNF visit & & & & & $* * *$ \\
\hline Yes & 1,597 & 14.7 & 39,780 & 4.0 & \\
\hline No & 9,268 & 85.3 & 958,005 & 96.0 & \\
\hline
\end{tabular}




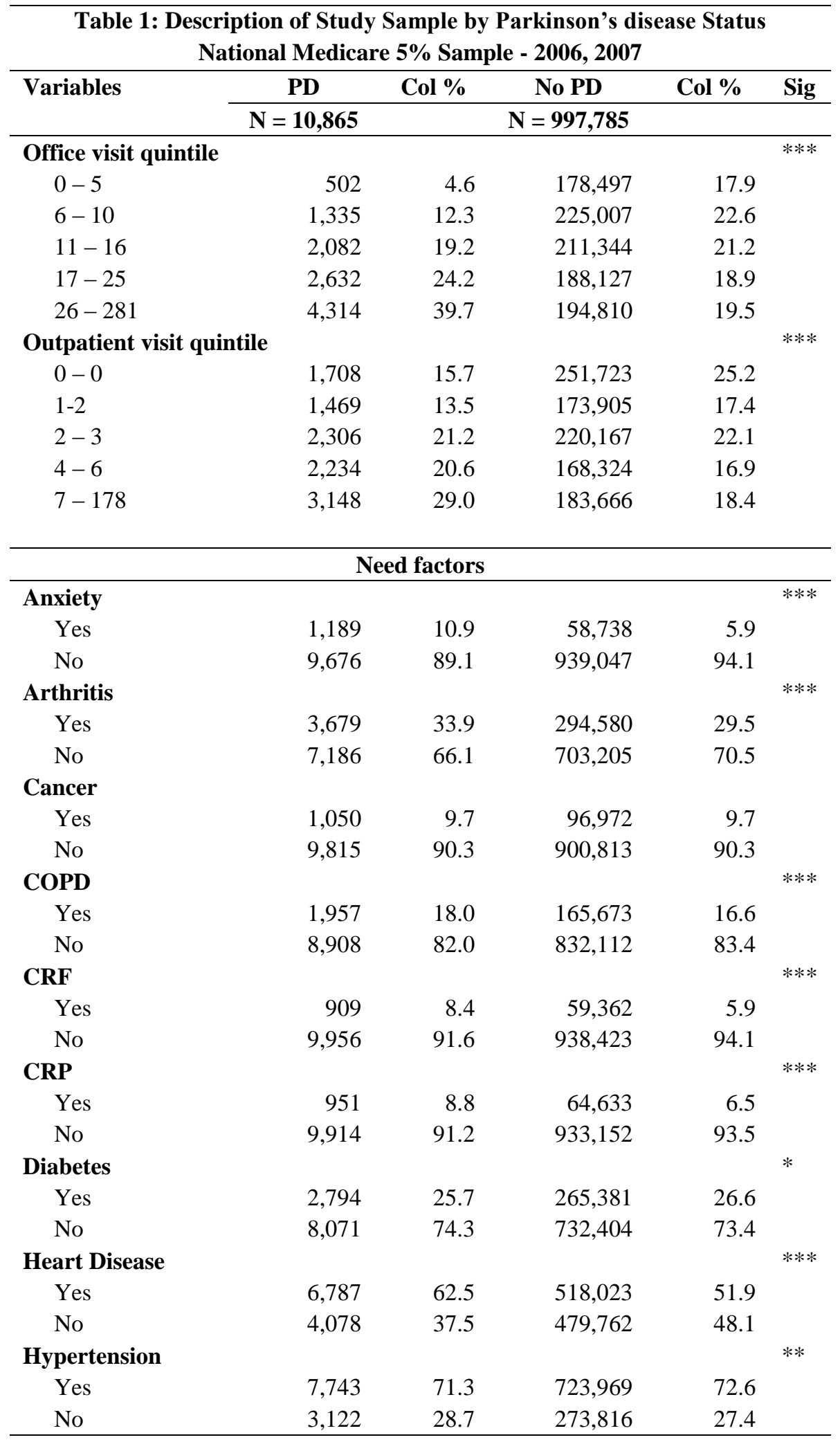

(Contd.) 


\begin{tabular}{|c|c|c|c|c|c|}
\hline \multicolumn{6}{|c|}{$\begin{array}{r}\text { Table 1: Description of Study Sample by Parkinson's di } \\
\text { National Medicare 5\% Sample - 2006, } 2007\end{array}$} \\
\hline \multirow[t]{2}{*}{ Variables } & PD & Col \% & No PD & Col \% & Sig \\
\hline & $\mathrm{N}=\mathbf{1 0 , 8 6 5}$ & & $N=997,785$ & & \\
\hline Major Depression & & & & & *** \\
\hline Yes & 2,568 & 23.6 & 87,822 & 8.8 & \\
\hline No & 8,297 & 76.4 & 909,963 & 91.2 & \\
\hline Stroke & & & & & $* * *$ \\
\hline Yes & 1,849 & 17.0 & 68,577 & 6.9 & \\
\hline No & 9,016 & 83.0 & 929,208 & 93.1 & \\
\hline Thyroid disorders & & & & & $* * *$ \\
\hline Yes & 2,837 & 26.1 & 224,754 & 22.5 & \\
\hline No & 8,028 & 73.9 & 773,031 & 77.5 & \\
\hline
\end{tabular}

Note: Based on 10,865 and 997,785 elderly (age 65 or older) Medicare beneficiaries with and without Parkinson's Disease who were continuously enrolled in Medicare Part A and Part B during 2006 and 2007 and were not enrolled in Health Maintenance organizations during 2006 and 2007; had a positive direct total healthcare expenditures; Individuals with end-stage renal disease (ESRD) as well as those without full year enrollments due to death or some other reason were excluded from the final sample.

PD: Parkinson's disease; SUD: Substance Use Disorder; COPD: Chronic Obstructive Pulmonary Disorder; CRF: Chronic Renal Failure; CRP: Chronic Renal Problem; DME: Durable Medical Equipment; HHA: Home Health Agency; SNF: Skilled Nursing Facility

$* * * \mathbf{p}<.001 ; * * .001 \leq \mathbf{p}<.01 ; * .01 \leq \mathbf{p}<.05$ 
Table 2: Number and Percent with Home Healthcare Use by Parkinson's disease National Medicare 5\% Sample, 2006-2007

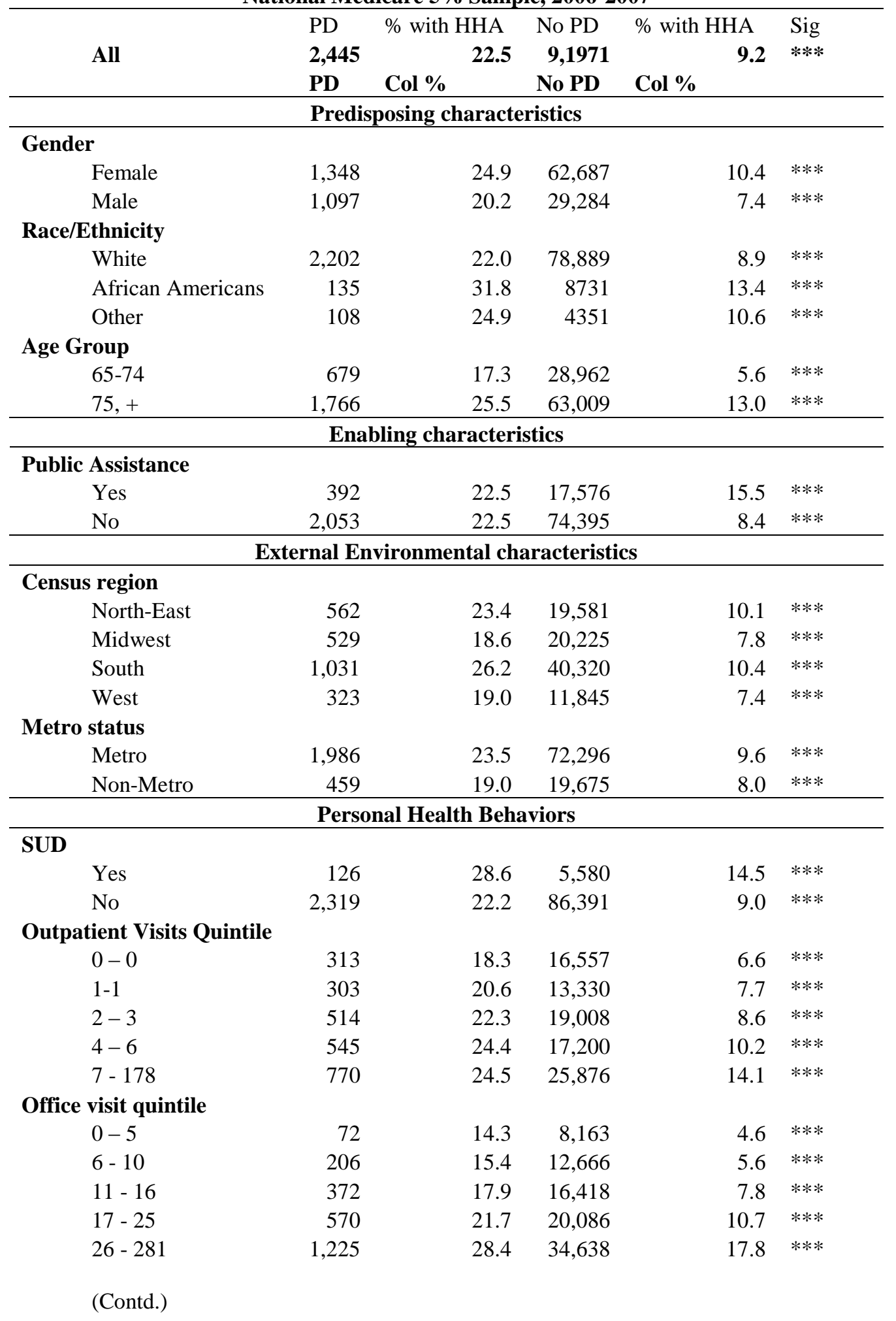


Table 2: Number and Percent with Home Healthcare Use by Parkinson's disease National Medicare 5\% Sample, 2006-2007

\begin{tabular}{|c|c|c|c|c|c|}
\hline \multirow[b]{2}{*}{ All } & PD & $\%$ with HHA & No PD & $\%$ with HHA & $\begin{array}{l}\text { Sig } \\
* * *\end{array}$ \\
\hline & $\begin{array}{l}2,445 \\
\text { PD }\end{array}$ & Col \% & $\begin{array}{l}9,1971 \\
\text { No PD }\end{array}$ & Col \% & \\
\hline \multicolumn{6}{|c|}{ Need factors } \\
\hline \multicolumn{6}{|l|}{ Anxiety } \\
\hline Yes & 334 & 28.1 & 8,594 & 14.6 & $* * *$ \\
\hline No & 2,111 & 21.8 & 83,377 & 8.9 & $* * *$ \\
\hline \multicolumn{6}{|l|}{ Arthritis } \\
\hline Yes & 1,024 & 27.8 & 41,726 & 14.2 & $* * *$ \\
\hline No & 1,421 & 19.8 & 50,245 & 7.1 & $* * *$ \\
\hline \multicolumn{6}{|l|}{ Cancer } \\
\hline Yes & 278 & 26.5 & 11,475 & 11.8 & $* * *$ \\
\hline No & 2,167 & 22.1 & 80,496 & 8.9 & $* * *$ \\
\hline \multicolumn{6}{|l|}{ COPD } \\
\hline Yes & 569 & 29.1 & 25,518 & 15.4 & $* * *$ \\
\hline No & 1,876 & 21.1 & 66,453 & 8.0 & $* * *$ \\
\hline \multicolumn{6}{|l|}{ CRF } \\
\hline Yes & 270 & 29.7 & 11,376 & 19.2 & $* * *$ \\
\hline No & 2,175 & 21.8 & 80,595 & 8.6 & $* * *$ \\
\hline \multicolumn{6}{|l|}{ CRP } \\
\hline Yes & 293 & 30.8 & 11,462 & 17.7 & $* * *$ \\
\hline No & 2,152 & 21.7 & 80,509 & 8.6 & $* * *$ \\
\hline \multicolumn{6}{|l|}{ Diabetes } \\
\hline Yes & 725 & 25.9 & 33,506 & 12.6 & $* * *$ \\
\hline No & 1,720 & 21.3 & 58,465 & 8.0 & $* * *$ \\
\hline \multicolumn{6}{|c|}{ Diabetic Nephropathy } \\
\hline Yes & 41 & 30.4 & 2,232 & 19.6 & $* *$ \\
\hline No & 2,404 & 22.4 & 89,739 & 9.1 & $* * *$ \\
\hline \multicolumn{6}{|c|}{ Heart disease } \\
\hline Yes & 1,714 & 25.3 & 64,601 & 12.5 & $* * *$ \\
\hline No & 731 & 17.9 & 27370 & 5.7 & $* * *$ \\
\hline \multicolumn{6}{|c|}{ Hypertension } \\
\hline Yes & 1,892 & 24.4 & 76,422 & 10.6 & $* * *$ \\
\hline No & 553 & 17.7 & 15,549 & 5.7 & $* * *$ \\
\hline \multicolumn{6}{|l|}{ Depression } \\
\hline Yes & 684 & 26.6 & 14,613 & 16.6 & $* * *$ \\
\hline No & 1,761 & 21.2 & 77,358 & 8.5 & $* * *$ \\
\hline \multicolumn{6}{|l|}{ Stroke } \\
\hline Yes & 538 & 29.1 & 13,148 & 19.2 & $* * *$ \\
\hline No & 1,907 & 21.2 & 78,823 & 8.5 & $* * *$ \\
\hline \multicolumn{6}{|c|}{ Thyroid disorder } \\
\hline Yes & 736 & 25.9 & 25,900 & 11.5 & $* * *$ \\
\hline No & 1,709 & 21.3 & 66,071 & 8.5 & $* * *$ \\
\hline
\end{tabular}

Note: Based on 2,445 and 91,971 elderly (age 65 or older) Medicare beneficiaries with and without Parkinson's disease who were continuously enrolled in Medicare Part A and Part B during 2006 and 2007 and were not enrolled in Health Maintenance organizations during 2006 and 2007; had a positive direct total healthcare expenditures; Individuals with end-stage renal disease (ESRD) as well as those without full year enrollments due to death or some 
other reason were excluded from the final sample. For ease of reading, percentage without home healthcare use by Parkinson's disease status is not presented.

Asterisks represent significant group differences by Parkinson's disease status based on chi-square tests.

SUD: Substance Use Disorder; COPD: Chronic Obstructive Pulmonary Disorder; CRF: Chronic Renal Failure; CRP: Chronic Renal Problem; DME: Durable Medical Equipment; HHA: Home Health Agency; SNF: Skilled Nursing Facility

$* * * p<.001 ; * * .001 \leq p<.01 ; * .01 \leq p<.05$ 


\begin{tabular}{|c|c|c|c|}
\hline \multicolumn{4}{|c|}{$\begin{array}{c}\text { Table 3: Adjusted Odds Ratios and 95\% Confidence Intervals } \\
\text { from Logistic Regression on Home Healthcare Use } \\
\text { National Medicare 5\% sample, 2006-2007 }\end{array}$} \\
\hline & AOR & $95 \% \mathrm{CI}$ & Sig \\
\hline \multicolumn{4}{|l|}{ Parkinson's disease } \\
\hline Yes & 2.07 & {$[1.97,2.17]$} & $* * *$ \\
\hline No & & & \\
\hline \multicolumn{4}{|c|}{ Predisposing characteristics } \\
\hline \multicolumn{4}{|l|}{ Gender } \\
\hline Female & 1.30 & {$[1.28,1.32]$} & $* * *$ \\
\hline Male & & & \\
\hline \multicolumn{4}{|l|}{ Race/Ethnicity } \\
\hline White & & & \\
\hline African American & 1.35 & {$[1.31,1.38]$} & $* * *$ \\
\hline Others & 1.04 & {$[1.00,1.08]$} & $*$ \\
\hline \multicolumn{4}{|l|}{ Age Group } \\
\hline $\begin{array}{l}75,+ \\
65-74\end{array}$ & 2.21 & {$[2.18,2.25]$} & $* * *$ \\
\hline
\end{tabular}

\begin{tabular}{|c|c|c|c|c|}
\hline \multicolumn{5}{|c|}{ Enabling characteristics } \\
\hline \multicolumn{5}{|c|}{ Public Assistance } \\
\hline & Yes & 1.34 & {$[1.31,1.36]$} & $* * *$ \\
\hline \multicolumn{5}{|c|}{ No } \\
\hline \multicolumn{5}{|c|}{ External Environmental characteristics } \\
\hline \multicolumn{5}{|l|}{$\begin{array}{l}\text { Census } \\
\text { Region }\end{array}$} \\
\hline & North-East & 1.28 & {$[1.25,1.31]$} & $* * *$ \\
\hline & Midwest & 1.04 & {$[1.02,1.07]$} & $* * *$ \\
\hline & South & 1.42 & {$[1.39,1.45]$} & $* * *$ \\
\hline & West & & & \\
\hline \multicolumn{5}{|c|}{ Metro status } \\
\hline & Metro & 1.20 & {$[1.18,1.22]$} & $* * *$ \\
\hline & Non-metro & & & \\
\hline
\end{tabular}

Personal Health Behavior

\begin{tabular}{ccccc}
\hline SUD & & & & \\
& Yes & 1.19 & {$[1.15,1.23]$} & $* * *$ \\
& No & & & \\
\multicolumn{2}{c}{$\begin{array}{c}\text { Outpatient visit quintile } \\
0-0\end{array}$} & 0.93 & {$[0.91,0.95]$} & $* * *$ \\
$1-1$ & 0.94 & {$[0.92,0.97]$} & $* * *$ \\
$2-3$ & 0.94 & {$[0.92,0.96]$} & $* * *$ \\
$4-6$ & 0.96 & {$[0.94,0.98]$} & $* * *$ \\
$7-178$ & & & \\
\hline
\end{tabular}




\begin{tabular}{|c|c|c|c|}
\hline & AOR & $95 \% \mathrm{CI}$ & Sig \\
\hline \multicolumn{4}{|c|}{ Office visit quintile } \\
\hline $0-5$ & 0.70 & {$[0.68,0.72]$} & $* * *$ \\
\hline $6-10$ & 0.68 & {$[0.67,0.70]$} & $* * *$ \\
\hline $11-16$ & 0.77 & {$[0.75,0.79]$} & $* * *$ \\
\hline $17-25$ & 0.86 & {$[0.84,0.88]$} & $* * *$ \\
\hline \multicolumn{4}{|c|}{$26-281$} \\
\hline SNF visits & 0.95 & {$[0.94,0.96]$} & $* * *$ \\
\hline Inpatient visits & 1.31 & {$[1.30,1.32]$} & $* * *$ \\
\hline Hospice visits & 0.98 & {$[0.97,0.99]$} & $* * *$ \\
\hline DME visits & 1.05 & {$[1.05,1.05]$} & $* * *$ \\
\hline
\end{tabular}

Need characteristics

\begin{tabular}{|c|c|c|c|c|}
\hline \multicolumn{5}{|l|}{ Anxiety } \\
\hline & Yes & 1.04 & {$[1.01,1.07]$} & $* *$ \\
\hline & No & & & \\
\hline \multicolumn{5}{|c|}{ Arthritis } \\
\hline & Yes & 1.50 & {$[1.48,1.53]$} & $* * *$ \\
\hline & No & & & \\
\hline \multicolumn{5}{|l|}{ Cancer } \\
\hline & Yes & 1.03 & {$[1.01,1.06]$} & $* *$ \\
\hline & No & & & \\
\hline \multicolumn{5}{|l|}{ COPD } \\
\hline & Yes & 1.13 & {$[1.11,1.15]$} & $* * *$ \\
\hline & No & & & \\
\hline \multicolumn{5}{|l|}{ CRF } \\
\hline & Yes & 1.17 & {$[1.14,1.20]$} & $* * *$ \\
\hline & No & & & \\
\hline \multicolumn{5}{|l|}{ CRP } \\
\hline & Yes & 1.11 & {$[1.08,1.14]$} & $* * *$ \\
\hline & No & & & \\
\hline \multicolumn{5}{|c|}{ Diabetes } \\
\hline & Yes & 1.17 & {$[1.15,1.19]$} & $* * *$ \\
\hline & No & & & \\
\hline \multicolumn{5}{|c|}{ Diabetic Nephropathy } \\
\hline & Yes & 1.13 & {$[1.07,1.19]$} & $* * *$ \\
\hline & No & & & \\
\hline & (Contd.) & & & \\
\hline
\end{tabular}


Table 3: Adjusted Odds Ratios and 95\% Confidence Intervals

from Logistic Regression on Home Healthcare Use

National Medicare 5\% sample, 2006-2007

\begin{tabular}{|c|c|c|c|}
\hline & AOR & $95 \% \mathrm{CI}$ & Sig \\
\hline \multicolumn{4}{|l|}{ Heart disease } \\
\hline Yes & 1.29 & {$[1.27,1.31]$} & $* * *$ \\
\hline \multicolumn{4}{|l|}{ No } \\
\hline \multicolumn{4}{|l|}{ Hypertension } \\
\hline Yes & 1.10 & {$[1.08,1.13]$} & $* * *$ \\
\hline \multicolumn{4}{|l|}{ No } \\
\hline \multicolumn{4}{|l|}{ Depression } \\
\hline Yes & 1.22 & {$[1.19,1.25]$} & $* * *$ \\
\hline No & & & \\
\hline \multicolumn{4}{|l|}{ Stroke } \\
\hline Yes & 1.32 & {$[1.29,1.35]$} & $* * *$ \\
\hline No & & & \\
\hline \multicolumn{4}{|l|}{ Thyroid disorder } \\
\hline Yes & 1.02 & {$[1.00,1.03]$} & \\
\hline No & & & \\
\hline
\end{tabular}

Note: Based on 10,865 and 997,785 elderly (age 65 or older) Medicare beneficiaries with and without Parkinson's Disease who were continuously enrolled in Medicare Part A and Part B during 2006 and 2007 and were not enrolled in Health Maintenance organizations during 2006 and 2007; had a positive direct total healthcare expenditures; Individuals with end-stage renal disease (ESRD) as well as those without full year enrollments due to death or some other reason were excluded from the final sample.

PD: Parkinson's disease; AOR: Adjusted Odds Ratio; CI: Confidence Intervals; SUD: Substance Use Disorder; COPD: Chronic Obstructive Pulmonary Disorder; CRF: Chronic Renal Failure; CRP: Chronic Renal Problem; DME: Durable Medical Equipment; SNF: Skilled Nursing Facility

$* * * \mathbf{p}<.001 ; * * .001 \leq \mathbf{p}<.01 ; * .01 \leq \mathbf{p}<.05$ 


\begin{tabular}{|c|c|c|c|c|}
\hline \multicolumn{5}{|c|}{$\begin{array}{l}\text { Table 4: Average Total and Home Healthcare Expenditures amo } \\
\text { Users } \\
\text { Elderly Individuals with and without PD } \\
\text { National Medicare 5\% sample, 2006,2007 } \\
\end{array}$} \\
\hline & \multicolumn{2}{|c|}{$\begin{array}{c}\text { PD } \\
N=2,445\end{array}$} & \multicolumn{2}{|c|}{$\begin{array}{c}\text { No PD } \\
\mathbf{N}=91,971\end{array}$} \\
\hline & Average & Std. Dev & Average & Std. Dev \\
\hline Total $* *$ & 31,154 & 27,249 & 29,465 & 27,107 \\
\hline HHA $* * *$ & 6,792 & 6,640 & 5,060 & 5,849 \\
\hline \% spent on Home Healthcare & $21.8 \%$ & & $17.2 \%$ & \\
\hline
\end{tabular}

Note: Based on 2,445 and 91,971 elderly (age 65 or older) Medicare beneficiaries with and without Parkinson's disease who were continuously enrolled in Medicare Part A and Part B during 2006 and 2007 and were not enrolled in Health Maintenance organizations during 2006 and 2007; had a positive direct home healthcare expenditures; Individuals with end-stage renal disease (ESRD) as well as those without full year enrollments due to death or some other reason were excluded from the final sample. For ease of reading, percentage without home healthcare use by Parkinson's disease status is not presented.

Group differences determined using t-test

$* * * \mathbf{p}<.001 ; * * .001 \leq \mathbf{p}<.01$ 
Table 5: Regression Estimates, Standard Errors from Ordinary Least Squares Regression on Log-transformed Home Healthcare Expenditures

National Medicare 5\% Sample - 2006, 2007

\begin{tabular}{|c|c|c|c|c|c|c|c|c|c|}
\hline & \multicolumn{3}{|c|}{ PD } & \multicolumn{3}{|c|}{ No PD } & \multicolumn{3}{|c|}{ Pooled } \\
\hline & Beta & S.E. & Sig & Beta & S.E. & Sig & Beta & S.E. & Sig \\
\hline Intercept & 8.082 & 0.102 & $* * *$ & 7.729 & 0.018 & $* * *$ & 7.730 & 0.018 & $* * *$ \\
\hline \multicolumn{10}{|c|}{ Predisposing characteristics } \\
\hline \multicolumn{10}{|l|}{ Gender } \\
\hline Female & 0.076 & 0.041 & & 0.096 & 0.007 & $* * *$ & 0.095 & 0.007 & $* * *$ \\
\hline \multicolumn{10}{|l|}{ Male } \\
\hline \multicolumn{10}{|l|}{ Race/Ethnicity } \\
\hline \multicolumn{10}{|l|}{ White } \\
\hline AA & 0.166 & 0.087 & & 0.241 & 0.011 & $* * *$ & 0.240 & 0.011 & $* * *$ \\
\hline Other & 0.086 & 0.100 & & 0.166 & 0.016 & $* * *$ & 0.164 & 0.016 & $* * *$ \\
\hline \multicolumn{10}{|l|}{ Age group } \\
\hline $65-74$ years & -0.086 & 0.044 & & $0.166^{-}$ & 0.007 & $* * *$ & -0.164 & 0.007 & $* * *$ \\
\hline $75,+$ years & & & & & & & & & \\
\hline
\end{tabular}

Enabling characteristic

\begin{tabular}{|c|c|c|c|c|c|c|c|c|c|}
\hline \multicolumn{10}{|c|}{ Public assistance } \\
\hline Yes & 0.110 & 0.057 & & 0.184 & 0.009 & $* * *$ & 0.182 & 0.009 & $* * *$ \\
\hline No & & & & & & & & & \\
\hline \multicolumn{10}{|c|}{ External environmental characteristics } \\
\hline \multicolumn{10}{|l|}{ Census region } \\
\hline Midwest & -0.065 & 0.069 & & $0.068^{-}$ & 0.011 & $* * *$ & -0.068 & 0.011 & $* * *$ \\
\hline North-East & -0.095 & 0.067 & & $0.14^{-}$ & 0.011 & $* * *$ & -0.141 & 0.011 & $* * *$ \\
\hline South & 0.171 & 0.062 & $* *$ & 0.167 & 0.010 & $* * *$ & 0.168 & 0.010 & $* * *$ \\
\hline \multicolumn{10}{|l|}{ West } \\
\hline \multicolumn{10}{|l|}{ Metro status } \\
\hline Metro & 0.095 & 0.052 & & 0.069 & 0.008 & $* * *$ & 0.070 & 0.008 & $* * *$ \\
\hline \multicolumn{10}{|l|}{ Non-Metro } \\
\hline \multicolumn{10}{|c|}{ Need factors- Baseline comorbidities and resource use } \\
\hline \multicolumn{10}{|l|}{ Anxiety } \\
\hline Yes & -0.003 & 0.060 & & $0.006^{-}$ & 0.011 & & -0.006 & 0.011 & \\
\hline \multicolumn{10}{|l|}{ No } \\
\hline \multicolumn{10}{|l|}{ Arthritis } \\
\hline Yes & 0.063 & 0.041 & & 0.094 & 0.007 & $* * *$ & 0.093 & 0.007 & $* * *$ \\
\hline No & & & & & & & & & \\
\hline
\end{tabular}

(Contd.) 
Table 5: Regression Estimates, Standard Errors from Ordinary Least Squares Regression on Log-transformed Home Healthcare Expenditures

National Medicare 5\% Sample - 2006, 2007

\begin{tabular}{|c|c|c|c|c|c|c|c|c|c|}
\hline & \multicolumn{3}{|c|}{ PD } & \multicolumn{3}{|c|}{ No PD } & \multicolumn{3}{|c|}{ Pooled } \\
\hline & Beta & S.E. & Sig & Beta & S.E. & Sig & Beta & S.E. & Sig \\
\hline \multicolumn{10}{|l|}{ Cancer } \\
\hline Yes & -0.083 & 0.062 & & $0.053^{-}$ & 0.010 & $* * *$ & -0.054 & 0.010 & $* * *$ \\
\hline \multicolumn{10}{|l|}{ No } \\
\hline \multicolumn{10}{|l|}{ COPD } \\
\hline Yes & -0.047 & 0.049 & & $0.040^{-}$ & 0.008 & $* * *$ & -0.040 & 0.008 & $* * *$ \\
\hline \multicolumn{10}{|l|}{ No } \\
\hline \multicolumn{10}{|l|}{ CRF } \\
\hline Yes & 0.005 & 0.070 & & 0.016 & 0.011 & & 0.016 & 0.011 & \\
\hline \multicolumn{10}{|l|}{ No } \\
\hline \multicolumn{10}{|l|}{ CRP } \\
\hline Yes & -0.078 & 0.066 & & 0.010 & 0.011 & & 0.008 & 0.011 & \\
\hline \multicolumn{10}{|l|}{ No } \\
\hline \multicolumn{10}{|l|}{ Diabetes } \\
\hline Yes & -0.009 & 0.045 & & 0.075 & 0.007 & $* * *$ & 0.072 & 0.007 & $* * *$ \\
\hline \multicolumn{10}{|l|}{ No } \\
\hline \multicolumn{10}{|c|}{ Diabetic Nephropathy } \\
\hline Yes & 0.299 & 0.158 & & 0.087 & 0.022 & $* * *$ & 0.091 & 0.021 & $* * *$ \\
\hline \multicolumn{10}{|l|}{ No } \\
\hline \multicolumn{10}{|c|}{ Heart disease } \\
\hline Yes & 0.052 & 0.048 & & 0.043 & 0.008 & $* * *$ & 0.043 & 0.008 & $* * *$ \\
\hline \multicolumn{10}{|l|}{ No } \\
\hline \multicolumn{10}{|c|}{ Hypertension } \\
\hline Yes & 0.012 & 0.050 & & 0.010 & 0.009 & & 0.009 & 0.009 & \\
\hline \multicolumn{10}{|l|}{ No } \\
\hline \multicolumn{10}{|c|}{ Major Depressive Disorder } \\
\hline Yes & 0.035 & 0.047 & & 0.095 & 0.009 & $* * *$ & 0.094 & 0.009 & $* * *$ \\
\hline \multicolumn{10}{|l|}{ No } \\
\hline \multicolumn{10}{|l|}{ Stroke } \\
\hline Yes & -0.025 & 0.049 & & 0.153 & 0.009 & $* * *$ & 0.146 & 0.009 & $* * *$ \\
\hline \multicolumn{10}{|l|}{ No } \\
\hline \multicolumn{10}{|c|}{ Thyroid Disorder } \\
\hline Yes & -0.035 & 0.044 & & 0.019 & 0.007 & $* *$ & 0.018 & 0.007 & $*$ \\
\hline No & & & & & & & & & \\
\hline (Contd.) & & & & & & & & & \\
\hline
\end{tabular}


Table 5: Regression Estimates, Standard Errors from Ordinary Least Squares Regression on Log-transformed Home Healthcare Expenditures

National Medicare 5\% Sample - 2006, 2007

\begin{tabular}{|c|c|c|c|c|c|c|c|c|c|}
\hline & \multicolumn{3}{|c|}{ PD } & \multicolumn{3}{|c|}{ No PD } & \multicolumn{3}{|c|}{ Pooled } \\
\hline & Beta & S.E. & Sig & Beta & S.E. & Sig & Beta & S.E. & Sig \\
\hline \multicolumn{10}{|c|}{ Personal Health Choices } \\
\hline \multicolumn{10}{|l|}{ SUD } \\
\hline Yes & -0.117 & 0.089 & & 0.031 & 0.014 & $*$ & -0.034 & 0.014 & $*$ \\
\hline \multicolumn{10}{|l|}{ No } \\
\hline \multicolumn{10}{|c|}{ Outpatient Visit Quintile } \\
\hline $0-0$ & 0.056 & 0.069 & & 0.053 & 0.011 & $* * *$ & 0.053 & 0.010 & $* * *$ \\
\hline $1-1$ & 0.083 & 0.067 & & 0.016 & 0.011 & & 0.018 & 0.011 & \\
\hline $2-3$ & 0.020 & 0.056 & & 0.010 & 0.009 & & 0.010 & 0.009 & \\
\hline $4-6$ & 0.053 & 0.054 & & $0.029^{-}$ & 0.010 & $* *$ & -0.027 & 0.009 & $* *$ \\
\hline \multicolumn{10}{|l|}{$7-178$} \\
\hline \multicolumn{10}{|c|}{ Office Visit Quintiles } \\
\hline $0-5$ & -0.275 & 0.126 & * & $0.044^{-}$ & 0.014 & $* *$ & -0.047 & 0.014 & $* * *$ \\
\hline $6-10$ & -0.068 & 0.082 & & $0.050^{-}$ & 0.012 & $* * *$ & -0.051 & 0.011 & $* * *$ \\
\hline $11-16$ & -0.022 & 0.064 & & $0.044^{-}$ & 0.010 & $* * *$ & -0.043 & 0.010 & $* * *$ \\
\hline $17-25$ & -0.079 & 0.052 & & $0.047^{-}$ & 0.009 & $* * *$ & -0.048 & 0.009 & $* * *$ \\
\hline $26-281$ & & & & & & & & & \\
\hline \multicolumn{10}{|c|}{ Other Resource Utilizations } \\
\hline SNF visits & 0.033 & 0.017 & & 0.061 & 0.004 & $* * *$ & 0.059 & 0.004 & $* * *$ \\
\hline Inpatient visits & 0.082 & 0.018 & $* * *$ & 0.022 & 0.003 & $* * *$ & 0.024 & 0.003 & $* * *$ \\
\hline Hospice visits & 0.024 & 0.027 & & 0.027 & 0.005 & $* * *$ & 0.027 & 0.005 & $* * *$ \\
\hline DME visits & 0.015 & 0.003 & $* * *$ & 0.017 & 0.000 & $* * *$ & 0.017 & 0.000 & $* * *$ \\
\hline
\end{tabular}

Pooled regression coefficient for the presence or absence of PD

\section{Parkinson's Disease}

Yes

$0.313 \quad 0.020 \quad * * *$

No

Note: Based on 2,445 and 91,971 elderly (age 65 or older) Medicare beneficiaries with and without Parkinson's disease who were continuously enrolled in Medicare Part A and Part B during 2006 and 2007 and were not enrolled in Health Maintenance organizations during 2006 and 2007; had a positive direct home healthcare expenditures; Individuals with end-stage renal disease (ESRD) as well as those without full year enrollments due to death or some other reason were excluded from the final sample.

SUD: Substance Use Disorder; COPD: Chronic Obstructive Pulmonary Disorder; CRF: Chronic Renal Failure; CRP: Chronic Renal Problem; DME: Durable Medical Equipment; SNF: Skilled Nursing Facility

$* * * \mathbf{p}<.001 ; * * .001 \leq \mathbf{p}<.01 ; * .01 \leq \mathbf{p}<.05$ 
Table 6: Non-Linear decomposition of baseline home healthcare use among elderly

Medicare beneficiaries with and without PD

Multivariate Decomposition of Non-Linear dependent variable

Medicare 5\% claims database $(2006,2007)$

\begin{tabular}{|c|c|}
\hline Variables & $\begin{array}{l}\text { Weights } \\
\text { (in percentage points) } \\
\text { Pooled }\end{array}$ \\
\hline \multicolumn{2}{|c|}{ Predisposing characteristics } \\
\hline gender, race/ethnicity, age & 0.008 \\
\hline \multicolumn{2}{|c|}{ Enabling characteristic } \\
\hline Public assistance & -0.002 \\
\hline \multicolumn{2}{|c|}{ Need characteristics } \\
\hline Physical health conditions & 0.0038 \\
\hline $\begin{array}{l}\text { Mental health conditions (anxiety, } \\
\text { depression) }\end{array}$ & 0.002 \\
\hline \multicolumn{2}{|c|}{ Personal Health choices } \\
\hline Any type of SUD & 0.00002 \\
\hline Baseline resource use & 0.0235 \\
\hline \multicolumn{2}{|c|}{ External environment } \\
\hline Census region, metro-status & 0.0001 \\
\hline Total explained & 0.0354 \\
\hline Unexplained portion & 0.09746 \\
\hline Percentage explained & $26.64 \%$ \\
\hline
\end{tabular}

Note: Based on 10,865 and 997,785 elderly (age 65 or older) Medicare beneficiaries with and without PD Difference in home healthcare use $=13.28$ percentage points. Percentage points in home healthcare use are explained by each independent variable. The percentage explained is derived by dividing the total explained portion by the 13.28 percentage point difference between elderly Medicare beneficiaries with and without PD. 
Table 7: Linear decomposition of logged home healthcare expenditures among elderly Medicare beneficiaries with and without PD

Blinder-Oaxaca Linear Decomposition Technique

Medicare 5\% claims database $(2006,2007)$

\begin{tabular}{|c|c|c|c|}
\hline \multirow[t]{2}{*}{ Variables } & \multicolumn{3}{|c|}{$\begin{array}{l}\text { Weights } \\
\text { (in percentage points) }\end{array}$} \\
\hline & Pooled & PD & No PD \\
\hline \multicolumn{4}{|c|}{ Predisposing characteristics } \\
\hline gender, race/ethnicity, age & -0.05 & -0.039 & -0.048 \\
\hline \multicolumn{4}{|c|}{ Enabling characteristic } \\
\hline Public assistance & -0.016 & -0.009 & -0.017 \\
\hline \multicolumn{4}{|c|}{ Need characteristics } \\
\hline Physical health conditions & 0.014 & 0.003 & 0.013 \\
\hline Mental health conditions (anxiety, depression) & 0.032 & 0.012 & 0.033 \\
\hline \multicolumn{4}{|c|}{ Personal Health choices } \\
\hline Any type of SUD & 0.0009 & 0.003 & 0.0008 \\
\hline Baseline resource use & 0.105 & 0.143 & 0.105 \\
\hline \multicolumn{4}{|c|}{ External environment } \\
\hline Census region, metro-status & -0.009 & -0.005 & -0.009 \\
\hline Total explained & 0.077 & 0.108 & 0.078 \\
\hline Unexplained portion & 0.923 & 0.892 & 0.922 \\
\hline Percentage explained & $7.7 \%$ & $10.8 \%$ & $7.8 \%$ \\
\hline
\end{tabular}

Note: Based on 2,445 and 91,971 elderly (age 65 or older) Medicare beneficiaries with and without PD who had a positive home healthcare expenditures

$\ln _{\text {exp }}(\mathrm{PD})=8.44$ and $\ln _{\text {exp }}($ No PD $)=8.10$; total difference $=0.34$

SUD: Substance Use Disorder 


\section{CHAPTER 3}

Page 59 of 129 


\section{CHAPTER 3: Parkinson's disease and Burden on Informal Caregivers: Results from the National Alliance of Caregiving Survey}

\section{INTRODUCTION}

Parkinson's disease (PD), the second most common neurodegenerative disease, is characterized by motor and non-motor symptoms (Muangpaisan, Mathews, Hori, \& Seidel, 2011). With the progression of PD, the motor (rigidity, postural instability, resting tremors) and non-motor (loss of smell, visual hallucinations, sleep disorders) symptoms worsen leading to severe disability (Muangpaisan et al., 2011; Park \& Stacy, 2009). In addition to motor and nonmotor symptoms, individuals with PD also exhibit cognitive impairment and behavioral issues (Lau \& Au, 2011). Due to movement difficulties and cognitive decline, individuals with PD frequently experience limitations in activities of daily living (ADLs) well as instrumental activities of daily living (IADLs) (Cahn et al., 1998; Noyes, Liu, Li, Holloway, \& Dick, 2006; Whetten-Goldstein, Sloan, Kulas, Cutson, \& Schenkman, 1997). It has been estimated that up to two-thirds of elderly individuals with PD experience ADL and IADL difficulties (Noyes et al., 2006; Whetten-Goldstein et al., 1997).

\section{Parkinson's disease and Informal Caregivers}

Because of limitations of ADLs, IADLs, motor and non-motor symptoms, cognitive impairment and behavioral issues individuals with PD rely on formal and informal caregivers for performing their daily activities (Noyes et al., 2006; Whetten-Goldstein et al., 1997). An overwhelming majority (as high as 78\%) of individuals with PD relied on their caregivers for ADL/IADL activities (Noyes et al., 2006; Whetten-Goldstein et al., 1997). As majority of elderly individuals with PD live in communities, caregiving is mainly provided by spouse or children of individuals with PD (Lau \& $\mathrm{Au}, 2011)$. A meta-analysis found that majority $(86.4 \%)$ of the caregivers of PD were spouses, and $10.1 \%$ of the caregivers were adult children of individuals 
with PD (Lau \& Au, 2011). When caregiving is provided by close family members, relatives, or friends who do not have any organizational affiliations or certificates for caregiving they are considered as informal caregivers (Rakoski et al., 2012). It has been estimated that in the U.S 65.7 million adult individuals provide informal caregiving to individuals who are ill, disabled or aged [The National Alliance for Caregiving and AARP (2009), Caregiving in the U.S. National Alliance for Caregiving. Washington, DC.] and 43.5 million adult caregivers provide care for older individuals (age $\geq 50$ years). According to the American Time Use Survey in 2011, an estimated average of 3.12 hours per day was spent in providing informal care to elderly individuals for several different activities such as eating, drinking, managing funds, grocery shopping, and other household activities etc. (http://www.bls.gov/news.release/atus.htm).

\section{Parkinson's disease and Informal Caregiver Burden}

Although caregiving is a part of life, providing care to individuals with chronic illness, functional limitations, and cognitive decline can be burdensome. This is because providing care to these individuals can be highly stressful as caregiving involves fear or uncertainty, shift in roles, financial burden, social isolation, little time alone, demands of constant care and feel of guilt

(http://www.wfmh.org/PDF/Caring\%20for\%20the\%20Caregiver\%2011_04_09\%20FINAL\%20 $\% 283 \% 29$.pdf). Moreover, with the increase in severity of the illness, caregivers have to undertake new and increased burdensome responsibilities, which generally lead to elevated levels of psychological, emotional, financial and physical burden of caregivers (Sanders-Dewey, Mullins, \& Chaney, 2001; Whetten-Goldstein et al., 1997).

In concept, caregiver burden is defined as "the strain or load borne by a person who cares for an elderly, chronically ill, or disabled family member or other person. ... the point 
where the experience is no longer a viable or healthy option for either the caregiver or the person receiving care" (Kasuya, Polgar-Bailey, \& Takeuchi, 2000). However, in practice it is challenging to precisely measure informal caregiver burden. Caregiver burden is often measured by Zarit Burden Inventory, which is a 22 -item caregiver-reported scale or a visual analogue scale (VAS) known as Caregiver Distress Scale. ZBI measures many aspects of caregiver burden including emotional and physical health of the caregivers, financial issues of the caregivers, the impact of caregiving on their social life (Seng et al., 2010). Caregiver Distress Scale measures caregiver stress on a scale of zero to ten with zero indicating no stress and 10 indicating overwhelming stress (Cifu et al., 2006). Simpler measures have been used in the existing literature. Some studies have measured the caregiver burden by the number of hours spent on caregiving and the costs associated with it (Parrish, Giunta, \& Adams, 2003; Rakoski et al., 2012).

Informal caregiving is especially burdensome among caregivers of individuals with PD. Evidence of this association comes mainly from studies that have been conducted in international settings. Studies conducted in different countries (Korea, Denmark, Norway, Ireland, Sweden, Spain, Brazil, Australia, Italy, and United Kingdom) have shown that the informal caregiver burden of those caring for individuals with PD was higher as compared to the caregiver burden of individuals caring for individuals with other chronic disease conditions (D'Amelio et al., 2009; Hounsgaard, Pedersen, \& Wagner, 2011; Kim et al., 2007; Lökk, 2009; Lökk, 2009; MartínezMartín et al., 2005; O'Connor \& McCabe, 2011; O'Reilly, Finnan, Allwright, Smith, \& BenShlomo, 1996; Peters, Fitzpatrick, Doll, Playford, \& Jenkinson, 2011; Stella, Banzato, Quagliato, Viana, \& Christofoletti, 2009; Thommessen et al., 2002). In one study conducted in Korea, it 
was observed that caregivers of individuals with PD experienced higher burden of caregiving compared to other general chronic diseases (Kim et al., 2007).

Only a handful of studies have evaluated the informal caregiver burden among those providing care to individuals with PD in the U.S. (Carter, Stewart, Lyons, \& Archbold, 2008; Cifu et al., 2006; Edwards \& Ruettiger, 2002; Parrish et al., 2003). According to a 1999 study of 324 informal caregivers of individuals with PD in California area, it was reported that informal caregivers provided an estimated average of 96 hours/week, caring for individuals with PD (Parrish et al., 2003). In addition, a majority (over 70\%) of caregivers suffered ADLs (eating, dressing, toileting, transferring), IADLs (taking medication), and other health related issues due to caregiving. Informal caregiver burden is also associated with many factors. One study conducted among 41 caregivers of individuals with PD in six Midwestern states of U.S. showed that greater assistance with ADLs was significantly associated with caregiver burden (Edwards \& Ruettiger, 2002). Using data from 49 caregivers of individuals with PD from the Parkinson's disease Research, Education, and Clinical Center (PADRECC) in Richmond, Virginia, U.S., it was found that caregiver burden increased when individuals with PD had greater levels of difficulty in performing ADLs (Cifu et al., 2006). Another study using data from an 8-year clinical trial DATATOP, found that among 219 caregivers of individuals with PD, clinical symptoms of PD, depression, motor and non-motor psychological symptoms were associated with caregiver burden (Carter et al., 2008).

\section{Need for the study}

Although these studies evaluated informal caregiver burden among individuals with PD, they are limited by geographical locations within the U.S. (Edwards \& Ruettiger, 2002) and small sample size (Cifu et al., 2006). Many of these studies are outdated with data from as early 
as1999 (Parrish et al., 2003). Additionally, none of these studies estimated costs associated with informal caregiving among caregivers of individuals with PD. Furthermore, according to the Administration on Aging of the Department of Health and Human Services, by 2030 there will be an estimated 72.1 million elderly individuals (age $\geq 65$ years) as compared to 39.6 million elderly individuals in 2009 (http://www.aoa.gov/Aging_Statistics/). Similarly, the number of individuals with PD is expected to rise two-fold by 2030 (Park \& Stacy, 2009). This growth in the number of individuals with PD has implications for caregiving burden and costs associated with informal caregiving. In this context, it is important to identify caregivers who are at high risk for high care burden so that programs and interventions can be developed to improve the well-being of the caregivers.

Therefore, the primary objective of the current study was to estimate the extent of caregiver burden and costs associated with informal caregiving and examine factors associated with such burden among caregivers of individuals with PD. For purposes of the current study, we used a nationally representative data from the National Alliance of Caregiving, American Association of Retired Persons (NAC/AARP) survey using 2004 and 2009 data.

\section{Conceptual Framework}

The conceptual framework used for this study was the Stress-Process Model developed by Conde-Sala et al. (2010). According to this frame-work, different factors associated with the burden of caregiving are: (i) Contextual variables which encompasses socio-demographic factors of both care-recipients and caregivers as well as factors associated with caregiving; (ii) primary stressors such as the progression of the disease or symptoms of patients; and (iii) secondary stressors which constitutes caregiving related factors which leads to difficulties in different settings such as family, work or financial (Conde-Sala et al. 2010). One of the advantages of this 
model is that it utilizes a multidimensional perspective on the factors associated with caregiving burden and takes into account both observed and conceptual aspects (Kim et al. 2012). We used a modified version of this conceptual model as some of the variables are not available due to limitations of the dataset.

\section{Figure 1: Stress Process Model}

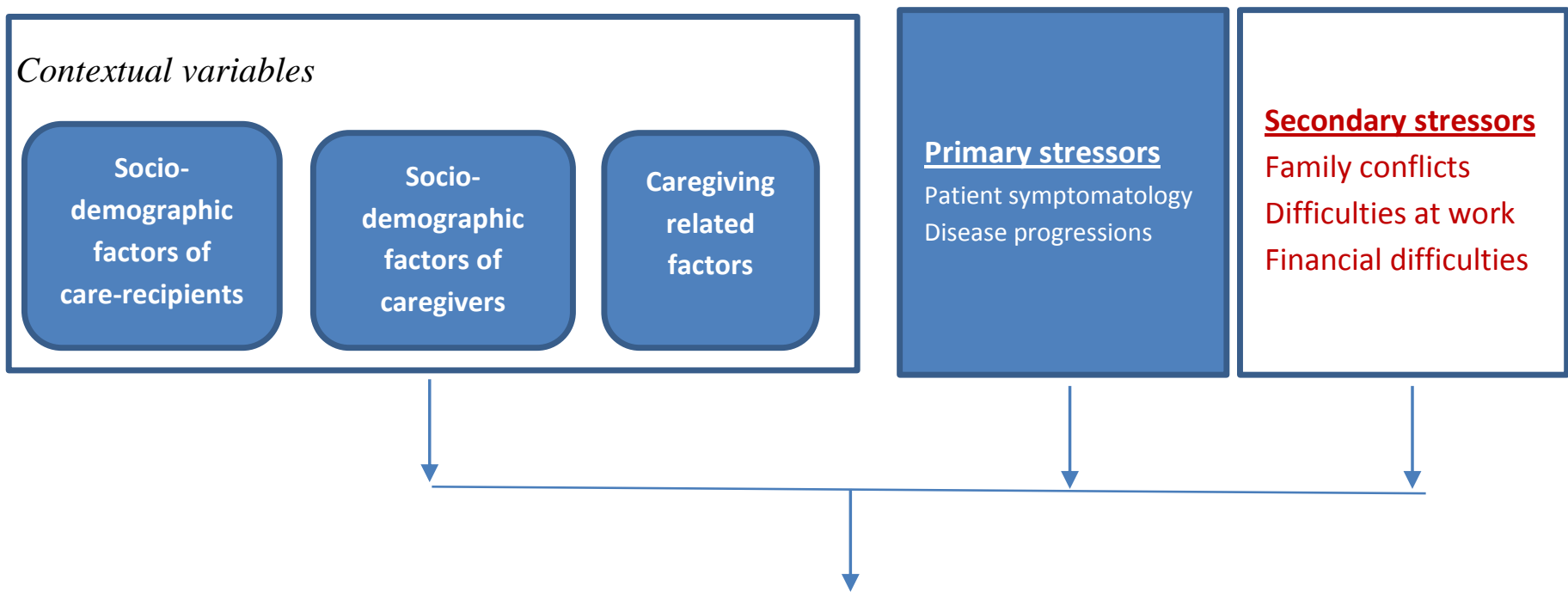

\section{Caregiver symptoms:}

\section{Burden}

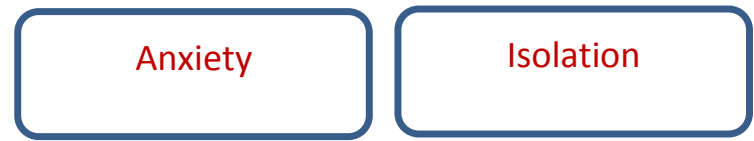

Physical health

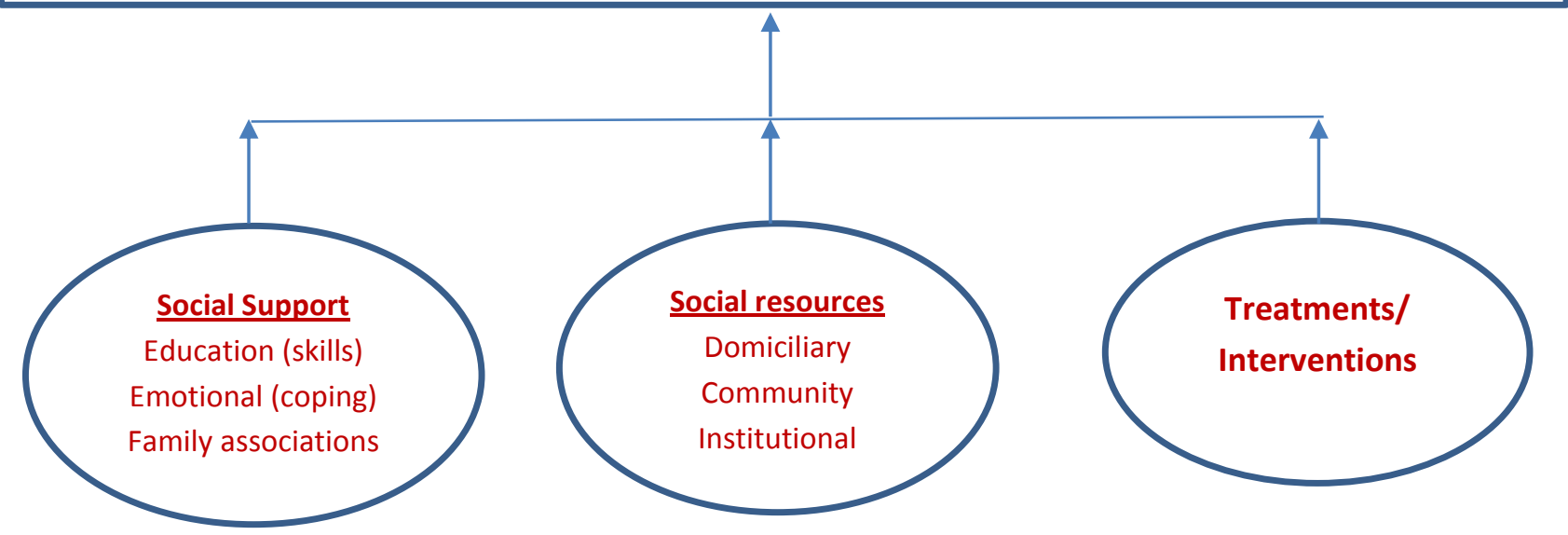




\section{Highlighted parts were examined in this study}

Model adapted from Conde-sala et al. (2010): Conde-Sala J.L., Garre-Olmo J., Turro-Garriga O., Vilalta-Franch J. \& Lopez-Pousa S. (2010). Differential features of burden between spouse and adult-child caregivers of patients with Alzheimer's disease: an exploratory comparative design. International Journal of Nursing Studies 47(10), 1262-1273.

\section{METHODS}

\section{Study Design}

We adopted a retrospective cross-sectional study design with observational data.

\section{Data Source: National Alliance for Caregiving (NAC)}

We used multiple years $(2004,2009)$ of data from the National Alliance for Caregiving, American Association of Retired Persons (NAC/AARP) survey. The nationwide survey data were collected by NAC/AARP by using a random digit dialing on the basis of surname. For the NAC data collected in 2004, 6,139 adults (age $\geq 18$ years) residing in the US were interviewed, and 6,806 adult individuals within US were interviewed for the data collected in 2009. The survey design of NAC included oversampling of minorities to attain a total of 200 African American caregivers, 200 Hispanic caregivers, and 200 Asian caregivers (NAC/AARP 2004c; NAC/AARP 2009c). The national random digit dialing (RDD) was stratified by geographical location in order to obtain a set of telephone numbers that were proportionate to the population of that area. The survey consisted of 1,247 and 1,397 caregivers for 2004 and 2009 NAC survey data (NAC/AARP 2004a; NAC/AARP 2009a).

\section{Study Sample}

The study sample consisted of elderly care-recipients aged 65 years or older. The carerecipients were categorized as individuals with (i) PD and (ii) no PD.

Individuals who provided help with at least one activity of daily living or instrumental activity of daily living were classified as informal Caregivers (Kim et al. 2012). The question in 
the survey that helped to classify caregivers was "In the last 12 months, has anyone in your household provided unpaid care to a relative or friend 50 years or older to help them take care of themselves? Unpaid care may include help with personal needs or household chores. It might be managing a person's finances, arranging for outside services, or visiting regularly to see how they are doing. This person need not live with you." Pooling data from 2004 and 2009 NAC survey, we had 32 caregivers who provided care to elderly care-recipients with PD and 1,639 caregivers who provided care to other elderly care-recipients without PD meeting the study inclusion criteria. The complex multistage sampling design of NAC survey was adjusted by incorporating the survey weights in the SAS survey statistical procedures, such as SURVEYFREQ and SURVEYMEANS. The SURVEYREG procedure was used to conduct the Ordinary Least Square (OLS) regression analysis by adjusting for complex survey design.

\section{Data Collection/Field Methodology}

The nationally representative data was collected via telephone interviews. After establishing telephone contact, the interviewer asked to speak to an individual in the household who had the most-recent birthday and were 18 years or older. If the initial respondent was not the caregiver, then the interviewer requested to speak to the caregiver and only one caregiver from each household was interviewed. Household information, demographic information as well as other appropriate data on both caregivers and care-recipients was collected in the NAC survey. The interview was terminated in the cases where the randomly selected primary respondent stated that there was no caregiver in the household (NAC/AARP 2004c; NAC/AARP 2009c). 


\section{Approvals}

NAC/AARP approved the use of the anonymous and de-identified survey data. The Institutional Review Board (IRB) of West Virginia University approved this study before the initiating the data analysis.

\section{Dependent Variables}

Caregiver burden

Caregiver burden was measured based on three questions on physical strain ("How much of a physical strain caring for recipient is/was for you?"), emotional stress (“How emotionally stressful caring for recipient is/was for you?") and financial hardship ("How much of a financial hardship caring for recipient is/was for you?"). Responses from these three questions on a scale from 1 to $5(1=$ not at all strain/stress/hardship; $2=, 3=, 4=, 5=$ very high strain/stress/hardship) were used to develop caregiver burden measure (Kim et al. 2012). Factor analysis using Principal Component Analysis showed one factor solution and the reliability analysis revealed high Cronbach's alpha value (Cronbach's alpha for PD sample $=0.74$, Cronbach's alpha for No PD sample $=0.72$ ). Therefore, a composite scale was developed by calculating the mean of the three items, where a score of 1 and 5 indicated lowest and highest caregiver burden respectively. This method is validated in the existing literature (Kim et al. 2012).

\section{Key Independent Variable}

The key independent variable for this study was care-recipients' presence or absence of PD. Identification of individuals with PD was based on the question in the survey which queried what was the "Main problem or illness recipient has/had" for which caregiving was provided. 


\section{Other Independent Variables}

\section{Characteristics of care-recipients}

The characteristics of care-recipients that were included in this study were: age, sex (male/female), living situation (lives in caregiver household, lives elsewhere), number of activities of daily living (ADLs) limitations, number of instrumental activities of daily living (IADLs) limitations. The six items of ADLs comprised of (a) eating; (b) dressing; (c) bathing; (d) toileting; (e) mobility inside own house; and (f) getting in and out of bed. IADLs consisted of five activities: (i) grocery shopping; (ii) cooking; (iii) managing money; (iv) taking medications; and (v) using the telephone. Number of ADLs and IADLs were used for the purpose of analysis.

\section{Characteristics of caregivers}

Characteristics of caregivers consisted of age, sex (male/female), and marital status (married, unmarried living with others, unmarried living alone).

\section{Other independent variables}

Other independent variables consisted of number of hours of caregiving per week and presence or absence of paid caregivers.

\section{Cost associated with informal caregiving}

Costs associated with informal caregiving were calculated by multiplying hours spent on informal caregiving by informal caregivers with the estimated market wage rate of a paid caregiver (Rakoski et al., 2012). Annual costs were estimated by multiplying each caregiver's weekly hours of informal caregiving by 52 and the median hourly wage for a home health aide (US\$10.10) (Rakoski et al., 2012) (http://www.bls.gov/oes/current/oes311011.htm). The $10^{\text {th }}$ and $90^{\text {th }}$ percentile of the cost associated with informal caregiving was also estimated using the respective hourly wage value of a home health aide $\left(\$ 8.03\right.$ and $\$ 14.17$ for $10^{\text {th }}$ and $90^{\text {th }}$ percentile respectively). 


\section{Sub-group/Sensitivity Analysis}

Sub-group analysis was conducted by comparing caregiver burden among caregivers of elderly care-recipients with PD to those with Alzheimer's disease, confusion, dementia, and forgetfulness.

\section{Statistical Analyses}

Unadjusted differences in caregiver burden among care-recipients with and without PD were determined by using t-tests. Multiple linear regressions were conducted to compare caregiver burden and costs after adjusting for care-recipient, caregiver characteristics and other independent variables (age of caregiver, sex of caregiver, caregiver marital status, living situation of care-recipient, ADLs, IADLs, presence or absence of paid caregiver, and the number of hours of caregiving provided per week). Three OLS regression analyses were conducted, which utilized informal caregiver burden, number of hours per week of caregiving, and logtransformed informal cost of caregiving. The cost of informal caregiving was logarithmically transformed for the multiple OLS model as the cost data are generally skewed. Dependent variable and the independent variables adjusted in the final multivariate analysis were checked for missing data, and none of the variables had missing values of more than $5 \%$. Nationally representative data were generated by adjusting for population weights in the bivariate and multivariate analyses. In the NAC/AARP survey, the population weights were calculated on the basis of subset of totally screened respondents in the base study who constituted the original individuals who were randomly selected. A single-stage weighting procedure was used to achieve the nationally representative estimates. All analyses will be conducted using SAS 9.3 (SAS Institute, Cary, NC). 


\section{RESULTS}

Table 1 displays the care-recipient and caregiver characteristics by presence or absence of PD.

\section{Sample description by care-recipient characteristics}

The mean age of care-recipients with PD was 81.29 ( \pm 6.53$)$ years, while the mean age of carerecipients without PD was $80.69( \pm 8.17)$. The mean score of ADLs among care-recipients with and without PD were $3.14( \pm 2.02)$ and $1.71( \pm 1.96)$ respectively. Care-recipients with PD had a mean IADL score of $4.82( \pm 2.01)$, whereas those without PD had a mean score of $4.41( \pm 1.84)$. Majority of the care-recipients with (55.8\%) and without (68.7\%) PD was females.

\section{Sample description by caregiver characteristics}

In terms of the caregivers, the mean age of caregivers for care-recipients with and without PD was $55.03( \pm 14.19)$ years and $52.05( \pm 14.35)$ years respectively. Majority of the caregivers for care-recipients $(51.8 \%)$ with PD were male, whereas majority of caregivers $(59.8 \%)$ for care-recipients for those without PD were females. Nearly two-thirds of caregivers of care-recipients with (67.6\%) and without PD (61.3\%) were married. Majority of the carerecipients in both groups lived in places other than the caregiver's house.

\section{Other Independent Variables}

The mean number of caregiving hours per week reported by caregivers of care-recipients with and without PD was $27.51( \pm 35.04)$ hours and $21.62( \pm 28.71)$ hours respectively. Majority of the care-recipients with $(51.9 \%)$ and without (54\%) PD did not have a paid caregiver.

Table 2 summarizes the unadjusted group differences in caregiver burden by caregiver characteristics. 


\section{Unadjusted group differences by care-recipient characteristics}

Statistically significant differences in caregiver burden were observed by sex of caregiver, marital status of caregiver, care-recipient's residency status, functional status (ADL and IADL), as well as by the presence or absence of a paid caregiver. It was observed that male caregivers of care-recipients with PD $(2.5 \pm 0.25)$ had higher mean caregiver burden compared to the male caregivers of care-recipients without PD (2.02 \pm 0.04$)$. Married caregivers of carerecipients with PD $(2.31 \pm 0.23)$ reported a significantly higher average caregiver burden than the married caregivers of care-recipients without PD $(2.1 \pm 0.04)$. As expected, higher the functional limitations (ADL and IADL) of care-recipients, higher were the reported mean caregiver burden. Average number of hours per week of informal caregiving was substantially higher among caregivers of care-recipients with PD, who resided within the same household as the caregivers as compared to those living elsewhere $(55.5 \pm 12.27$ vs. $12.72 \pm 4.3)$. With the increase in the number of functional limitations (ADL and IADL), the number of hours of informal caregiving per week also increased significantly in both the groups. Similar findings were observed with the annual informal cost of caregiving.

Table 3 shows the findings from multiple linear regressions. These regressions were adjusted for survey weights. Three multiple linear regression analyses were conducted, which utilized caregiver burden, number of hours per week of caregiving, and log-transformed informal cost of caregiving. Factors that were adjusted in analysis that used caregiver burden as the dependent variable were presence or absence of PD, age of caregiver, sex of caregiver, marital status of caregiver, functional status (ADLs and IADLs), presence or absence of a paid caregiver, hours per week of informal caregiving and the whether the care-recipient was staying within or outside the caregiver house. For the analyses that used number of hours per week of informal caregiving and the log-transformed informal cost of caregiving, the factors that were adjusted 
included presence or absence of $\mathrm{PD}$, age of caregiver, sex of caregiver, marital status of caregiver, functional status (ADLs and IADLs), presence or absence of a paid caregiver and the whether the care-recipient was staying within or outside the caregiver house. It was observed that in all the three different regression analyses, caregiver burden did not differ by the presence or absence of PD. ADLs and IADLs were consistently positively associated with caregiver burden in all the three models. Female caregivers were also found to be significantly more likely to experience higher caregiving burden compared to male caregivers in all the three models.

\section{Cost associated with informal caregiving}

The median wage of a home health aide (\$10.10) for 2013 was obtained from the Bureau of Labor Statistics. Using this median wage and the mean number of hours of caregiving (Table 1), the national yearly informal cost of caregiving for care-recipients with and without PD was estimated to be approximately $\$ 14,450$ and $\$ 11,360$ respectively. The $10^{\text {th }}$ and $90^{\text {th }}$ percentile hourly wage value of a home health aide are $\$ 8.03$ and $\$ 14.17$ respectively. Using this wage values, the national yearly informal caregiving costs ranged between $\$ 11,500$ and $\$ 20,300$ for care-recipients with PD, while that of care-recipients without PD ranged between $\$ 9,050$ and $\$ 16,000$ (all wage values rounded up).

\section{Sub-group/Sensitivity analysis}

Sub-group analysis was conducted by comparing the caregiver burden among caregivers of care-recipients with PD and those with Alzheimer's disease, confusion, dementia, and forgetfulness. After adjusting for all the care-recipient, caregiver and other independent variables, it was observed that the caregiving burden did not differ between these two groups ( $\beta$ $=-0.25, \mathrm{p}=0.1091)$. 


\section{DISCUSSION}

Using a nationally representative sample of caregivers in the United States (U.S.), the present study examined the informal caregiver burden and cost associated with caregiver burden among care-recipients with and without PD. To the best of author's knowledge, this is the first nationally representative study comparing informal caregiving burden and costs among carerecipients with and without $\mathrm{PD}$. The study hypothesized that, informal caregiving burden will be higher among those who provided care to elderly individuals with PD compared to caregivers of elderly without PD, due to special needs of elderly individuals with PD in terms of limitations of ADLs, IADLs, motor and non-motor symptoms, cognitive impairment and behavioral issues (Noyes et al., 2006; Whetten-Goldstein et al., 1997). However, findings from this nationally representative study revealed that there were no significant differences in caregiving burden among caregivers of care-recipients with and without PD. Although the caregivers of elderly individuals with PD spent 1.4 times more hours in providing informal care compared to caregivers of elderly without PD, the difference was not statistically significant. This lack of statistical significance could be due to the small sample size of the care-recipients with PD. For example, post-hoc power analysis revealed that a minimum of 373 elderly individuals in each group will be needed to detect a statistically significant difference.

A noteworthy finding in our study is the association between the functional status of the care-recipients and caregiver burden. It was observed that ADL and IADL were significantly positively associated with caregiver burden in all the three models. For instance, in Model 2, for

each unit increase in ADL, the number of hours of informal caregiving per week will increase by 4.468 units $(\beta=4.468$, S.E. $=0.398, \mathrm{p}<0.001)$. Similarly, in Model 2 , for each unit increase in IADL, the number of hours of informal caregiving per week will increase by 2.755 units $(\beta=$ 2.755 , S.E. $=0.343, \mathrm{p}<0.001)$. These findings are consistent with earlier studies conducted by 
Edwards \& Ruettinger (2002) and Cifu et al., (2006), who observed that higher caregiver burden was associated with increased difficulties with ADL performance. Although prior studies have not examined the relationship between IADL and caregiver burden, our study documents that increase in the number of difficulties with IADLs was also associated with greater caregiver burden.

The average hours per week of caregiving for care-recipients with PD was estimated to be $27.51( \pm 35.04)$ hours as compared to $21.62( \pm 28.71)$ hours. Therefore, caregivers of carerecipients with PD spent substantially higher number of hours per week in caregiving compared to those without PD. A study conducted by Parrish et al. (2003) found that informal caregivers spent 96 hours/week in caregiving of care-recipients with PD. The average number of hours of caregiving per week from the current study is considerably lower compared to the Parrish et al. study. The study conducted by Parrish et al. (2003) was geographically limited as it was conducted only in California and hence the findings from this study provides the estimate of national average of hours per week of caregiving for care-recipients with PD. The high amount of time spent on caregiving can lead to serious stress among caregivers and it has been in documented in the existing literature that if more than 16 hours of caregiving per week is provided, it leads to higher rates of nursing home placements of the care-recipients (Etters, Goodall, \& Harrison, 2008).

One of the unique contributions of this study is that it provided a nation-wide estimation of costs associated with informal caregiving of for elderly individuals PD. Additionally, this study compared costs associated with informal caregiving of care-recipients with and without PD. It was found that the costs associated with informal caregiving of care-recipients with PD were 1.27 times higher than care-recipients without PD. The high annual costs of informal care 
provided to the elderly individuals with PD have significant financial implications. With the aging population of U.S. and the consequent expected increase in the number of individuals with $\mathrm{PD}$, efforts need to be devoted towards reducing informal caregiving burden.

Findings from this study also revealed that female caregivers are significantly more likely to experience caregiver burden compared to male caregivers. This is consistent with the finding from Edwards \& Scheetz (2002) study where female caregivers reported double the burden as compared to male caregivers. In general, the prevalence of PD is higher among men which in turn influences the gender of caregivers, and it has been observed in existing studies (Edwards \& Scheetz 2002) as well as in this study that the number of female caregivers are higher among the care-recipients of PD. Some of the reasons that we can speculate to explain the increased caregiving burden among female caregivers may include the perception of not taking adequate care of the care-recipients despite being the sole caregivers in most cases (Hooker et al. 2000). Moreover, female caregivers sometimes believe that they are responsible for the condition of the care-recipients (Hooker et al. 2000).

In this study, it was also indicated that use of paid caregiver is negatively associated with caregiver burden. This finding is intuitive as the use of paid caregivers can lead to reduced caregiving burden among informal caregivers. Existing studies did not account for paid caregivers as one of the individual level variables. 


\section{Strengths/Limitations}

Some of the strengths of this study include nationally representative sample of elderly care-recipients and their caregivers, ability to identify PD, and comprehensive list of variables for both care-recipients and caregivers from survey data.

However, there are some limitations of this study. The study sample was small with only 32 caregivers of care-recipients with PD. This small sample size may affect the power of the analyses. This data did not have information related to clinical factors such as the presence of physical (e.g. diabetes) and/or mental conditions (e.g. depression, anxiety). Adjusting for comorbid conditions may explain more variance in the caregiver burden. Moreover, duration and severity of diseases was available. However, ADLs and IADLs may serve as global proxies for severity of illness. Additionally, as this is a survey, presence of recall bias cannot be ruled out.

\section{CONCLUSION}

This is the first nationally representative study of caregiver burden among care-recipients with PD. No significant differences were observed among in terms of caregiver burden among caregivers of care-recipients with and without PD. However, findings from this study suggest that caregivers of care-recipients with PD experience higher burden in terms of number of hours of caregiving provided per week and also higher annual costs of informal caregiving. Number of ADLs and IADLs explained most of the variance in caregiver burden. Thus findings from this study suggest that several factors need to be taken into consideration while developing an appropriate intervention to help caregivers deal with their caregiver burden. 


\section{REFERENCES}

Aarsland, D., Brønnick, K., Ehrt, U., De Deyn, ,P.P., Tekin, S., Emre, M., et al. (2007). Neuropsychiatric symptoms in patients with parkinson's disease and dementia: Frequency, profile and associated care giver stress. Journal of Neurology, Neurosurgery, and Psychiatry, 78(1), 36-42.

Bureau of Labor Statistics. http://www.bls.gov/oes/current/oes311011.htm. Accessed on 12March-2014

Cahn, D. A., Sullivan, E. V., Shear, P. K., Pfefferbaum, A., Heit, G., \& Silverberg, G. (1998). Differential contributions of cognitive and motor component processes to physical and instrumental activities of daily living in parkinson's disease. Archives of Clinical Neuropsychology: The Official Journal of the National Academy of Neuropsychologists, 13(7), 575-583.

Carter, J. H., Stewart, B. J., Lyons, K. S., \& Archbold, P. G. (2008). Do motor and nonmotor symptoms in PD patients predict caregiver strain and depression? Movement Disorders: Official Journal of the Movement Disorder Society, 23(9), 1211-1216. doi:10.1002/mds.21686

Chappell, N. L., \& Reid, R. C. (2002). Burden and well-being among caregivers: Examining the distinction. The Gerontologist, 42(6), 772-780.

Cifu, D. X., Carne, W., Brown, R., Pegg, P., Ong, J., Qutubuddin, A., et al. (2006). Caregiver distress in parkinsonism. Journal of Rehabilitation Research and Development, 43(4), 499508.

Conde-Sala J.L., Garre-Olmo J., Turro-Garriga O., Vilalta-Franch J. \& Lopez-Pousa S. (2010). Differential features of burden between spouse and adult-child caregivers of patients with Alzheimer's disease: an exploratory comparative design. International Journal of Nursing Studies 47(10), 1262-1273.

D'Amelio, M., Terruso, V., Palmeri, B., Di Benedetto, N., Famoso, G., Cottone, P., et al. (2009). Predictors of caregiver burden in partners of patients with parkinson's disease. Neurological Sciences: Official Journal of the Italian Neurological Society and of the Italian Society of Clinical Neurophysiology, 30(2), 171-174. doi:10.1007/s10072-009-0024-z

Edwards, N. E., \& Ruettiger, K. M. (2002). The influence of caregiver burden on patients' management of parkinson's disease: Implications for rehabilitation nursing. Rehabilitation Nursing: The Official Journal of the Association of Rehabilitation Nurses, 27(5), 182.

Edwards NE, Scheetz PS. Predictors of burden for caregivers of patients with Parkinson's disease. J Neurosci Nurs. 2002 Aug;34(4):184-90. PubMed PMID: 12197259 
Etters L, Goodall D, Harrison BE (2008). Caregiver burden among dementia patient caregivers: a review of the literature. J Am Acad Nurse Pract. Aug;20(8):423-8. doi: 10.1111/j.17457599.2008.00342.x. Review. PubMed PMID: 18786017

Fernandez, H. H., Tabamo, R. E., David, R. R., \& Friedman, J. H. (2001). Predictors of depressive symptoms among spouse caregivers in parkinson's disease. Movement Disorders: Official Journal of the Movement Disorder Society, 16(6), 1123-1125.

Hooker K, Manoogian-O'Dell M, Monahan DJ, Frazier LD, Shifren K.(2000) Does type of disease matter? Gender differences among Alzheimer's and Parkinson's diseasespouse caregivers. Gerontologist. Oct;40(5):568-73. PubMed PMID: 11037935

Hounsgaard, L., Pedersen, B., \& Wagner, L. (2011). The daily living for informal caregivers with a partner with parkinson's disease - an interview study of women's experiences of care decisions and self-management. Journal of Nursing \& Healthcare of Chronic Illnesses, 3(4), 504-512. doi:10.1111/j.1752-9824.2011.01126.x

Kasuya, R. T., Polgar-Bailey, P., \& Takeuchi, R. (2000). Caregiver burden and burnout. A guide for primary care physicians. Postgraduate Medicine, 108(7), 119-123.

Kim, K. S., Kim, B. J., Kim, K. H., Choe, M., Yi, M., Hah, Y., et al. (2007). Subjective and objective caregiver burden in parkinson's disease. Taehan Kanho Hakhoe Chi, 37(2), 242248.

Kim H, Chang M, Rose K, Kim S (2012). Predictors of caregiver burden in caregivers of individuals with dementia. Journal of Advanced Nursing. Apr;68(4):846-55. doi: 10.1111/j.1365-2648.2011.05787.x. Epub 2011 Jul 28. PubMed PMID: 21793872

Lau, K., \& Au, A. (2011). Correlates of informal caregiver distress in parkinson's disease: A meta-analysis. Clinical Gerontologist, 34(2), 117-131. doi:10.1080/07317115.2011.539521

Lökk, J. (2009). Reduced life-space of non-professional caregivers to parkinson's disease patients with increased disease duration. Clinical Neurology and Neurosurgery, 111(7), 583-587. doi:10.1016/j.clineuro.2009.05.011

Martinez-Martin, P., Arroyo, S., Rojo-Abuin, J., Rodriguez-Blazquez, C., Frades, B., \& de, P. C. (2008). Burden, perceived health status, and mood among caregivers of parkinson's disease patients. Movement Disorders: Official Journal of the Movement Disorder Society, 23(12), 1673-1680. doi:10.1002/mds.22106

Martínez-Martín, P., Benito-León, J., Alonso, F., Catalán, M. J., Pondal, M., Zamarbide, I., et al. (2005). Quality of life of caregivers in parkinson's disease. Quality of Life Research: An International Journal of Quality of Life Aspects of Treatment, Care and Rehabilitation, 14(2), 463-472. 
Muangpaisan, W., Mathews, A., Hori, H., \& Seidel, D. (2011). A systematic review of the worldwide prevalence and incidence of parkinson's disease. Journal of the Medical Association of Thailand $=$ Chotmaihet Thangphaet, 94(6), 749-755.

National Alliance for Caregiving, American Association of Retired Persons (NAC/AARP) (2004a) Caregiving in the U.S. Appendix C: CATI Questionnaire. Retrieved from http://www.caregiving.org/data/04questionnaire.pdf on 12-March-2014.

National Alliance for Caregiving, American Association of Retired Persons (NAC/AARP) (2004b) Families Care: Alzheimer's Caregiving in the United States 2004. Retrieved from http://www.caregiving.org/data/alzcaregivers04.pdf on 12-March-2014.

National Alliance for Caregiving, American Association of Retired Persons (NAC/AARP) (2004c) Caregiving in the U.S. Appendix A: Detailed Methodology Retrieved from http://www.caregiving.org/data/04methodology.pdf on 12-March-2014.

National Alliance for Caregiving, American Association of Retired Persons (NAC/AARP) (2009a) Caregiving in the U.S. Appendix C: CATI Questionnaire. Retrieved from http://www.caregiving.org/data/04questionnaire.pdf on 12-March-2014.

National Alliance for Caregiving, American Association of Retired Persons (NAC/AARP) (2009b) Families Care: Alzheimer's Caregiving in the United States 2004. Retrieved from http://www.caregiving.org/data/alzcaregivers04.pdf on 12-March-2014.

National Alliance for Caregiving, American Association of Retired Persons (NAC/AARP) (2009c) Caregiving in the U.S. Appendix A: Detailed Methodology Retrieved from http://www.caregiving.org/data/04methodology.pdf on 12-March-2014.

Noyes, K., Liu, H., Li, Y., Holloway, R., \& Dick, A. W. (2006). Economic burden associated with parkinson's disease on elderly medicare beneficiaries. Movement Disorders: Official Journal of the Movement Disorder Society, 21(3), 362-372.

O'Connor, E.,J., \& McCabe, M. P. (2011). Predictors of quality of life in carers for people with a progressive neurological illness: A longitudinal study. Quality of Life Research: An International Journal of Quality of Life Aspects of Treatment, Care and Rehabilitation, 20(5), 703-711. doi:10.1007/s11136-010-9804-4

O'Reilly, F., Finnan, F., Allwright, S., Smith, G. D., \& Ben-Shlomo, Y. (1996). The effects of caring for a spouse with parkinson's disease on social, psychological and physical wellbeing. The British Journal of General Practice: The Journal of the Royal College of General Practitioners, 46(410), 507-512.

Park, A., \& Stacy, M. (2009). Non-motor symptoms in parkinson's disease. Journal of Neurology, 256 Suppl 3, 293-298. doi:10.1007/s00415-009-5240-1 
Parrish, M., Giunta, N., \& Adams, S. (2003). Parkinson's disease caregiving: Implications for care management. Care Management Journals: Journal of Case Management ; the Journal of Long Term Home Health Care, 4(1), 53-60.

Peters, M., Fitzpatrick, R., Doll, H., Playford, D., \& Jenkinson, C. (2011). Does self-reported well-being of patients with parkinson's disease influence caregiver strain and quality of life? Parkinsonism \& Related Disorders, 17(5), 348-352. doi:10.1016/j.parkreldis.2011.02.009

Rakoski, M. O., McCammon, R. J., Piette, J. D., Iwashyna, T. J., Marrero, J. A., Lok, A. S., et al. (2012). Burden of cirrhosis on older americans and their families: Analysis of the health and retirement study. Hepatology (Baltimore, Md.), 55(1), 184-191. doi:10.1002/hep.24616

Sanders-Dewey, N., Mullins, L. L., \& Chaney, J. M. (2001). Coping style, perceived uncertainty in illness, and distress in individuals with parkinson's disease and their caregivers. Rehabilitation Psychology, 46(4), 363-381.

Seng, B. K., Luo, N., Ng, W. Y., Lim, J., Chionh, H. L., Goh, J., et al. (2010). Validity and reliability of the zarit burden interview in assessing caregiving burden. Annals of the Academy of Medicine, Singapore, 39(10), 758-763.

Stella, F., Banzato, C. E. M., Quagliato, E. M. A. B., Viana, M. A., \& Christofoletti, G. (2009). Psychopathological features in patients with parkinson's disease and related caregivers' burden. International Journal of Geriatric Psychiatry, 24(10), 1158-1165. doi: $10.1002 / g p s .2240$

Thommessen, B., Aarsland, D., Braekhus, A., Oksengaard, A. R., Engedal, K., \& Laake, K. (2002). The psychosocial burden on spouses of the elderly with stroke, dementia and parkinson's disease. International Journal of Geriatric Psychiatry, 17(1), 78-84.

Whetten-Goldstein, K., Sloan, F., Kulas, E., Cutson, T., \& Schenkman, M. (1997). The burden of parkinson's disease on society, family, and the individual. Journal of the American Geriatrics Society, 45(7), 844-849. 


\begin{tabular}{|c|c|c|c|c|c|}
\hline \multicolumn{6}{|c|}{$\begin{array}{l}\text { Table 1: Demographic characteristics of Caregivers and Care-recipients of } \\
\text { with and without PD } \\
\text { National Alliance for Caregiving, 2004, 2009, } N=1,671\end{array}$} \\
\hline & $\begin{array}{c}\text { PD } \\
\mathbf{N}=32\end{array}$ & & $\begin{array}{c}\text { No PD } \\
\mathbf{N}=1,639\end{array}$ & & Sig \\
\hline \multicolumn{6}{|l|}{ Care-recipient characteristics } \\
\hline & Mean \pm S.D & & Mean \pm S.D & & \\
\hline Age (years) & $81.29 \pm 6.53$ & & $80.69 \pm 8.17$ & & \\
\hline ADL score & $3.14 \pm 2.02$ & & $1.71 \pm 1.96$ & & $* *$ \\
\hline IADL score & $4.82 \pm 2.01$ & & $4.41 \pm 1.84$ & & \\
\hline \multicolumn{6}{|l|}{ Caregiver characteristics } \\
\hline Age (years) & $55.03 \pm 14.19$ & & $52.05 \pm 14.35$ & & \\
\hline \multicolumn{6}{|l|}{ Other Independent Variables } \\
\hline Hours of caregiving per week & $27.51 \pm 35.04$ & & $21.62 \pm 28.71$ & & \\
\hline \multicolumn{6}{|l|}{ Care-recipient characteristics } \\
\hline Gender & $\mathbf{N}$ & Col \% & $\mathbf{N}$ & Col \% & \\
\hline Male & 15 & 40.7 & 468 & 29.8 & \\
\hline Female & 16 & 55.8 & 1,147 & 68.7 & \\
\hline Missing & 1 & 3.5 & 24 & 1.6 & \\
\hline \multicolumn{6}{|l|}{ Caregiver characteristics } \\
\hline Gender & $\mathbf{N}$ & Col \% & $\mathbf{N}$ & Col \% & \\
\hline Male & 15 & 51.8 & 594 & 40.2 & \\
\hline Female & 17 & 48.2 & 1,045 & 59.8 & \\
\hline \multicolumn{6}{|l|}{ Marital status } \\
\hline Married & 21 & 67.6 & 999 & 61.3 & \\
\hline Others & 11 & 32.4 & 640 & 38.7 & \\
\hline \multicolumn{6}{|l|}{ Living status of care-recipient } \\
\hline Lives in CG household & 11 & 35.3 & 381 & 19.2 & $*$ \\
\hline Lives elsewhere & 21 & 64.7 & 1,258 & 80.8 & \\
\hline \multicolumn{6}{|l|}{ Other Independent Variables } \\
\hline \multicolumn{6}{|l|}{ Paid Caregiver } \\
\hline Yes & 17 & 48.1 & 728 & 46.0 & \\
\hline No & 15 & 51.9 & 911 & 54.0 & \\
\hline
\end{tabular}

Note: Based on 1,671 elderly care-recipients aged 65 or older.

CG: Caregiver; ADL: Activities of daily living; IADL: Instrumental activities of daily living 
Table 2: Caregiver Burden (Mean and Standard Deviations) by Caregiver and Other Characteristics

National Alliance for Caregiving, 2004, 2009, N= 1,671

\begin{tabular}{|c|c|c|c|c|c|c|c|c|c|}
\hline & \multicolumn{3}{|c|}{ CG Burden Scale † } & \multicolumn{3}{|c|}{ Number of hours/week $t$} & \multicolumn{3}{|c|}{ Informal CG cost $\neq$} \\
\hline & PD & No PD & Sig & PD & No PD & Sig & PD & No PD & Sig \\
\hline & $\mathrm{N}=32$ & $\mathrm{~N}=1,639$ & & $\mathrm{~N}=32$ & $\mathrm{~N}=1,639$ & & $\mathrm{~N}=32$ & $\mathrm{~N}=1,639$ & \\
\hline \multicolumn{10}{|l|}{ Characteristics } \\
\hline \multicolumn{10}{|l|}{ Sex of Caregiver } \\
\hline Female & $1.95 \pm 0.29$ & $2.25 \pm 0.04$ & & $20.56 \pm 8.29$ & $21.26 \pm 0.98$ & & $10,798 \pm 4,358$ & $11,166 \pm 517$ & \\
\hline Male & $2.5 \pm 0.25$ & $2.02 \pm 0.04$ & & $34.57 \pm 9.91$ & $18.2 \pm 1.22$ & & $18,158 \pm 5,203$ & $9,560 \pm 639$ & \\
\hline \multicolumn{10}{|l|}{ Marital Status of Caregiver } \\
\hline Married & $2.31 \pm 0.23$ & $2.1 \pm 0.04$ & & $26.19 \pm 8.26$ & $19.24 \pm 0.9$ & & $13,579 \pm 4,340$ & $10,107 \pm 503$ & \\
\hline Others & $2.08 \pm 0.39$ & $2.24 \pm 0.05$ & & $31.18 \pm 11.44$ & $21.28 \pm 1.26$ & & $16,381 \pm 6,010$ & $11,174 \pm 670$ & \\
\hline Care-recipient residency status & & & $* *$ & & & $* * *$ & & & $* * *$ \\
\hline Lives in CG household & $2.44 \pm 0.33$ & $2.63 \pm 0.06$ & & $55.5 \pm 12.27$ & $47.46 \pm 2.15$ & & $29,151 \pm 6,446$ & $24,926 \pm 1,151$ & \\
\hline Lives elsewhere & $2.13 \pm 0.25$ & $2.04 \pm 0.03$ & & $12.72 \pm 4.3$ & $13.52 \pm 0.6$ & & $6,684 \pm 2,261$ & $7,105 \pm 334$ & \\
\hline ADLS & & & $* * *$ & & & $* * *$ & & & $* * *$ \\
\hline None & $1.15 \pm 0.15$ & $1.77 \pm 0.04$ & & $11.59 \pm 5.42$ & $9.85 \pm 0.6$ & & $6,090 \pm 2,844$ & $5,170 \pm 333$ & \\
\hline "1-2" & $1.97 \pm 0.42$ & $2.06 \pm 0.05$ & & $26.13 \pm 13.71$ & $16.35 \pm 1.18$ & & $13,723 \pm 7,198$ & $8,587 \pm 620$ & \\
\hline $3,+$ & $2.67 \pm 0.18$ & $2.75 \pm 0.06$ & & $33.22 \pm 9.18$ & $37.57 \pm 1.7$ & & $17,446 \pm 4,826$ & $19,729 \pm 932$ & \\
\hline IADLS & & & $* * *$ & & & $* * *$ & & & $* * *$ \\
\hline None $\neq$ & 1.66 & $1.58 \pm 0.19$ & & 2.00 & $3.78 \pm 1.8$ & & 1,050 & $1,987 \pm 953$ & \\
\hline "1-2" & $1.89 \pm 0.51$ & $1.61 \pm 0.05$ & & $4.35 \pm 0.79$ & $7.75 \pm 1.1$ & & $2,283 \pm 413$ & $4,069 \pm 615$ & \\
\hline $3,+$ & $2.32 \pm 0.23$ & $2.28 \pm 0.03$ & & $32.83 \pm 7.68$ & 23.0 & \pm 0.88 & $17,241 \pm 4,032$ & $12,115 \pm 463$ & \\
\hline Presence of Paid Caregiver & & & & & & $*$ & & & $*$ \\
\hline Yes & $2.2 \pm 0.27$ & $2.3 \pm 0.05$ & & $25.11 \pm 10.01$ & $21.74 \pm 1.2$ & & $13,188 \pm 5,258$ & $11,420 \pm 653$ & \\
\hline No & $2.27 \pm 0.31$ & $2.03 \pm 0.04$ & & $30.32 \pm 8.96$ & $18.57 \pm 0.9$ & & $15,924 \pm 4,708$ & $9,754 \pm 493$ & \\
\hline
\end{tabular}

$\$$ Dependent variable was the number of hours spent in caregiving per week

$\neq$ Dependent variable was the cost of informal caregiving in terms of 2013 US dollars

ADL: Activities of daily living; IADL: Instrumental activities of daily living

$* * * \mathbf{p}<.001 ; * * .001 \leq p<.01 ; * .01 \leq p<.05$ 
Table 3: Parameter Estimates and Standard Errors from Ordinary Least Square Regressions on Caregiver Burden, Number of Caregiving Hours and Log-transformed Costs Associated with Informal Care giving

National Alliance of Caregivers Survey $(2004,2009)$, N = 1,671

\begin{tabular}{|c|c|c|c|c|c|c|c|c|c|}
\hline \multirow[b]{2}{*}{ Characteristics } & \multicolumn{3}{|c|}{ CG Burden Scale $\dagger$} & \multicolumn{3}{|c|}{ Number of hours/week } & \multicolumn{3}{|c|}{$\begin{array}{c}\text { Log-transformed } \\
\text { Informal CG Cost } \neq\end{array}$} \\
\hline & Beta & S.E. & Sig & Beta & S.E. & Sig & Beta & S.E. & Sig \\
\hline Intercept & 0.985 & 0.101 & $* * *$ & -13.005 & 2.382 & $* * *$ & 6.598 & 0.132 & $* * *$ \\
\hline \multicolumn{10}{|l|}{ Parkinson's disease } \\
\hline $\begin{array}{l}\text { Yes } \\
\text { No }\end{array}$ & -0.153 & 0.146 & & -2.637 & 4.874 & & -0.133 & 0.227 & \\
\hline Age of Caregiver & 0.003 & 0.002 & & 0.175 & 0.042 & $* * *$ & 0.006 & 0.002 & $* *$ \\
\hline \multicolumn{10}{|l|}{ Sex of Caregiver } \\
\hline $\begin{array}{l}\text { Female } \\
\text { Male }\end{array}$ & 0.173 & 0.049 & $* * *$ & 2.316 & 1.155 & $*$ & 0.170 & 0.057 & $* *$ \\
\hline \multicolumn{10}{|l|}{ Marital Status of Caregiver } \\
\hline $\begin{array}{l}\text { Married } \\
\text { Others }\end{array}$ & -0.103 & 0.051 & $*$ & -0.667 & 1.210 & & -0.132 & 0.057 & $*$ \\
\hline \multicolumn{10}{|l|}{ Care-recipient residency status } \\
\hline $\begin{array}{l}\text { Lives in Caregiver household } \\
\text { Lives elsewhere }\end{array}$ & -0.031 & 0.071 & & 23.413 & 2.267 & $* * *$ & 0.836 & 0.077 & $* * *$ \\
\hline ADLS & 0.132 & 0.015 & $* * *$ & 4.468 & 0.398 & $* * *$ & 0.207 & 0.015 & $* * *$ \\
\hline IADLS & 0.139 & 0.015 & $* * *$ & 2.755 & 0.343 & $* * *$ & 0.258 & 0.018 & $* * *$ \\
\hline \multicolumn{10}{|l|}{ Presence of Paid Caregiver } \\
\hline Yes & 0.104 & 0.049 & $*$ & -0.965 & 1.200 & & -0.178 & 0.057 & $* *$ \\
\hline $\begin{array}{l}\text { No } \\
\text { Number of hours spent in } \\
\text { caregiving/week }\end{array}$ & 0.006 & 0.001 & $* * *$ & - & - & & - & - & \\
\hline
\end{tabular}

Note: $\mathrm{PD}=32$, No PD $=1,639$

$\dagger$ Dependent variable was the computed Caregiver Burden; This model was adjusted for presence or absence of PD, Age of caregiver, Sex of caregiver, Marital status of caregiver, care-recipient's residency status, ADL, IADL, presence or absence of paid caregiver, number of hours spent in caregiving per week

$\$$ Dependent variable was the number of hours spent in caregiving per week; This model was adjusted for presence or absence of PD, Age of caregiver, Sex of caregiver, Marital status of caregiver, care-recipient's residency status, ADL, IADL, presence or absence of paid caregiver

‡ Dependent variable was the log-transformed cost of informal caregiving; This model was adjusted for presence or absence of PD, Age of caregiver, Sex of caregiver, marital status of caregiver, care-recipient's residency status,

ADL, IADL, presence or absence of paid caregiver

ADL: Activities of daily living; IADL: Instrumental activities of daily living

$* * * \mathbf{p}<.001 ; * * .001 \leq \mathbf{p}<.01 ; * .01 \leq \mathbf{p}<.05$ 
CHAPTER 4

Page 85 of 129 


\section{CHAPTER 4: Chronic Illness with Complexity: Diabetes Care among Elderly Medicare Beneficiaries with Parkinson's disease and Diabetes}

\section{INTRODUCTION}

\section{Chronic Illness with Complexity (CIC)}

According to the National Quality Forum (NQF) and the Agency for Healthcare Research and Quality (AHRQ), CIC is defined as "two or more chronic conditions that have an adverse effect on health status, function status, or quality of life of the patient and require complex coordination of care" (http://www.qualityforum.org/WorkArea/linkit.aspx?LinkIdentifie). Due to the presence of multiple morbidities, individuals with CIC are at a higher risk of limitations of activities of daily living and disability (Weiss, 2007).

CIC is highly prevalent and has been increasing over time. In 2009, 145 million (approximately half the United States population) Americans had one or more chronic conditions, among which nearly half and more than a quarter of the individuals with chronic conditions had multiple morbidities (chronic care chart book). According to the National Health Interview Survey (NHIS) 2010, among elderly men $45.4 \%$ had 2-3 chronic illness and $17.1 \%$ had four or more chronic illness, whereas among elderly women $47.4 \%$ had 2-3 chronic illness and $14.5 \%$ had four or more chronic illness (NHIS 2010). Findings from 2009 MEPS revealed that among elderly individuals $42.5 \%$ had 2-3 chronic illness while $24.6 \%$ had four or more chronic illness (chronic care chart book).

CIC is associated with a wide array of negative health outcomes such as limitations of functional status, decreased health-related quality of life, higher healthcare expenditures, greater disability, adverse drug events, duplicative tests, contradictory medical advice, and lower survival rates (Condelius, Edberg, Jakobsson, \& Hallberg, 2008; Fortin, Bravo, Hudon, Vanasse, 
\& Lapointe, 2005; Fortin, Soubhi, Hudon, Bayliss, \& van, 2007; Gijsen et al., 2001; Marengoni, von Strauss, Rizzuto, Winblad, \& Fratiglioni, 2009; Schneider, O'Donnell, \& Dean, 2009; van, Buntinx, Metsemakers, Roos, \& Knottnerus, 1998). For example, the average annual healthcare expenditures among elderly individuals with two to three and four or more chronic illness was estimated to be US\$8,979 and US\$15,553 (2006 US dollars) respectively (chronic care chart book).

\section{Chronic Illness with Complexity: Co-occurring Parkinson's Diseases and Diabetes}

T2DM and its complications (micro- and macro-vascular) are the leading causes for morbidity and mortality in the United States (U.S.) (Shaw, Sicree, \& Zimmet, 2010). Parkinson's disease $(\mathrm{PD})$ is a progressive neurodegenerative disease characterized by muscular tremor, slowing of movement, partial facial paralysis, peculiarity of gait and posture (Muangpaisan et al., 2011; Park \& Stacy, 2009). According to the definition of CIC provided by AHRQ and NQF, cooccurring T2DM and PD can be considered as CIC their co-occurrence severely affects the quality of life, and impairs health and functional status. Moreover, co-occurring T2DM and PD require medical care from different specialties such as neurologists and endocrinologist, and require care in different settings including home-based as well as facility-based care (Lapane, Fernandez, \& Friedman, 1999; Nocera, Horvat, \& Ray, 2009). It has to be noted that the prevalence of T2DM among elderly individuals with PD is comparable or slightly lower compared to those without PD. A study conducted among elderly Medicare beneficiaries showed that the prevalence rate of metabolic conditions did not differ significantly between individuals with and without PD (Noyes, Liu, Li, Holloway, \& Dick, 2006). Another study conducted among a nationally representative sample of community-dwelling elderly individuals in the United States found that the prevalence of T2DM was actually lower among individuals with PD 
compared to matched controls without PD (Bhattacharjee \& Sambamoorthi, 2013). However, it has been estimated that by 2030, the prevalence of both T2DM and PD will increase by approximately two-folds due to the aging U.S. population (Dorsey et al. 2007) and will become a major public health concern in the near future.

\section{Need for the study}

\section{Chronic Illness with Complexity: Diabetes Process and Outcomes}

Co-occurring PD and diabetes can pose significant challenges to diabetes management. However, clinical guidelines for diabetes management for those with CIC are lacking. In general, guidelines for clinical practice are developed based on the expert consensus and the scientific evidence for a single disease state (Boyd et al., 2005). Standards of care and quality of care improvement efforts are based on these guidelines for clinical practice. As for example, there are separate guidelines for treating diabetes (such as the guidelines of the American Diabetes Association) and PD (European Parkinson's Disease Standards of Care Consensus Statement).

Furthermore, studies on diabetes care among individuals with CIC have revealed mixed findings. One study conducted among veterans with diabetes seeking care in seven different Veterans Affairs (VA) facilities from July 2007 through June 2008 reported that veterans with CIC were more likely to receive overall good quality for all three quality measures (glycemic, blood pressure and low density lipoprotein-cholesterol control) combined (adjusted OR, 2.17; 95\% CI, 1.96-2.39) (Woodard, Urech, Landrum, Wang, \& Petersen, 2011). Whereas, another study using the INTERMED classification system for case complexity found that greater complexity among individuals with T2DM was associated with higher HbA1c values (Fischer et al., 2000). Therefore, the aim of this study was to assess process and intermediate clinical 
outcomes of diabetes care among elderly individuals with CIC (T2DM and PD) compared to those without CIC (T2DM without PD).

\section{Conceptual Framework}

The current study adapts elements from the Vector model of Complexity proposed by Safford and colleagues (Safford, Allison, \& Kiefe, 2007). This framework allows one to examine CIC with different factors such as socio-economic (e.g. insurance status), cultural (e.g. race/ethnicity), biological/genetic (e.g. gender), external environmental (e.g. region), and healthcare use (e.g. co-medication use) contributing to complexity. Patient complexity can occur from any axis, but primary focus is often given on the underlying biological axis by physicians. Each of the axes in this model is interconnected with the other as depicted by the web, and even in case of not being connected by adjacent web, the axes are still connected with each other. 
Figure 1: Conceptual Framework: Vector model of Complexity

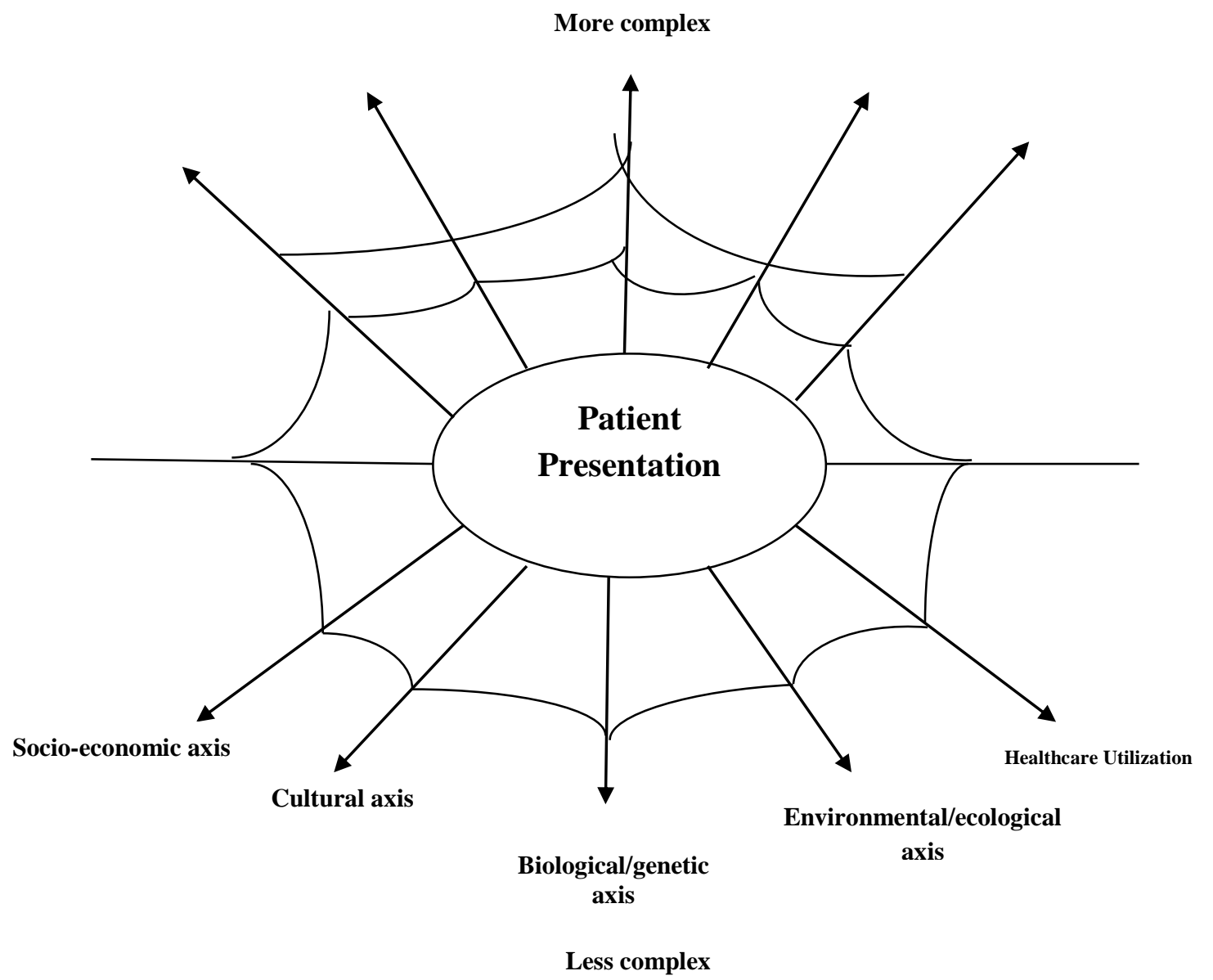

Figure 2: Outcomes oriented model of the determinants of health






\section{METHODS}

\section{Study Design}

A retrospective cohort design (2007-2008, 2008-2009, 2009-2010, 2010-2011) using matched case-control approach with observational data was used for the purposes of this study. For each elderly individual with T2DM, the observation period consisted of 24 months with 12month baseline period and 12-month follow-up period. For example, if T2DM and PD cases were identified in 2007, 2007 served as the baseline year, and 2008 served as the follow-up period. Process of care and intermediate clinical outcomes were measured during the follow-up year (i.e. 2008).

\section{Data Source}

The Humana Medicare Advantage Part D database (MAPD) from January 2007 through December 31, 2011 was used for this study. The Humana claims database consists of more than 12 million current and previous enrollees among which 1.9 million enrollees are from MAPD plans. This study used medical, prescription, laboratory claims and person enrollment summary files. The medical claims contained information related to the type of plan, treatment date, type of admission (trauma, elective, emergency etc.), inpatient length of stay, diagnosis and procedural codes, and total Medicare allowable charges associated with each claim. Prescription claims included information on prescription fill date, medication dispensed, quantity of medication dispensed, net amount paid by Humana and out-of-pocket costs for enrollees.. The laboratory Claims contained information on lab test identifying codes, lab results and abnormal value indicator. However, laboratory results are available only for approximately $30 \%$ of the laboratory claims. The patient enrollment summary file included information on the MAPD enrollees age, sex, race/ethnicity, and enrollment dates. 


\section{Study Population}

The study population consisted of elderly Medicare beneficiaries ( $\geq 65$ years) with T2DM. Elderly Medicare beneficiaries with T2DM were identified by the presence of a minimum of one inpatient or two outpatient visits (at least of 30 days apart) with a primary or secondary diagnosis of T2DM [International Classification of Diseases $9^{\text {th }}$ Modification (ICD-9CM) code: 250.x0 or 250.x2] (Wang, Wei, Miao, Xie, \& Baser, 2013; Xie et al., 2013).

\section{Inclusion Criteria:}

Other inclusion criteria were: (i) continuous enrollment of 24 months (at baseline and follow-up year); and (ii) receipt of at least one oral antidiabetic drug (OAD) or insulin during the baseline year.

\section{Dependent Variables}

\section{Process of Care}

The three processes of care measures used in this study included: (i) HbA1c testing; (ii) lipids testing; and (iii) nephropathy screening. These measures were considered to meet the American Diabetes Association (ADA) guidelines if: (1) HbA1c testing was conducted at least two times a year with a gap of at least three months; (2) lipid testing was conducted at least once a year; and (3) nephropathy screening was conducted at least once a year. A detailed description of the CPT and HCPCS codes are provided in Appendix I.

\section{Intermediate Clinical Outcomes}

\section{Glycemic control}

HbA1c $>9 \%$ represents poor glycemic control and is considered to be a poor performance marker among all elderly individuals with CIC (Meduru 2007). One study has used HbA1c $<7 \%$ is representative of optimal glycemic control (Meduru et al., 2007). However, 
among elderly individuals $\mathrm{HbA} 1 \mathrm{C}<8 \%$ is often considered as acceptable glycemic control (HEDIS. Technical Specifications). Therefore, glycemic control outcomes were classified into three groups based on $\mathrm{HbA} 1 \mathrm{c}$ values as follows: (i) $<8 \%$; (ii) $\geq 8 \%$. This outcome was measured only among those with $\mathrm{HbA1c}$ values.

\section{Lipid Control}

Lipid control outcomes were based on Low Density Lipoprotein Cholesterol (LDL-C), High Density Lipoprotein Cholesterol (HDL-C), triglycerides, and total cholesterol. These lipid control outcomes were categorized based on the American Diabetes Association guidelines. LDL-C was categorized as follows: (i) $<100 \mathrm{mg} / \mathrm{dl}$; (ii) $\geq 100 \mathrm{mg} / \mathrm{dl}$ and (iii) no LDL-C value. HDL-C was categorized into two groups for both men and women as follows: (i) $\leq 40 \mathrm{mg} / \mathrm{dl}$ for men; (ii) $>40 \mathrm{mg} / \mathrm{dl}$ for men; (iii) $\leq 50 \mathrm{mg} / \mathrm{dl}$ for women; and (iv) $>50 \mathrm{mg} / \mathrm{dl}$ for women. Triglycerides were classified into two groups as follows: (i) $<150 \mathrm{mg} / \mathrm{dl}$; (ii) $\geq 150 \mathrm{mg} / \mathrm{dl}$, and

(iii) no triglyceride values. Total cholesterol was divided into groups as follows: (i) $<200 \mathrm{mg} / \mathrm{dl}$; (ii) $\geq 200 \mathrm{mg} / \mathrm{dl}$ (ADA guidelines). Again these were restricted to individuals with available laboratory values.

\section{Key Independent variable: Presence of PD}

The key independent variable for all analyses was presence or absence of PD. Identification of PD was achieved by using ICD-9-CM code of 332.xx during the baseline year. The diagnosis of PD was ascertained by the presence of at least one inpatient or two outpatient visits (30 days apart) with a primary or secondary diagnosis of PD (ICD-9-CM code: 332.xx). PD cases were matched with those without PD using propensity scores generated by conducting a logistic regression on presence/absence of $\mathrm{PD}$ which adjusted for gender, age, and diabetes complications severity index (DCSI). One case was matched to three controls based on 8 to 1 
GREEDY matching technique using propensity score. For 8 to 1 GREEDY matching, the cases and control with same propensity score till the $8^{\text {th }}$ digit are matched, and if they do not match on 8 digits, then it goes to 7-digit matching and so on. The GREEDY matching technique employs a sample without replacement algorithm and if there are more than one matches, then selection of control becomes random. Additionally, it was ensured that controls should be from the same calendar year as the cases (i.e. if individuals were identified with PD in 2008, all controls will be from 2008).

\section{Independent variables}

\section{Patient Complexities}

According to the American Geriatric Society (AGS) guidelines, individuals having specific conditions such as cognitive impairment, depression, fall and falls risk, polypharmacy, and urinary incontinence should be provided individualized treatment (Inouye et al. 2007). These characteristics were measured during the baseline period. Elderly Medicare beneficiaries were considered to have cognitive impairment due to physical illnesses if they had a diagnosis of Huntington's disease, delirium, dementia, amnestic and other cognitive disorders; whereas if they have a diagnosis of bipolar disorder, schizophrenia and other psychotic disorders, they were considered to have cognitive impairment due to mental illnesses. Elderly Medicare beneficiaries were considered to have any cognitive impairment if they had either mental and/or physical cognitive impairment. To identify accidental falls, E-codes E880 through E888 were used whereas V-code V15.88 was used as a proxy measure for falls risk (Mehta et al. 2010; Tinetti et al. 2006). Number of therapeutic classes of prescribed medications was used to define polypharmacy, and was categorized into quintiles: (i) 0-0, (ii) 1-1, (iii) 2-3, (iv) 4-5, and (v) 6-31. 


\section{Dominant Comorbid Conditions}

Using the framework of Kerr and Piette, cancer, end stage renal disease, and end stage liver disease were included as a dominant comorbid condition in this study (Piette et al. 2006).

\section{Other independent Variables}

Other independent variables consisted of socio-economic, cultural, and

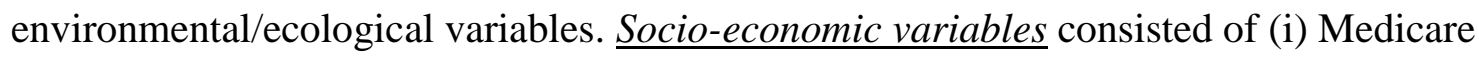
prescription drug coverage gap; and (ii) insurance status (Private Fee-for-service, Health Maintenance Organization, and other insurance). Environmental factors consisted of (i) region (South, Mid-West, and Other regions). The cultural factor was defined by race/ethnicity (Whites, African- Americans, Hispanics, and Others).

\section{Statistical Analyses}

Unadjusted differences among elderly individuals with and without Parkinson's disease were determined using chi-square tests. Conditional Logistic regression analyses and conditional multinomial logistic regression analyses were conducted for binary dependent variables and dependent variables with more than two levels respectively. As $30 \%$ of the study cohort did not have laboratory values, sample selection models were also conducted to test selection bias among individuals with and without laboratory values. This was accomplished using "Heckprob" selectivity corrected regression. These models consisted of a selection equation in which the presence or absence of laboratory values were modeled. In the outcome equation, the intermediate outcomes were modeled. For example, for HbA1c control, a logistic regression analysis on the presence or absence of HbAlc values was conducted. In the outcome equation, glycemic control $(<8 \%$ and $\geq 8 \%)$ was modeled. The Wald test of independence showed that the chi-square probability value was 0.7968 indicating that there is no influence of unobserved variables on glycemic control outcome in this dataset. Similar findings were observed with the 
lipid outcomes. Therefore, we report results from analyses among elderly individuals with available $\mathrm{HbA} 1 \mathrm{C}$ values and lipid values.

\section{Propensity Score Matching}

Before propensity score matching, there were 2,727 individuals with PD and diabetes (cases), and 249,763 individuals with diabetes only (controls). After propensity score matching and removing pairs with inexact matches, there were 2,703 individuals with PD and diabetes and 8,109 individuals with diabetes only (1:3 case to control matching). The cohort development is depicted in Figure 1. Age (in years) and Diabetes Complications Severity Index (DCSI) total were continuous variables and the group differences in these two variables were ascertained by ttests. For gender the group differences were ascertained by using chi-square. The number of individuals with Parkinson's disease (PD) and before and after matching in each year are different because of the fact that we found that 1,282 individuals without PD in previous years were diagnosed with PD in the following year, and as these individuals were included in the control dataset for a particular year, they were deleted from the control dataset so that we do not have overlap between case and control group during matching. For each year, the individuals with PD in the matched sample were unique cases.

The two groups were matched on age, gender and DCSI scores. The c-statistics of the logistic regression to calculate propensity score for each year were found to be satisfactory (around 0.70 ). From Table 1, it can be noted that, before propensity score matching, the two groups differed significantly from each other in terms of age, DCSI total and gender distribution. Before matching, among individuals with T2DM and PD, the total mean DCSI score was significantly higher compared to those with only diabetes. In terms of age, individuals with PD and diabetes had a significantly higher mean age as compared to those with diabetes only prior to 
propensity score matching. The PD and diabetes group had significantly higher number of males as compared to the group with diabetes only before matching. The propensity score matched sample was found to be well balanced in terms of the variables that were used to match the two groups. After matching there were no significant differences between the two groups in terms of age, DCSI and gender. From Table 2, it can be noted that when the 4 panels (2007-2008, 20082009, 2009-2010, and 2010-2011) were stacked, there were no statistically significant group differences in terms of age, gender and DCSI.

\section{RESULTS}

\section{Description of Study Sample by PD status}

Table 3 exhibits baseline characteristics of T2DM elderly individuals with and without PD. There was significantly higher proportion of African-Americans (14.4\%) among individuals with only diabetes. Overall, both the groups (individuals with T2DM and PD and with diabetes only) had higher proportions of whites ( $75.7 \%$ and $74.3 \%$ respectively). In terms of region and plan types, there were higher proportion of individuals in the South region (around 75\%) and Health Maintenance Organizations in both the groups (around 48\%). There was significantly higher proportion of individuals who did not reach donut hole (56.6\%) among individuals with only diabetes, whereas the group with PD and diabetes had higher proportions of individuals entering (44.9\%) and having entry and exit information regarding donut hole (17.7\%). Individuals with PD and diabetes had significantly greater proportion of polypharmacy users in the higher quintiles (4-5, and 6-31). With respect to the conditions specific to elderly individuals, individuals with PD and diabetes had significantly higher proportion of urinary incontinence (10.4\%), major depressive disorders (26.7\%), cognitive impairment (33.4\%), and falls and falls 
risk (9.9\%). Individuals with PD and diabetes had a higher proportion of baseline emergency room (55.5\%) and baseline home health visit (60.9\%).

\section{Description of Process of Care and Intermediate Clinical Outcomes}

Table 4 summarizes the findings in terms of process of care measures and intermediate clinical outcomes. Overall, $66.84 \%$ had ADA recommended HbA1c testing. A lower percentage of individuals with T2DM and PD received HbA1c testing (63.7\%) compared to those with T2DM and no PD (67.9\%, P-value <0.001).

An overwhelming majority of individuals with T2DM received lipid testing (84.65\%). A lower percentage of elderly individuals with T2DM and PD (80.4\%) received lipid testing compared to those with T2DM and no PD $(86.1 \%$, p-value $<0.001)$. No statistically significant differences were observed in the two groups in terms of nephropathy screening.

Among elderly individuals with available HbA1C values, an overwhelming majority had HbA1C value of $<8 \%$ in both individuals with T2DM and PD (86\%) and T2DM and no PD (83.8\%). Elderly individuals with T2DM and PD had statistically significantly better intermediate clinical outcomes compared to those with T2DM and no PD in terms of LDL-C< $100 \mathrm{mg} / \mathrm{dl}(75.5 \%$ vs. $69.8 \%)$, triglycerides $<150 \mathrm{mg} / \mathrm{dl}$ (63.8\% vs. $58.6 \%)$, total cholesterol < $200 \mathrm{mg} / \mathrm{dl}(87.2 \%$ vs. $83 \%)$ and HDL-C $\geq 50 \mathrm{mg} / \mathrm{dl}(39.8 \%$ vs. $35.7 \%)$.

\section{Multivariable Conditional Logistic Regression on Process of Care}

Table 5 shows the results of conditional logistic regression analyses conducted with HbAlc testing as the dependent variable adjusting for the matched pair design. After controlling for Parkinson's disease, race/ethnicity, region, plan-type, donut hole, polypharmacy, urinary incontinence, depression, falls and fall risk, cognitive impairment due to physical conditions, cognitive impairment due to mental conditions, dominant conditions, baseline emergency room 
visits, baseline home health visits and adjusting for the matched pair design, it was observed that individuals with PD and diabetes were 12\% (AOR: 0.88, 95\%CI: 0.79-0.97) and 18\% (AOR: 0.82, 95\%CI: 0.72-0.94) less likely to meet the annual ADA recommended HbA1c and lipid testing respectively compared to individuals with diabetes and without PD. However, there were no statistically significant difference between individuals with and without PD in terms of nephropathy testing (AOR: 0.99, 95\%CI: 0.88-1.10).

Table 6 depicts the results from conditional multinomial logistic regression with glycemic control as the dependent variable. After adjusting for Parkinson's disease, race/ethnicity, region, plan-type, donut hole, polypharmacy, urinary incontinence, depression, falls and fall risk, cognitive impairment due to physical conditions, cognitive impairment due to mental conditions, dominant conditions, baseline emergency room visits, baseline home health visits and matched pair design, it was observed that individuals with T2DM and PD were 34\% (AOR: 1.34, 95\%CI: 1.10-1.63) more likely to have better glycemic control (HbAlc $<8 \%$ ) compared to those with T2DM and without PD. Individuals with T2DM and PD were higher likely to have better outcomes in terms of LDL-C $(<100 \mathrm{mg} / \mathrm{dl})$ (AOR: 1.29, 95\%CI: 1.06-1.59), triglyceride (<150mg/dl) (AOR: 1.31, 95\%CI: 1.06-1.62), total cholesterol (<200mg/dl) (AOR: 1.46, 95\%CI: $1.08-1.97)$ and HDL-C ( $\geq 50 \mathrm{mg} / \mathrm{dl})$ (AOR: $1.20,95 \% \mathrm{CI}: 1.04-1.39)$.

\section{DISCUSSION}

This study examined the association between CIC and process and intermediate outcomes of diabetes care among elderly individuals with T2DM. CIC was defined as the co-occurrence of T2DM and PD. Results from this study indicated that among individuals with T2DM, those with PD did not receive the ADA recommended $\mathrm{HbA1c}$ and lipid testing compared to those without PD. These findings suggest that, CIC is a barrier to achieving clinically recommended process of 
care measures. Some of the reasons which may lead to not achieving the ADA recommended HbA1c and lipid testing can be that elderly Medicare beneficiaries may not be aware of the benefits of meeting these goals, or there can be a gap in patient-provider communication, or the elderly Medicare beneficiaries may not be visiting their physicians on a regular basis (Delaronde, 2005). Some ways in which these barriers can be overcome include educating patients and underscoring and helping in attending group consultations by healthcare providers (Van Dam et al. 2003). Moreover, for managed care settings, telephone follow-up and/or reminders have been seen to be effective (Rubin, Dietrich \& Hawk, 1998). Another plausible reason for not achieving ADA recommended goals may be due to competing demands of elderly Medicare beneficiaries with T2DM and PD. It is possible that the severity of PD may be high in this group of patients and providers might be focusing on treating PD than T2DM. However, as the measure of severity of PD in claims database is not available, this remains one of the unmeasured factors that can be influencing the study findings.

A noteworthy finding from our study is the relationship between CIC and intermediate clinical outcomes of diabetes care. For glycemic and lipid outcomes, elderly individuals with T2DM and PD were more likely to achieve control compared to those with T2DM and no PD. A plausible explanation for better outcomes among those with T2DM and PD could be due to pathophysiological conditions of the two diseases. For example, it has been suggested that insulin resistance and insulin deficiency, which are the cardinal characteristics of T2DM, can lead to neurodegeneration (Peila, Rodriguez, White, \& Launer, 2004; Rönnemaa et al., 2008; Rönnemaa et al., 2009). It is possible that given the risk of neurodegeneration due to T2DM, the providers may be aggressively treating individuals with T2DM and PD for better glycemic and lipid outcomes in order to prevent further neurodegeneration. The findings from this study are 
consistent with a study conducted among elderly veterans, which showed that veterans with CIC were more likely to receive overall good outcomes for all 3quality measures (glycemic, blood pressure and low density lipoprotein-cholesterol) combined (adjusted OR, 2.17; 95\% CI, 1.962.39) (Woodard, Urech, Landrum, Wang, \& Petersen, 2011). One of the similarities between VA and the Medicare Advantage plans is that they follow the Integrated Delivery System (IDS) model. In the IDS model, the primary physician serves as the gate-keeper and maintains proper referral systems. The coordination of care among different types of specialists (Endocrinologists, Neurologists etc.) is ensured in the IDS models which in turn could lead to better management of individuals with CIC. The consistent finding of better glycemic and lipid outcomes among individuals with CIC in these two studies can be partially attributed to the better care coordination in these systems.

However, the findings from this study is inconsistent with the findings from the study using the INTERMED classification system for case complexity which found that among individuals with T2DM, greater complexity was associated with higher HbA1c values (Fischer et al., 2000). The INTERMED classification system utilized different factors such as biological, psychosocial and health care related aspects of T2DM to classify patient complexity and had only 61 patients in the study. The results presented were in the preliminary forms and it required further validation. Hence, it is possible that due to different classification system used to determine patient complexity, greater risk of poor diabetes control among individuals with higher complexity was observed. 


\section{Strengths and Limitations}

Strengths of this study include the use of large sample size, nationwide sample of commercially insured elderly individuals, exhaustive list of variables, availability of laboratory values and use of a robust study design.

As with other studies, this study also has limitations. Findings from this study cannot be generalizable to other populations or settings (e.g. fee-for-service Medicare beneficiaries). Laboratory values are available for only one-third of the population. Unmeasured confounders such lifestyle risk factors (e.g. body mass index and smoking status), physician specialty, duration and severity of PD could influence the study outcomes.

\section{CONCLUSION}

To the best of author's knowledge, this is the first study to examine the effect or influence of the presence of a chronic illness with complexity such as PD on the process and outcomes of diabetes care. Individuals with PD and diabetes were less likely to achieve ADA recommended annual $\mathrm{HbA} 1 \mathrm{c}$ and lipid testing goals compared to those with diabetes but without PD. Future research needs to explore the reasons for lower rates of $\mathrm{HbA} 1 \mathrm{C}$ and lipid testing among elderly individuals with T2DM and PD. However, among individuals with CIC, the intermediate glycemic and lipid outcomes were better compared to those without CIC. These findings suggest that the integrated delivery system of Medicare Advantage plans may be beneficial to elderly with CIC. 


\section{REFERENCES}

American Diabetes Association (ADA) 2012. Standards of Diabetes Care. Diabetes Care, 35(Suppl 1), S11-S63.

Becker, C., Brobert, G. P., Johansson, S., Jick, S. S., \& Meier, C. R. (2008). Diabetes in patients with idiopathic parkinson's disease. Diabetes Care, 31(9), 1808-1812. doi:10.2337/dc080479

Bhattacharjee, S., \& Sambamoorthi, U. (2013). Co-occurring chronic conditions and healthcare expenditures associated with parkinson's disease: A propensity score matched analysis. Parkinsonism \& Related Disorders.

Boyd, C. M., Darer, J., Boult, C., Fried, L. P., Boult, L., \& Wu, A. W. (2005). Clinical practice guidelines and quality of care for older patients with multiple comorbid diseases: Implications for pay for performance. JAMA: The Journal of the American Medical Association, 294(6), 716-724.

Cardoso, S., Correia, S., Santos, R. X., Carvalho, C., Santos, M. S., Oliveira, C. R., et al. (2009). Insulin is a two-edged knife on the brain. Journal of Alzheimer's Disease: JAD, 18(3), 483507. doi:10.3233/JAD-2009-1155

Cereda, E., Barichella, M., Pedrolli, C., Klersy, C., Cassani, E., Caccialanza, R., et al. (2011). Diabetes and risk of parkinson's disease: A systematic review and meta-analysis. Diabetes Care, 34(12), 2614-2623. doi:10.2337/dc11-1584

Chang HY, Weiner JP, Richards TM, Bleich SN, Segal JB 2012. Validating the adapted Diabetes Complications Severity Index in claims data. Am J Manag Care. 18:721-726

Comments Report for Multiple Chronic Conditions Measurement Framework. http://www.qualityforum.org/WorkArea/linkit.aspx?LinkIdentifie

Condelius, A., Edberg, A., Jakobsson, U., \& Hallberg, I. R. (2008). Hospital admissions among people $65+$ related to multimorbidity, municipal and outpatient care. Archives of Gerontology and Geriatrics, 46(1), 41-55.

Craft, S., \& Watson, G. S. (2004). Insulin and neurodegenerative disease: Shared and specific mechanisms. Lancet Neurology, 3(3), 169-178.

Chronic Care: Making the Case for Ongoing Care. Available from URL: http://www.rwjf.org/content/dam/farm/reports/reports/2010/rwjf54583 [Accessed 2013 May 23].

Centers for Disease Control and Preventions. Prevalence of Multiple Chronic Conditions Among US Adults: Estimates From the National Health Interview Survey, 2010. April 2013. 
Available from URL: http://www.cdc.gov/pcd/issues/2013/12_0203.htm [Accessed 2013 May 23].

D'Amelio, M., Ragonese, P., Callari, G., Di Benedetto, N., Palmeri, B., Terruso, V., et al. (2009). Diabetes preceding parkinson's disease onset. A case-control study. Parkinsonism \& Related Disorders, 15(9), 660-664. doi:10.1016/j.parkreldis.2009.02.013

Delaronde S. Barriers to A1C testing among a managed care population. Diabetes Educ. 2005 Mar-Apr;31(2):235-9.

Dorsey ER, Constantinescu R, Thompson JP, Biglan KM, Holloway RG, Kieburtz K, Marshall FJ, Ravina BM, Schifitto G, Siderowf A, Tanner CM. Projected number of people with Parkinson disease in the most populous nations, 2005 through 2030. Neurology. 2007 Jan 30;68(5):384-6. Epub 2006 Nov 2. PubMed PMID: 17082464

Driver, J. A., Smith, A., Buring, J. E., Gaziano, J. M., Kurth, T., \& Logroscino, G. (2008). Prospective cohort study of type 2 diabetes and the risk of parkinson's disease. Diabetes Care, 31(10), 2003-2005. doi:10.2337/dc08-0688

Fischer, C. J., Stiefel, F. C., De Jonge, P., Guex, P., Troendle, A., Bulliard, C., et al. (2000). Case complexity and clinical outcome in diabetes mellitus. A prospective study using the INTERMED. Diabetes \& Metabolism, 26(4), 295-302.

Fortin, M., Bravo, G., Hudon, C., Vanasse, A., \& Lapointe, L. (2005). Prevalence of multimorbidity among adults seen in family practice. Annals of Family Medicine, 3(3), 223228.

Fortin, M., Soubhi, H., Hudon, C., Bayliss, E. A., \& van, d. A. (2007). Multimorbidity's many challenges. BMJ (Clinical Research Ed.), 334(7602), 1016-1017.

Gijsen, R., Hoeymans, N., Schellevis, F. G., Ruwaard, D., Satariano, W. A., \& van den Bos, ,G.A. (2001). Causes and consequences of comorbidity: A review. Journal of Clinical Epidemiology, 54(7), 661-674.

HEDIS. Technical Specifications, Vol. 2. Washington, DC: National Committee for Quality Assurance, 2011.

Hu, G., Jousilahti, P., Bidel, S., Antikainen, R., \& Tuomilehto, J. (2007). Type 2 diabetes and the risk of parkinson's disease. Diabetes Care, 30(4), 842-847.

Inouye SK, Studenski S, Tinetti ME, Kuchel GA. Geriatric syndromes: clinical, research, and policy implications of a core geriatric concept. J Am Geriatr Soc. 2007 May;55(5):780-91.

Kyizom T, Singh S, Singh KP, Tandon OP, Kumar R (2010). Effect of pranayama \& yoga-asana on cognitive brain functions in type 2 diabetes-P3 event related evoked potential (ERP). Indian J Med Res. May;131:636-40. 
Lapane, K. L., Fernandez, H. H., \& Friedman, J. H. (1999). Prevalence, clinical characteristics, and pharmacologic treatment of parkinson's disease in residents in long-term care facilities. SAGE study group. Pharmacotherapy, 19(11), 1321-1327.

Marengoni, A., von Strauss, E., Rizzuto, D., Winblad, B., \& Fratiglioni, L. (2009). The impact of chronic multimorbidity and disability on functional decline and survival in elderly persons. A community-based, longitudinal study. Journal of Internal Medicine, 265(2), 288-295. doi:10.1111/j.1365-2796.2008.02017.x

Meduru, P., Helmer, D., Rajan, M., Tseng, C., Pogach, L., \& Sambamoorthi, U. (2007). Chronic illness with complexity: Implications for performance measurement of optimal glycemic control. Journal of General Internal Medicine, 22 Suppl 3, 408-418.

Mehta S, Chen H, Johnson ML, Aparasu RR (2010). Risk of falls and fractures in older adults using antipsychotic agents: a propensity-matched retrospective cohort study. Drugs Aging. $27: 815-829$

Muangpaisan, W., Mathews, A., Hori, H., \& Seidel, D. (2011). A systematic review of the worldwide prevalence and incidence of parkinson's disease. Journal of the Medical Association of Thailand $=$ Chotmaihet Thangphaet, 94(6), 749-755.

Nocera, J., Horvat, M., \& Ray, C. T. (2009). Effects of home-based exercise on postural control and sensory organization in individuals with parkinson disease. Parkinsonism \& Related Disorders, 15(10), 742-745. doi:10.1016/j.parkreldis.2009.07.002

Noyes, K., Liu, H., Li, Y., Holloway, R., \& Dick, A. W. (2006). Economic burden associated with parkinson's disease on elderly medicare beneficiaries. Movement Disorders: Official Journal of the Movement Disorder Society, 21(3), 362-372.

Park, A., \& Stacy, M. (2009). Non-motor symptoms in parkinson's disease. Journal of Neurology, 256 Suppl 3, 293-298. doi:10.1007/s00415-009-5240-1

Peila, R., Rodriguez, B. L., White, L. R., \& Launer, L. J. (2004). Fasting insulin and incident dementia in an elderly population of japanese-american men. Neurology, 63(2), 228-233.

Piette JD, Kerr EA 2006. The Impact of Comorbid Chronic Conditions on Diabetes Care. Diabetes Care. March 29:725-731

Pentakota SR, Rajan M, Fincke BG, Tseng CL, Miller DR, Christiansen CL, Kerr EA, Pogach LM. 2012. Does diabetes care differ by type of chronic comorbidity?: An evaluation of the Piette and Kerr framework. Diabetes Care. Jun;35(6):1285-92. doi: 10.2337/dc11-1569. Epub 2012 Mar 19. PubMed PMID: 22432109; PubMed Central PMCID: PMC3357228

Rönnemaa, E., Zethelius, B., Sundelöf, J., Sundström, J., Degerman-Gunnarsson, M., Berne, C., et al. (2008). Impaired insulin secretion increases the risk of alzheimer disease. Neurology, 71(14), 1065-1071. doi:10.1212/01.wnl.0000310646.32212.3a 
Rönnemaa, E., Zethelius, B., Sundelöf, J., Sundström, J., Degerman-Gunnarsson, M., Lannfelt, L., et al. (2009). Glucose metabolism and the risk of alzheimer's disease and dementia: A population-based 12 year follow-up study in 71-year-old men. Diabetologia, 52(8), 15041510. doi:10.1007/s00125-009-1393-9

Rubin RJ, Dietrich KA, Hawk AD. Clinical and economic impact of implementing a comprehensive diabetes management program in managed care. J Clin Endocrinol Metab. 1998 Aug;83(8):2635-42.

Safford, M. M., Allison, J. J., \& Kiefe, C. I. (2007). Patient complexity: More than comorbidity. the vector model of complexity. Journal of General Internal Medicine, 22 Suppl 3, 382-390.

Schernhammer, E., Hansen, J., Rugbjerg, K., Wermuth, L., \& Ritz, B. (2011). Diabetes and the risk of developing parkinson's disease in denmark. Diabetes Care, 34(5), 1102-1108. doi:10.2337/dc10-1333

Schneider, K. M., O'Donnell, B.,E., \& Dean, D. (2009). Prevalence of multiple chronic conditions in the united states' medicare population. Health and Quality of Life Outcomes, 7 , 82-82. doi:10.1186/1477-7525-7-82

Sevick, M. A., Trauth, J. M., Ling, B. S., Anderson, R. T., Piatt, G. A., Kilbourne, A. M., et al. (2007). Patients with complex chronic diseases: Perspectives on supporting selfmanagement. Journal of General Internal Medicine, 22 Suppl 3, 438-444.

Shaw JE, Sicree RA, Zimmet PZ (2010). Global estimates of the prevalence of diabetes for 2010 and 2030. Diabetes Res Clin Pract. 2010 Jan; 87(1):4-14

Simon, K. C., Chen, H., Schwarzschild, M., \& Ascherio, A. (2007). Hypertension, hypercholesterolemia, diabetes, and risk of parkinson disease. Neurology, 69(17), 16881695.

Tinetti ME, Gordon C, Sogolow E, Lapin P, Bradley EH 2006. Fall-risk evaluation and management: challenges in adopting geriatric care practices. Gerontologist. 46:717-725.

van, d. A., Buntinx, F., Metsemakers, J. F., Roos, S., \& Knottnerus, J. A. (1998). Multimorbidity in general practice: Prevalence, incidence, and determinants of co-occurring chronic and recurrent diseases. Journal of Clinical Epidemiology, 51(5), 367-375.

van Dam HA, van der Horst F, van den Borne B, Ryckman R, Crebolder H.Provider-patient interaction in diabetes care: effects on patient self-care and outcomes. A systematic review. Patient Educ Couns. 2003 Sep;51(1):17-28.

Wang, L., Wei, W., Miao, R., Xie, L., \& Baser, O. (2013). Real-world outcomes of US employees with type 2 diabetes mellitus treated with insulin glargine or neutral protamine hagedorn insulin: A comparative retrospective database study. BMJ Open, 3(4) doi:10.1136/bmjopen-2012-002348 
Weiss, K. B. (2007). Managing complexity in chronic care: An overview of the VA state-of-theart (SOTA) conference. Journal of General Internal Medicine, 22 Suppl 3, 374-378.

Woodard, L. D., Urech, T., Landrum, C. R., Wang, D., \& Petersen, L. A. (2011). Impact of comorbidity type on measures of quality for diabetes care. Medical Care, 49(6), 605-610. doi:10.1097/MLR.0b013e31820f0ed0

Xie, L., Zhou, S., Wei, W., Gill, J., Pan, C., \& Baser, O. (2013). Does pen help? A real-world outcomes study of switching from vial to disposable pen among insulin glargine-treated patients with type 2 diabetes mellitus. Diabetes Technology \& Therapeutics, 15(3), 230-236. doi:10.1089/dia.2012.0253

Xu, Q., Park, Y., Huang, X., Hollenbeck, A., Blair, A., Schatzkin, A., et al. (2011). Diabetes and risk of parkinson's disease. Diabetes Care, 34(4), 910-915. doi:10.2337/dc10-1922

Young BA, Lin E, Von Korff M, et al. 2008. Diabetes complications severity index and risk of mortality, hospitalization, and healthcare utilization. Am J Manag Care;14:15-23 
Table 1: Distribution of Matching Variables before and after Propensity Score Matching Humana Medicare Advantage Part-D Database (2007-2011)

\begin{tabular}{|c|c|c|c|c|c|c|}
\hline & \multicolumn{3}{|c|}{ Before Matching } & \multicolumn{3}{|c|}{ After Matching } \\
\hline \multicolumn{7}{|c|}{2007} \\
\hline & PD & No PD & & $\mathrm{PD}$ & No PD & \\
\hline & $\mathrm{N}=775$ & $\mathrm{~N}=101,306$ & Sig & $\mathrm{N}=775$ & $\mathrm{~N}=2,325$ & Sig \\
\hline Age $($ Mean \pm SD $)$ & $74.57( \pm 4.96)$ & $72.56( \pm 5.02)$ & $* * *$ & $74.57( \pm 4.96)$ & $74.56( \pm 4.95)$ & \\
\hline DCSI Total $($ Mean \pm SD $)$ & $3.42( \pm 2.38)$ & $2.22( \pm 2.11)$ & $* * *$ & $3.42( \pm 2.38)$ & $3.42( \pm 2.38)$ & \\
\hline Gender & & & $* * *$ & & & \\
\hline Male $(\mathbf{N}, \%)$ & $461(59.48 \%)$ & $47,844(47.23 \%)$ & & $461(59.48 \%)$ & $1,385(59.57 \%)$ & \\
\hline Female (N, \%) & $314(40.52 \%)$ & $53,462(52.77 \%)$ & & $314(40.52 \%)$ & $940(40.43 \%)$ & \\
\hline \multicolumn{7}{|c|}{2008} \\
\hline & PD & No PD & & $\mathrm{PD}$ & No PD & \\
\hline & $N=949$ & $\mathrm{~N}=120,136$ & Sig & $\mathrm{N}=571$ & $\mathrm{~N}=1,713$ & Sig \\
\hline Age $($ Mean \pm SD $)$ & $75.16( \pm 5.18)$ & $72.80( \pm 5.19)$ & $* * *$ & $74.95( \pm 5.32)$ & $74.94( \pm 5.32)$ & \\
\hline DCSI Total $($ Mean \pm SD $)$ & $3.46( \pm 2.34)$ & $2.31( \pm 2.15)$ & $* * *$ & $3.42( \pm 2.33)$ & $3.42( \pm 2.34)$ & \\
\hline Gender & & & $* * *$ & & & \\
\hline Male $(\mathbf{N}, \%)$ & $535(56.38 \%)$ & $56,985(47.43 \%)$ & & $307(53.77 \%)$ & $919(53.65 \%)$ & \\
\hline Female $(\mathbf{N}, \%)$ & $414(43.62 \%)$ & $63,151(52.57 \%)$ & & $264(46.23 \%)$ & $794(46.35 \%)$ & \\
\hline \multicolumn{7}{|c|}{2009} \\
\hline & PD & No PD & & PD & No PD & \\
\hline & $\mathrm{N}=1,208$ & $\mathrm{~N}=144,290$ & Sig & $N=667$ & $\mathrm{~N}=2,001$ & Sig \\
\hline Age $($ Mean \pm SD $)$ & $75.24( \pm 5.48)$ & $73.00( \pm 5.37)$ & $* * *$ & $74.54( \pm 5.61)$ & $74.59( \pm 5.60)$ & \\
\hline DCSI Total $($ Mean \pm SD $)$ & $3.59( \pm 2.38)$ & $2.44( \pm 2.19)$ & $* * *$ & $3.57( \pm 2.47)$ & $3.54( \pm 2.41)$ & \\
\hline Gender & & & $* * *$ & & & \\
\hline Male $(\mathbf{N}, \%)$ & $710(58.77 \%)$ & $68,650(47.58 \%)$ & & $382(57.27 \%)$ & $1,153(57.62 \%)$ & \\
\hline Female $(\mathrm{N}, \%)$ & $498(41.23 \%)$ & $75,640(52.42 \%)$ & & $285(42.73 \%)$ & $848(42.38 \%)$ & \\
\hline \multicolumn{7}{|c|}{2010} \\
\hline & PD & No PD & & PD & No PD & \\
\hline & $\mathrm{N}=1,384$ & $\mathrm{~N}=170,941$ & Sig & $\mathrm{N}=714$ & $\mathrm{~N}=2,142$ & Sig \\
\hline Age $($ Mean \pm SD $)$ & $75.43( \pm 5.63)$ & $73.20( \pm 5.48)$ & $* * *$ & $74.77( \pm 5.88)$ & $74.79( \pm 5.87)$ & \\
\hline DCSI Total $($ Mean \pm SD $)$ & $3.66( \pm 2.43)$ & $2.49( \pm 2.21)$ & $* * *$ & $3.65( \pm 2.44)$ & $3.64( \pm 2.42)$ & \\
\hline Gender & & & $* * *$ & & & \\
\hline Male $(\mathbf{N}, \%)$ & $815(58.89 \%)$ & $80,924(47.34 \%)$ & & $416(58.26 \%)$ & $1,250(58.36 \%)$ & \\
\hline Female (N, \%) & $569(41.11 \%)$ & $90,017(52.66 \%)$ & & $298(41.74 \%)$ & $892(41.64 \%)$ & \\
\hline
\end{tabular}

Note: This table presents the matching variable distribution before and after propensity score matching by individual year.

$* * * \mathrm{P}<0.001 ; * * 0.001 \leq \mathrm{P}<.01 ; * 0.01 \leq \mathrm{P}<0.05$ 
Table 2: Distribution of matching variables after Propensity Score Matching Humana Medicare Advantage Part-D Database (2007-2011 stacked)

\begin{tabular}{|c|c|c|c|c|}
\hline & $\begin{array}{l}\mathrm{PD} \\
\mathrm{N}=2,703\end{array}$ & $\begin{array}{l}\text { No PD } \\
\mathrm{N}=8,109\end{array}$ & $\mathrm{p}$-value & Sig \\
\hline Age $($ Mean \pm SD $)$ & $74.67( \pm 5.44)$ & $74.67( \pm 5.44)$ & 1.0000 & \\
\hline DCSI Total (Mean \pm SD) & $3.46( \pm 2.34)$ & $3.46( \pm 2.34)$ & 1.0000 & \\
\hline Gender & & & 1.0000 & \\
\hline Male (N, \%) & $1,554(57.5 \%)$ & $4,662(57.5 \%)$ & & \\
\hline Female (N, \%) & $1,149(42.5 \%)$ & $3,447(42.5 \%)$ & & \\
\hline
\end{tabular}

Note: Based on propensity score matched data (matched on baseline age, gender and Diabetes Complications Severity Index) from Humana Medicare Prescription-Drug Plan of 10,812 elderly Medicare beneficiaries (2,703cases with Parkinson's disease and type-2 Diabetes Mellitus and 8,109 controls with only type-2 Diabetes Mellitus) during the period of January 2007 to December 2011.

$* * * \mathrm{P}<0.001 ; * * 0.001 \leq \mathrm{P}<.01 ; * 0.01 \leq \mathrm{P}<0.05$ 


\begin{tabular}{|c|c|c|c|c|c|}
\hline \multicolumn{6}{|c|}{$\begin{array}{l}\text { Table 3: Baseline characteristics of Elderly Medicare Beneficiarie } \\
\text { matching } \\
\text { Humana Medicare Advantage Part-D Database (2007-2011) }\end{array}$} \\
\hline & PD & Col \% & No PD & Col \% & Sig \\
\hline Race/Ethnicity & & & & & $* * *$ \\
\hline White & 2,047 & 75.7 & 6,025 & 74.3 & \\
\hline African American & 293 & 10.8 & 1,168 & 14.4 & \\
\hline Other & 169 & 6.3 & 446 & 5.5 & \\
\hline Unknown & 194 & 7.2 & 470 & 5.8 & \\
\hline Region & & & & & $* * *$ \\
\hline South & 1,806 & 66.8 & 5,223 & 64.4 & \\
\hline Midwest & 604 & 22.3 & 1,778 & 21.9 & \\
\hline Other Region & 293 & 10.8 & 1,108 & 13.7 & \\
\hline Plan Type & & & & & $* * *$ \\
\hline HMO & 1,315 & 48.6 & 3,648 & 45.0 & \\
\hline PFFS & 918 & 34.0 & 2,536 & 31.3 & \\
\hline Others & 470 & 17.4 & 1,925 & 23.7 & \\
\hline Donut Hole & & & & & $* * *$ \\
\hline No DH & 1,012 & 37.4 & 4,590 & 56.6 & \\
\hline Beg DH & 1,213 & 44.9 & 2,937 & 36.2 & \\
\hline Beg/End DH & 478 & 17.7 & 582 & 7.2 & \\
\hline \multicolumn{6}{|l|}{ DCSI Quintile } \\
\hline $0-0$ & 619 & 22.9 & 1,857 & 22.9 & \\
\hline $1-1$ & 421 & 15.6 & 1,263 & 15.6 & \\
\hline $2-2$ & 619 & 22.9 & 1,857 & 22.9 & \\
\hline $3-4$ & 504 & 18.6 & 1,512 & 18.6 & \\
\hline $5-13$ & 540 & 20.0 & 1,620 & 20.0 & \\
\hline Polypharmacy quintile & & & & & $* * *$ \\
\hline $0-0$ & 357 & 13.2 & 1,644 & 20.3 & \\
\hline $1-1$ & 454 & 16.8 & 1,749 & 21.6 & \\
\hline $2-3$ & 539 & 19.9 & 1,818 & 22.4 & \\
\hline $4-5$ & 620 & 22.9 & 1,570 & 19.4 & \\
\hline $6-31$ & 733 & 27.1 & 1,328 & 16.4 & \\
\hline Urinary Incontinence & & & & & $* * *$ \\
\hline Yes & 280 & 10.4 & 353 & 4.4 & \\
\hline No & 2,423 & 89.6 & 7,756 & 95.6 & \\
\hline Major Depressive Disorder & & & & & $* * *$ \\
\hline Yes & 722 & 26.7 & 963 & 11.9 & \\
\hline No & 1,981 & 73.3 & 7,146 & 88.1 & \\
\hline Cognitive Impairment & & & & & $* * *$ \\
\hline Yes & 904 & 33.4 & 686 & 8.5 & \\
\hline No & 1,799 & 66.6 & 7,423 & 91.5 & \\
\hline \multicolumn{6}{|l|}{ Dominant Conditions } \\
\hline Yes & 340 & 12.6 & 989 & 12.2 & \\
\hline No & 2363 & 87.4 & 7120 & 87.8 & \\
\hline Falls and falls risk & & & & & $* * *$ \\
\hline Yes & 268 & 9.9 & 354 & 4.4 & \\
\hline No & 2435 & 90.1 & 7755 & 95.6 & \\
\hline Baseline ER visit & & & & & $* * *$ \\
\hline Yes & 1500 & 55.5 & 3172 & 39.1 & \\
\hline No & 1203 & 44.5 & 4937 & 60.9 & \\
\hline
\end{tabular}

Contd. 


\begin{tabular}{|c|c|c|c|c|c|}
\hline \multicolumn{6}{|c|}{$\begin{array}{l}\text { Table 3: Baseline characteristics of Elderly Medicare Beneficiaries after } \\
\text { matching } \\
\text { Humana Medicare Advantage Part-D Database (2007-2011) }\end{array}$} \\
\hline & PD & Col \% & No PD & Col \% & Sig \\
\hline Baseline HH visit & & & & & $* * *$ \\
\hline Yes & 1647 & 60.9 & 3736 & 46.1 & \\
\hline No & 1056 & 39.1 & 4373 & 53.9 & \\
\hline
\end{tabular}

Note: Based on propensity score matched data (matched on baseline age, gender and Diabetes Complications Severity Index) from Humana Medicare Prescription-Drug Plan of 10,812 elderly Medicare beneficiaries (2,703cases with Parkinson's disease and type-2 Diabetes Mellitus and 8,109 controls with only type-2 Diabetes Mellitus) during the period of January 2007 to December 2011.

PD: Parkinson's disease; AOR: Adjusted Odds Ratio; ER: Emergency Room; HH: Home Health; HMO: Health Maintenance Organization; PFFS: Private Fee for Service; Sig: Significance; LDL: Low Density Lipoprotein; HDL: High Density Lipoprotein; Trigly: Triglyceride; yr: Year; chol: Cholesterol.

Asterisks represent significant group differences in HbA1c testing according to American Diabetes Association (ADA) guidelines using conditional logistic regression adjusting for the matched pair design:

$* * * \mathrm{P}<0.001 ; * * 0.001 \leq \mathrm{P}<.01 ; * 0.01 \leq \mathrm{P}<0.05$

$\uparrow$ Dominant conditions consisted of cancers, end stage renal disease, end stage liver disease, and amputations 
Table 4: Description of Process of Care and Intermediate Clinical Outcomes Humana Medicare Advantage Part D database (2007-2011)

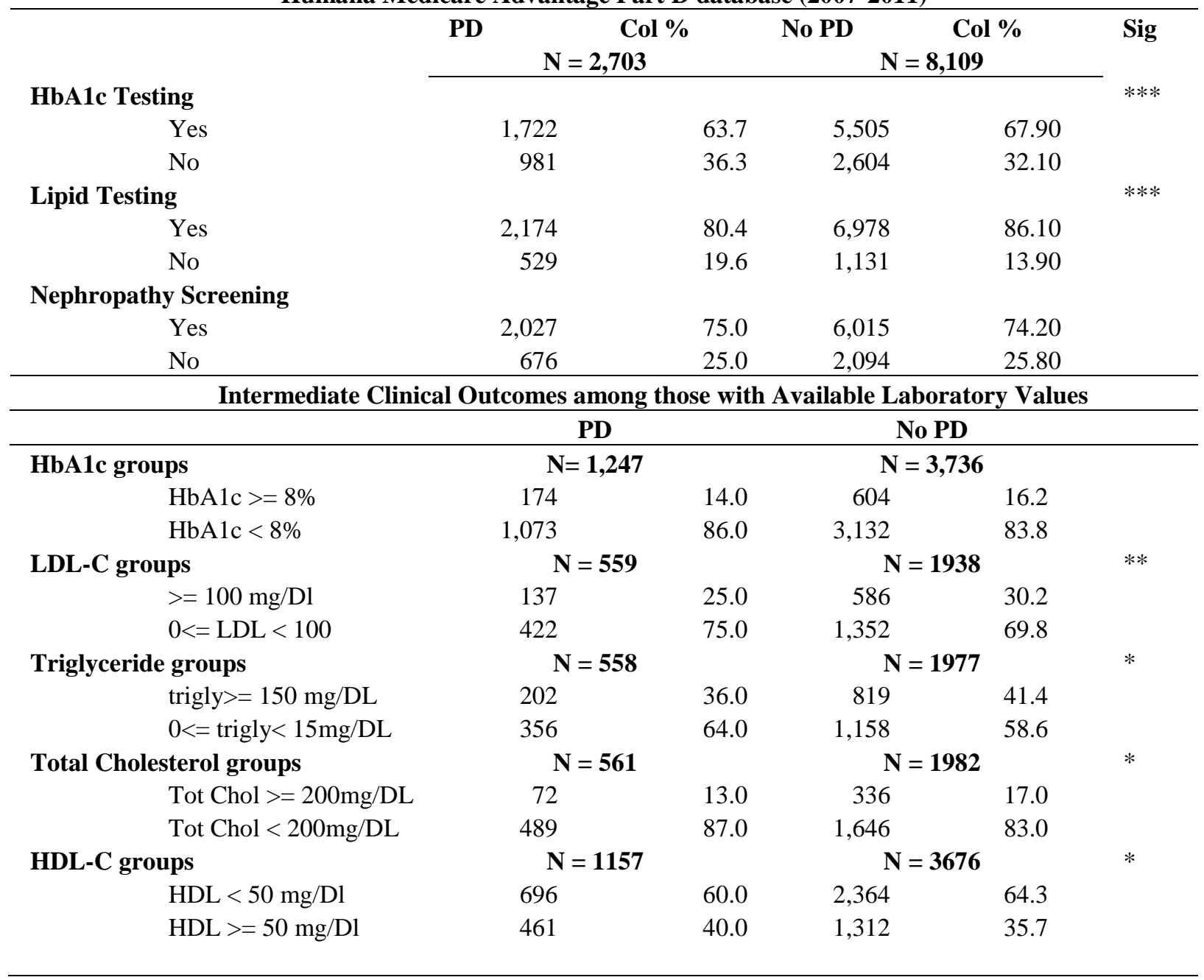

Note: Based on propensity score matched data (matched on baseline age, gender and Diabetes Complications Severity Index) from Humana Medicare Prescription-Drug Plan of 10,812 elderly Medicare beneficiaries (2,703 cases with Parkinson's disease and type-2 Diabetes Mellitus and 8,109 controls with only type-2 Diabetes Mellitus) during the period of January 2007 to December 2011 (except the bottom panel).

PD: Parkinson's disease; Sig: Significance; LDL: Low Density Lipoprotein; HDL: High Density Lipoprotein; Trigly: Triglyceride; yr: Year; chol: Cholesterol.

$* * * \mathrm{P}<0.001 ; * * 0.001 \leq \mathrm{P}<.01 ; * 0.01 \leq \mathrm{P}<0.05$ 
Table 5: Adjusted Odds Ratios and 95\% Confidence Intervals from

Conditional Logistic Regressions Process of Care Measures as per ADA

Guidelines

Humana Medicare Advantage Part D (2007-2011)

\begin{tabular}{lccc}
\hline $\begin{array}{l}\text { HbA1c Testing } \\
\text { PD }\end{array}$ & AOR & $\mathbf{9 5 \%}$ CI & Sig \\
$\begin{array}{l}\text { No PD (Reference Group) } \\
\text { Lipid Testing }\end{array}$ & 0.88 & {$[0.79,0.97]$} & $*$ \\
PD & & & \\
No PD (Reference Group) & 0.82 & {$[0.72,0.94]$} & $* *$ \\
$\begin{array}{l}\text { Nephropathy Testing } \\
\text { PD } \\
\text { No PD (Reference Group) }\end{array}$ & 0.99 & & \\
$\quad$ & & & \\
\end{tabular}

Note: Based on propensity score matched data (matched on baseline age, gender and Diabetes Complications

Severity Index) from Humana Medicare Prescription-Drug Plan of 10,812 elderly Medicare beneficiaries (2,703

cases with Parkinson's disease and type-2 Diabetes Mellitus and 8,109 controls with only type-2 Diabetes Mellitus)

during the period of January 2007 to December 2011.

Model adjusted for: Race/Ethnicity, Region, Insurance Plan Type, Donut Hole, Polypharmacy, Urinary

Incontinence, Cognitive Impairment due to physical conditions, Cognitive Impairment due to mental conditions, Falls and Falls Risk, Major Depressive Disorder, Baseline Emergency Room visit, Baseline Home Health visit,

Dominant conditions (cancers, end stage renal disease, end stage liver disease, and amputations).

PD: Parkinson's disease AOR: Adjusted Odds Ratio; CI: Confidence Interval; Sig: Significance.

$* * * \mathrm{P}<0.001 ; * * 0.001 \leq \mathrm{P}<.01 ; * 0.01 \leq \mathrm{P}<0.05$ 
Table 6: Adjusted Odds Ratios and 95\% Confidence Intervals from

Multinomial Conditional Logistic Regressions on Intermediate

Outcomes

Humana Medicare Advantage Part D (2007-2011)

\begin{tabular}{|c|c|c|c|}
\hline & AOR & $95 \% \mathrm{CI}$ & Sig \\
\hline $\begin{array}{c}\text { HbA1c }<\mathbf{8 \%} \text { vs } \geq \mathbf{8 \%} \\
\text { PD } \\
\text { No PD (Reference Group) }\end{array}$ & 1.34 & {$[1.10,1.63]$} & $* *$ \\
\hline $\begin{array}{l}\text { LDL-C }<\mathbf{1 0 0} \mathbf{~} \mathbf{~ g} / \mathbf{d L} \text { vs } \geq \mathbf{1 0 0} \mathbf{~ m g} / \mathbf{d L} \\
\text { PD } \\
\text { No PD (Reference Group) }\end{array}$ & 1.29 & {$[1.06,1.59]$} & $*$ \\
\hline $\begin{array}{l}\text { Triglyceride }<\mathbf{1 5 0} \mathbf{m g} / \mathbf{d L} \text { vs } \geq \mathbf{1 5 0} \mathbf{~ m g} / \mathbf{d l} \\
\text { PD } \\
\text { No PD (Reference Group) }\end{array}$ & 1.31 & {$[1.06,1.62]$} & $*$ \\
\hline $\begin{array}{l}\text { HDL-C } \geq \mathbf{5 0} \mathbf{~} \mathbf{~ g / d L ~ v s ~} \geq \mathbf{5 0} \mathbf{~} \mathbf{g} / \mathbf{d L} \\
\text { PD } \\
\text { No PD (Reference Group) }\end{array}$ & 1.20 & {$[1.04,1.39]$} & $*$ \\
\hline $\begin{array}{l}\text { Total Cholesterol }<\mathbf{2 0 0} \mathbf{~ m g} / \mathbf{d L} \text { vs. } \geq \mathbf{2 0 0} \\
\mathbf{m g} / \mathbf{d l} \\
\qquad \text { PD } \\
\text { No PD (Reference Group) }\end{array}$ & 1.46 & {$[1.08,1.97]$} & * \\
\hline
\end{tabular}

Note: Based on propensity score matched data (matched on baseline age, gender and Diabetes Complications Severity Index) from Humana Medicare Prescription-Drug Plan of 10,812 elderly Medicare beneficiaries (2,703 cases with Parkinson's disease and type-2 Diabetes Mellitus and 8,109 controls with only type-2 Diabetes Mellitus) during the period of January 2007 to December 2011.

Model adjusted for: Race/Ethnicity, Region, Insurance Plan Type, Donut Hole, Polypharmacy, Urinary Incontinence, Cognitive Impairment due to physical conditions, Cognitive Impairment due to mental conditions, Falls and Falls Risk, Major Depressive Disorder, Baseline Emergency Room visit, Baseline Home Health visit, Dominant conditions (cancers, end stage renal disease, end stage liver disease, and amputations).

PD: Parkinson's disease; AOR: Adjusted Odds Ratio; CI: Confidence Interval; Sig: Significance; LDL-C: Low Density Lipoprotein Cholesterol; HDL-C: High Density Lipoprotein Cholesterol.

$* * * \mathrm{P}<0.001 ; * * 0.001 \leq \mathrm{P}<.01 ; * 0.01 \leq \mathrm{P}<0.05$

Reference groups: $\geq 8 \%$ HbA1c; LDL-C $\geq 100 \mathrm{mg} / \mathrm{dL}$; Triglyceride $\geq 150 \mathrm{mg} / \mathrm{dL} ; \mathrm{LDL}-\mathrm{C} \geq 50 \mathrm{mg} / \mathrm{dL}$; Total Cholesterol $\geq 200 \mathrm{mg} / \mathrm{dL}$. 
Figure 1: Cohort development



Page 115 of 129 


\section{Appendix I}

\section{HbA1c testing}

Individuals with HbA1c testing at least two times a year (with a gap of at least one month) will be considered as meeting standard of care for diabetes management. HbA1c testing will be identified by the following Current Procedural Terminology (CPT) codes.

a. CPT codes: 83036, 83037 (Source : HEDIS, 2012)

b. CPT Category II : 3044F, 3045F, 3046F, 3047F (Source : HEDIS, 2012)

\section{Lipid testing}

Individuals who were tested at least once a year will be considered as meeting standard of care for diabetes management. Lipid testing will be identified by the following Current Procedural Terminology (CPT) codes.

a. CPT codes: $80061,83700,83701,83704,83721,83715,83716,83718,82465$, and 84478 (Source: Morrato et al. 2008; HEDIS, 2012)

b. CPT Category II: 3048F, 3049F, 3050F

\section{Nephropathy screening}

Individuals who were screened at least once a year for urine albumin and serum creatinine will be considered as meeting standard of care for diabetes management. Nephropathy screening will be identified using the following Current Procedural Terminology (CPT) codes.

a. CPT codes: $81000,81001,81002,81003,36800,36810,36815,50300,50340$, 50360, 50365, 50370, 50380, 90920, 90921, 90924, 90925, 90935, 90937, 90945 , 90947, 90989, 90993, 90997, and 9099982579 for serum creatinine lab (Mainous et al. 2001); 82042, 82043, 82044, 84156 (Source: HEDIS, 2012)

b. CPT Category II: 3060F, 3061F (Source: HEDIS, 2012) 


\section{CHAPTER 5}

Page 117 of 129 


\section{CHAPTER 5}

\section{DISCUSSION \& CONCLUSIONS SUMMARY OF FINDINGS}

The purpose of this dissertation was to use observational data from real-world settings to provide a comprehensive view of the burden of illness among elderly individuals with PD. We answered three research questions pertaining to the economic impact of both formal and informal caregiving burden and the impact of chronic illness with complexity on process and intermediate clinical outcomes among elderly individuals with PD. Economic impact of formal caregiving burden was assessed by estimating the home healthcare use and expenditures among elderly Medicare beneficiaries with PD compared to those without PD. Focusing on a Medicare population to assess the impact of economic burden of formal caregiving is appropriate as Medicare provides near universal coverage for elderly individuals in the U.S. Economic burden of the informal caregiving was estimated by multiplying number of caregiving hours per week by the median wage ( $\$ 10.10 /$ hour) of a household aide. Informal caregiver burden was also measured based on three questions on physical strain, emotional stress and financial hardship on the informal caregivers. Chronic illness with complexity (CIC) was defined as the co-occurrence of PD and type 2 diabetes mellitus (T2DM). It is important to assess the process and intermediate outcomes among elderly individuals with CIC as it has been estimated that by 2030 , the prevalence of both T2DM and PD will increase by approximately two-folds due to the aging U.S. population (Dorsey et al. 2007) and will become a major public health concern in the near future. Due to the unavailability of a single database that can answer all these research questions, 
we used a triangulation approach by using data from different sources to answer the research questions of this dissertation.

The first research question of this dissertation was to estimate the excess home healthcare use and expenditures among elderly Medicare beneficiaries with PD compared to those without PD using the national Medicare 5\% claims database (2006-2007). In this aim, we also estimated the extent to which the individual-level factors such as predisposing, enabling, need, personal health behaviors, and external environmental factors contributed to the differences in home healthcare use and expenditures between elderly Medicare beneficiaries with and without PD. Elderly Medicare beneficiaries with PD had 13.28 percentage points (PD: No PD:: 22.50\% vs. 9.22\%) higher home healthcare use compared to those without PD. Multivariate analysis also revealed similar findings with elderly Medicare beneficiaries with PD having greater than two times more likelihood to have home healthcare use compared to those without PD. It was estimated that the average home healthcare expenditures among elderly Medicare beneficiaries (who used home healthcare service) with PD was 1.34 times higher compared to those without PD (\$6,792 vs. \$5,060). Multivariate Ordinary Least Square (OLS) regression analysis showed consistent findings. These findings are consistent with previous studies which showed that home healthcare use and expenditures among individuals with PD are significantly higher among individuals with PD ((Bhattacharjee \& Sambamoorthi, 2013; Noyes et al., 2006; Pressley et al., 2003; Rubenstein, Chrischilles, \& Voelker, 1997)). The unique contribution of this study was to estimate the extent to which individual-level factors explained the home healthcare use and expenditures among elderly Medicare beneficiaries. Approximately $27 \%$ of the differences in home healthcare use between elderly Medicare beneficiaries with and without PD were explained by the predisposing, need, personal health choice and external environmental factors. 
However, only $11 \%$ of the total home healthcare expenditure differences between elderly Medicare beneficiaries with and without PD were explained by the individual-level factors used in this study. Personal health behaviors such as baseline resource use and need factors such as mental and physical health conditions explained the highest proportion of the home healthcare use and expenditure differences.

The second question of this dissertation focused on assessing the informal caregiver burden among caregivers of elderly care-recipients with PD compared to the informal caregivers of elderly care-recipients without PD using the nationally representative sample of National Alliance for Caregivers $(2004,2009)$. This research question also estimated costs associated with providing informal care to elderly individuals with and without PD. The caregiver burden as estimated on the computed caregiver scale was similar among individuals with and without PD (2.25 vs. 2.21). The average number of caregiving hours per week for care-recipients with PD was higher than those without PD (PD:: No PD $27.51( \pm 35.04)$ hours: $21.62( \pm 28.71))$. The average annual costs of informal caregiving for care-recipients with and without PD were approximately $\$ 14,448$ and $\$ 11,355$ respectively. However, these differences in terms of number of hours of informal caregiving per week and annual costs of informal caregiving were not statistically significant. After adjusting for care-recipient, caregiver characteristics and other independent variables, caregiver burden and costs did not differ significantly between elderly individuals with and without PD. One of the main reasons that we can speculate why we did not observe statistically significant differences in formal caregiver burden and costs between these two groups in bivariate and multivariate analyses may be the small sample size of the informal caregivers of care-recipients with PD $(\mathrm{N}=32)$. A noteworthy finding from this research question was the association between the functional status of the care-recipients and caregiver burden. It 
was observed that ADL and IADL were significantly positively associated with caregiver burden in all the three models. Previous studies conducted by Edwards \& Ruettinger (2002) and Cifu et al., (2006) also observed that higher caregiver burden was associated with increased difficulties with ADL performance. Although prior studies have not examined the relationship between IADL and caregiver burden, our study documents that increase in the number of difficulties with IADLs was also associated with greater caregiver burden.

The third research of this dissertation used the nation-wide claims database of Humana Medicare Advantage Part D enrollees to assess process and intermediate outcomes of diabetes care among elderly individuals with CIC (T2DM and PD) compared to those without CIC (T2DM without PD). Multivariable conditional logistic regressions revealed that elderly individuals with CIC were less likely to meet the annual American Diabetes Association (ADA) recommended annual $\mathrm{HbA} 1 \mathrm{c}$ and lipid testing compared to elderly individuals without CIC. However, multinomial conditional logistic regressions showed that elderly individuals with CIC were more likely to achieve glycemic and lipid controls. These findings are consistent with a study conducted among elderly veterans, which showed that veterans with CIC were more likely to receive overall good outcomes for all 3quality measures (glycemic, blood pressure and low density lipoprotein-cholesterol) combined (Woodard, Urech, Landrum, Wang, \& Petersen, 2011). However, these findings were inconsistent with the findings from the study using the INTERMED classification system for case complexity which found that among individuals with T2DM, greater complexity was associated with higher HbA1c values (Fischer et al., 2000). 


\section{CONCLUSIONS}

This dissertation assessed the burden of illness among elderly individuals with PD in three dimensions of economic burden of formal and informal caregiving, and the impact of CIC on the process and intermediate outcomes of care. We found that elderly Medicare beneficiaries with PD had significantly higher home healthcare use and expenditures compared to those without PD. The differences in home healthcare use and expenditures among elderly Medicare beneficiaries with and without PD were mainly explained by personal health behaviors such as baseline resource use and need factors such as physical and mental health conditions. In terms of economic burden of informal caregiving, we did not observe a significant difference in informal caregiving costs between caregivers of elderly individuals with and without PD, despite the costs of informal caregiving for elderly individuals with PD being 1.27 times higher than those without PD. Individuals with CIC were less likely to achieve ADA recommended annual HbA1c and lipid testing goals compared to those without CIC. However, individuals with CIC achieved glycemic and lipid control outcomes. Thus, these findings taken together underscore the advantage of using an integrated delivery system with better care coordination and providing "holistic care approach." As majority of elderly individuals with PD are community-dwelling, novel intervention techniques are needed to be developed to reduce the informal caregiving burden.

\section{IMPLICATIONS OF THE STUDY}

The findings from our three research questions have significant implications.

Reducing the cost curve and need for integrated care and following new care models such as

\section{Patient Centered Medical Homes}

From our first research question, it was observed that the home healthcare use and expenditures were significantly higher among elderly Medicare beneficiaries with PD compared 
to those without PD and personal health behaviors such as the baseline resource use and need factors such as physical and mental health conditions had the highest contribution to the explained portions of the differences in home healthcare use and expenditures among elderly Medicare beneficiaries with and without PD. Findings from this aim have health policy implications in terms of reducing cost burden for Medicare, which is the single most important payer of healthcare for the elderly. Although less than 5\% of total Medicare spending is accounted by home healthcare expenditures, Medicare home healthcare spending has grown substantially over the past decade. It has been estimated that total Medicare home healthcare expenditures increased from by $129 \%$ between 2000 and 2010 (Home Healthcare ServicesChapter 8) and the number of home healthcare users also increased from 2.5 million to 3.4 million between 2002-2010 (Health Care Spending-Medicare). The Center for Medicare and Medicaid Services (CMS) has been exploring ways in which they can contain this escalating home healthcare expenditures. As the post-regression decomposition technique results suggest that need factors such as physical and mental health conditions which often co-occur, there is a need for integrated care and following new care models such as Patient Centered Medical Homes to better manage the issue of co-occurring chronic conditions in this geriatric population which in turn may lead to better health outcomes and consequent reduction of the escalating cost curve.

\section{Financial implications of informal caregiving burden and costs}

The second research question of this study provided the first nationally representative estimates of costs of informal caregiving of care-recipients with PD. The average annual costs of informal caregiving for care-recipients with and without PD were approximately $\$ 14,448$ and $\$ 11,355$ respectively. The high annual costs of informal care provided to the elderly individuals with PD have significant financial implications. As the population of U.S. is aging, and there is 
an expected subsequent increase in the prevalence of PD, innovative intervention techniques need to be developed which can be devoted towards reducing informal caregiving burden and also curb the financial burdens of providing informal care.

\section{Advantages of an Integrated Delivery System}

From our third research question, we found that individuals with CIC were more likely to achieve better intermediate glycemic and lipid outcomes. One of the characteristics of the Medicare Advantage plans is that they follow the Integrated Delivery System (IDS) model. In the IDS model, the primary physician serves as the gate-keeper and maintains proper referral systems. The coordination of care among different types of specialists (Endocrinologists, Neurologists etc.) is ensured in the IDS models which in turn could lead to better management of individuals with CIC. Hence, this finding further underscores the benefits of following IDS where good coordination of care is generally available.

\section{LIMITATIONS}

Findings from this study should be interpreted with caution as there are some limitations associated with this study. For first research question (Aim 1), we did not have information on the prescription drug expenditures. Previous research suggests that prescription drug expenditures are one of the major drivers of the healthcare expenditures and so estimates from the Aim 1 can be under-estimated due to lack of information on prescription drug expenditures. The findings from Aim 1 are not generalizable to other populations or settings as we only used fee-for-service enrollees and excluded HMO enrollees from the study sample. Users of home healthcare may be different from non-users of home health care in unobserved variables. Aim 1 of this dissertation does not control for such selection bias. The Medicare 5\% claims database did not have many important and relevant variables that are associated with home healthcare use 
such as limitations of activities of daily living (ADL) and instrumental activities of daily living (IADL). This may lead to underestimation of the explained portion of the estimated differences in home healthcare expenditures among individuals with and without PD. However, by using a representative sample of Medicare beneficiaries with linked Medicare claims, we are able to estimate the extent to which unmeasured factors can underestimate explained portion of the differences in expenditures among individuals with and without PD. In terms of our second research question (Aim 2) of this dissertation we had some limitations as well. The study sample was small with only 32 caregivers of care-recipients with PD. This small sample size may affect the power of the analyses. We did not observe significant differences in informal caregiver burden in the Aim 2, which can be mostly attributed to the small sample size of the informal caregivers of care-recipients with PD. This data did not have information related to clinical factors such as presence of physical (e.g. diabetes) and/or mental conditions (e.g. depression, anxiety). Adjusting for comorbid conditions may explain more variance in the caregiver burden. Moreover, duration and severity of diseases was unavailable. However, ADLs and IADLs may serve as global proxies for severity of illness. Additionally, as this is a survey, presence of recall bias cannot be ruled out. For our third research question (Aim 3) of this dissertation, we had some limitations as well. This Aim used commercially enrolled elderly Medicare beneficiaries and hence the findings from this study cannot be generalizable to other populations or settings (e.g. fee-for-service Medicare beneficiaries). Moreover, laboratory values are available for only one-third of the population. Unmeasured confounders such lifestyle risk factors (e.g. body mass index and smoking status), physician specialty, duration and severity of PD could influence the study outcomes. 


\section{FUTURE RESEARCH}

Future studies should be conducted to answer the questions that were not answered in this dissertation, and those studies should also overcome the limitations of this dissertation. Using the individual-level factors included in Aim 1of this dissertation, only $27 \%$ and $11 \%$ of the home healthcare use and expenditures differences between elderly Medicare beneficiaries with and without PD was explained. Some important factors such as ADL, IADL, and physical and mental health status were not available in the Medicare 5\% claims database. Intuitively these factors can influence the home healthcare use and expenditures and hence future studies should include these factors to understand their influence on the home healthcare use and expenditures among elderly individuals with PD. In Aim 2 of this dissertation, we did not find an association between PD and informal caregiver burden which can be mainly attributed to the small sample size of the caregivers of care-recipients with PD. Future studies should try to overcome this problem by using a large dataset such as the Health and Retirement Survey linked to Medicare claims, which has an additional benefit of including the co-occurring chronic conditions which may also influence the informal caregiving burden. In Aim 3 of this dissertation, we found that among elderly individuals with PD and type 2 diabetes mellitus (T2DM), the rates of HbA1c and lipid testing were significantly lower compared to elderly individuals with T2DM and without PD. Future research needs to explore the reasons for lower rates of $\mathrm{HbA} 1 \mathrm{C}$ and lipid testing among elderly individuals with T2DM and PD and also devise appropriate interventions to overcome the barriers to testing. 


\section{REFERENCES}

Bhattacharjee, S., \& Sambamoorthi, U. (2013). Co-occurring chronic conditions and healthcare expenditures associated with parkinson's disease: A propensity score matched analysis. Parkinsonism \& Related Disorders.

Cifu, D. X., Carne, W., Brown, R., Pegg, P., Ong, J., Qutubuddin, A., et al. (2006). Caregiver distress in parkinsonism. Journal of Rehabilitation Research and Development, 43(4), 499508.

Dorsey ER, Constantinescu R, Thompson JP, Biglan KM, Holloway RG, Kieburtz K, Marshall FJ, Ravina BM, Schifitto G, Siderowf A, Tanner CM. Projected number of people with Parkinson disease in the most populous nations, 2005 through 2030. Neurology. 2007 Jan 30;68(5):384-6. Epub 2006 Nov 2.

Edwards NE, Scheetz PS. Predictors of burden for caregivers of patients with Parkinson's disease. J Neurosci Nurs. 2002 Aug;34(4):184-90. PubMed PMID: 12197259

Fischer, C. J., Stiefel, F. C., De Jonge, P., Guex, P., Troendle, A., Bulliard, C., et al. (2000). Case complexity and clinical outcome in diabetes mellitus. A prospective study using the INTERMED. Diabetes \& Metabolism, 26(4), 295-302.

Home Healthcare Services- Chapter 8. March 2012. Available from URL:

http://www.medpac.gov/chapters/Mar12_Ch08.pdf [Accessed 2013 May 23].

Noyes, K., Liu, H., Li, Y., Holloway, R., \& Dick, A. W. (2006). Economic burden associated with parkinson's disease on elderly medicare beneficiaries. Movement Disorders: Official Journal of the Movement Disorder Society, 21(3), 362-372.

Pressley, J. C., Louis, E. D., Tang, M., Cote, L., Cohen, P. D., Glied, S., et al. (2003). The impact of comorbid disease and injuries on resource use and expenditures in parkinsonism.

Neurology, 60(1), 87-93.

Rubenstein, L. M., Chrischilles, E. A., \& Voelker, M. D. (1997). The impact of parkinson's disease on health status, health expenditures, and productivity. estimates from the national medical expenditure survey. PharmacoEconomics, 12(4), 486-498.

Woodard, L. D., Urech, T., Landrum, C. R., Wang, D., \& Petersen, L. A. (2011). Impact of comorbidity type on measures of quality for diabetes care. Medical Care, 49(6), 605-610. doi:10.1097/MLR.0b013e31820f0ed0 